\title{
DESIGN, MANUFACTURE, DYNAMIC TESTING, AND FINITE ELEMENT ANALYSIS OF A COMPOSITE 6U CUBESAT
}

\author{
A Thesis \\ presented to \\ the Faculty of California Polytechnic State University, \\ San Luis Obispo
}

\author{
In Partial Fulfillment \\ of the Requirements for the Degree \\ Master of Science in Aerospace Engineering
}

by

Yanina Soledad Hallak

June 2016 
(C) 2016

Yanina Soledad Hallak

ALL RIGHTS RESERVED 


\section{COMMITTEE MEMBERSHIP}

TITLE: Design, Manufacture, Dynamic Testing, and Finite Element Analysis of a Composite 6U CubeSat

AUTHOR: Yanina Soledad Hallak

DATE SUBMITTED: June 2016

COMMITTEE CHAIR: Faysal Kolkailah, Ph.D., P.E.

Professor of Aerospace Engineering

COMMITTEE MEMBER: Eltahry Elgandour, Ph.D.

Lecturer of Aerospace Engineering

COMMITTEE MEMBER: Jordi Puig-Suari, Ph.D.

Professor of Aerospace Engineering

COMMITTEE MEMBER: Christian Nomme, MS

Design Engineer

General Electric, Norway 


\begin{abstract}
Design, Manufacture, Dynamic Testing, and Finite Element Analysis of a Composite 6U CubeSat

Yanina Soledad Hallak
\end{abstract}

CubeSats, specially the $6 \mathrm{U}$ standard, is nowadays the tendency where many developers point towards. The upscaling size of the standard and payloads entail the increase of the satellite overall mass. Composite materials have demonstrated the ability to fulfill expectations like reducing structural masses, having been applied to different types of spacecraft, including small satellites.

This Thesis is focused on designing, manufacturing, and dynamic testing of a $6 \mathrm{U}$ CubeSat made of carbon fiber, fiberglass, and aluminum.

The main objective of this study was obtaining a mass reduction of a $6 \mathrm{U}$ CubeSat structure, maintaining the stiffness and strength. Considering the thermal effects of the used materials an outgassing test of the used materials was performed and the experimental results are presented.

The CubeSat structure was entirely manufactured and tested at Cal Poly Aerospace Engineering Department facilities. A mechanical shock test and random vibration test were performed using a shock table and a shake table respectively. Results of both tests are presented. A correlation between the Experimental data and the Finite Element Model of the satellite was carried out. Finally, a comparison between $6 \mathrm{U}$ structure studied and aluminum $6 \mathrm{U}$ structures available in the market is presented.

Keywords: CubeSat, Random Vibration, Mechanical Shock, Composite Materials, Finite Element Analysis. 


\section{ACKNOWLEDGMENTS}

In first place I would like to say Thank You to Andrés Villa. My life buddy and the love of my life. Thanks for helping me out with the construction of my satellite, for your time, your advices, your willingness and your solutions for every problem. I am so happy of enjoying this "Californication" journey with you side by side. Thanks for helping me to make my dreams come true. The best is yet to come!

I would like to say big thanks to my advisor Dr Faysal Kolkailah. First because he accepted me in his Master program. Dr K you didn't know this, but this was my childhood dream. Second, thanks for being there all the time, for your training, your classes and your infinite kindness. Thanks also for introducing me your family, which is plenty of good moral values because of you. You have been not only my advisor but my dad away from home. I will always remember you, my Dear Dr K.

Christian Nomme, for being a great academic advisor and accepting be part of my committee without even know me. Thanks for being "present" from Norway. Thanks for your emails, advices, recommendations, and for pushing me up in the moments where all the things weren't go as planned. The quote "Be the type of person you want to meet" fits perfect with you. Takk!

Dr Jordi Puig-Suari. Thanks for signing in on my committee. It was an honor for me to have you on my Team, being the co-creator of the CubeSat standard. Thanks for your support and advices.

Dr Eltahry Elghandour, thanks for open up the doors of the Structures and Composites Lab for me. Without any doubt, the experience that I gained at the lab is in a big part because of your advices and guidance.

Professor Dave Esposto for helping me out with the design of my structure. Thanks for your time, knowledge, patience and dedication. You have helped me out as if you were part of my committee members and I won't ever forget all your tips, recommendations and advices.

Dr. Kira Abercromby - Thanks for helping me with the outgassing test, sharing with me your knowledge, time and lab equipment. As the Matlab code of Orbital Mechanics class says "Dr A is Awesome".

Chris Risner, a big thanks for working by my side in a critical moment of my Thesis. The dispenser we create turned out to be great and very useful for both Thesis. Thanks for all the information about Shock Test that you have shared with me. I hope my satellite gave you good data! Keep it up!

Kendra Bubert, thanks for helping me buying materials for my thesis. Cody MacThompson, Ladd Caine and Kevin "Kevo" Williams. Thank You to all of you for cutting aluminum pieces and put the dispenser together in two days. I learned that in the most difficult moments, the best people appear to help you. I wouldn't be able to test my structure if you weren't there in the correct moment to help me building it. 
Tiffany Nguyen and Kenji Yamamoto, both undergrad students and members of CubeSat Lab. Thanks guy! I will be always thankful with you for helping me conduct the random vibration test of my structure. Your time, patience and kindness is so much appreciated.

Thanks to DHV Technology for providing me information regarding to Solar Panels for Cubesat. Your information was really appreciated.

Fritz Kaminski, Jane Xiao, Richard de Luna, Mateja Andrejic, Reuben Lazarin, Martina Kroener, Sam and Hunty Moss for being such a great buddies at the Aerostructures and Composites Lab. Part of my great experience at Cal Poly was because of you guys! It would have been a completely different chapter of my life without having you guys there in the good times and also in the stressful thesis time. I will always remember all of you. Thanks to all.

María Laura Torino Pardo, for being my best friend, my soul sister and the person that for 20 years believes more in me that myself. One more time, as you mentioned, I am here finishing my thesis on time. Thanks for being there all the time that I need you.

To my mom Alicia Fiorenza and my dad Alberto Hallak for letting me choose the career path I have always wanted, even though that represented go away from home to make my dreams come true. To my sister Nadia Hallak, for pushing me up, what do you think if I use now the craft rocket you made for me when we were kids? And Thanks to my Grandma Carmen "Abue" Alonso, the heroin of my entire life, for being there always for me, with her support and endless love. If I have to choose be someone in life, I would definitely want to be her when I grow up! 


\section{TABLE OF CONTENTS}

$\begin{aligned} 2 & \text { Page }\end{aligned}$

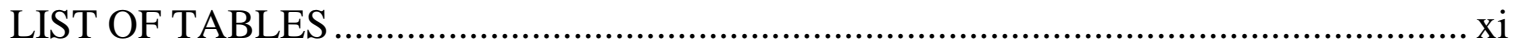

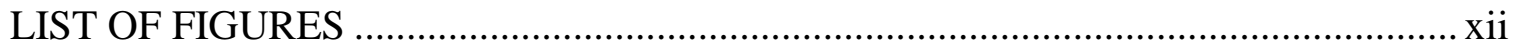

ABBREVIATIONS AND ACRONYMS …........................................................... xviii

CHAPTER

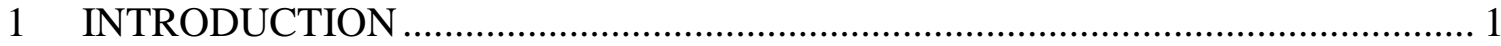

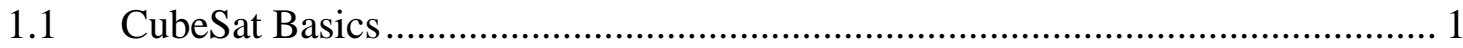

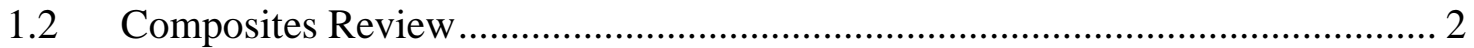

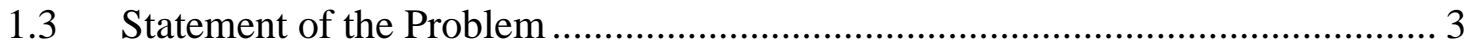

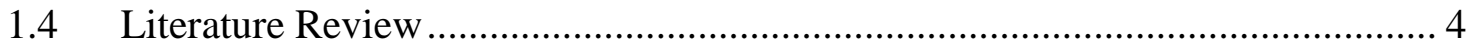

1.5 Motivation and Objective Overview ................................................................ 5

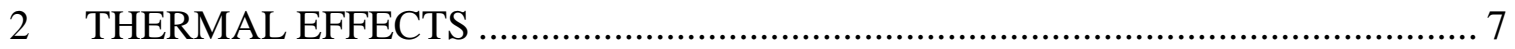

2.1 Thermal Expansion and Thermal Conductivity ............................................. 7

2.1.1 Expansion, Conductivity and Shielding............................................... 7

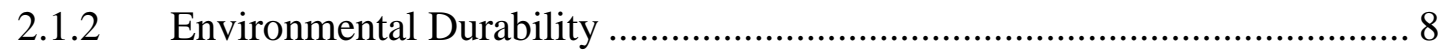

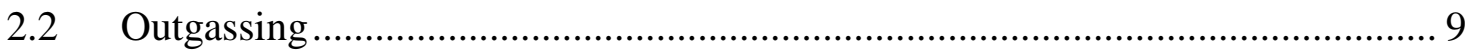

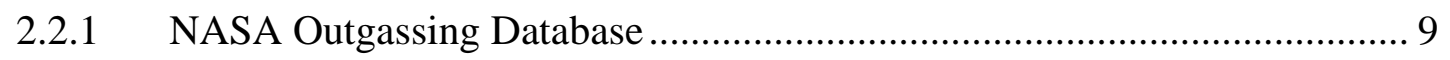

2.2.2 Material Selected ............................................................................... 10

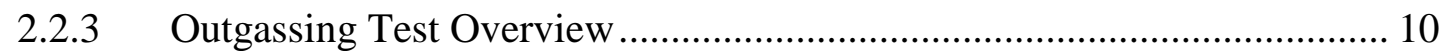

2.2.4 Test Set up and Procedure.................................................................. 11

2.2.5 Outgassing Test Results ................................................................... 13

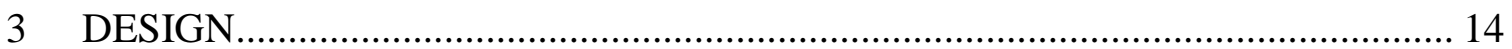

3.1 CubeSat Dimensional Requirements........................................................... 14

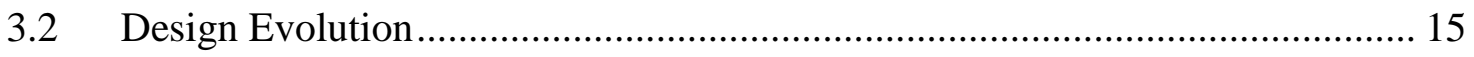

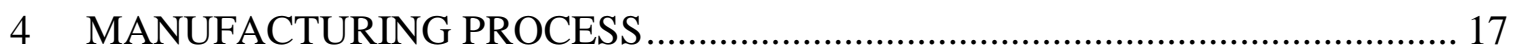

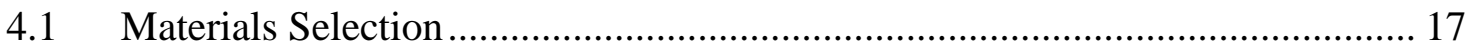

4.2 Structure Manufacturing Process .................................................................. 17

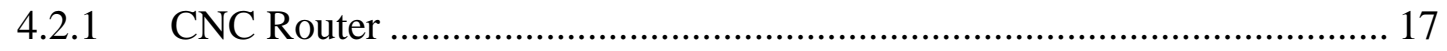

4.2.2 Fiber Glass Reinforced Plastic Internal Panels ......................................... 18

4.2.3 Carbon Fiber Shear Panels Fabrication..................................................... 21

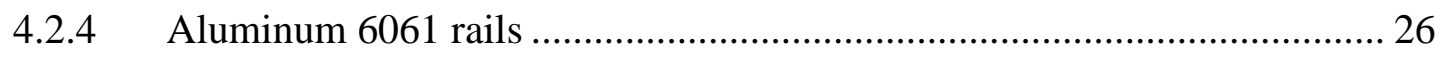

4.3 Payload Manufacturing Process .................................................................. 28

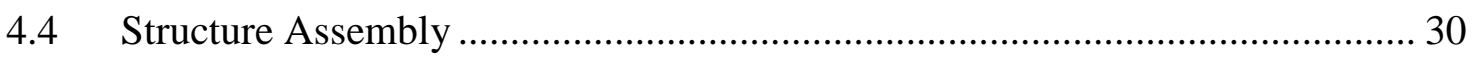




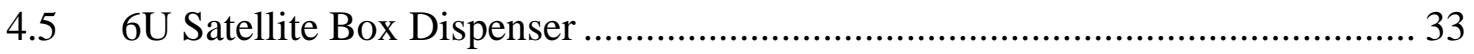

4.5.1 Satellite Dispenser Function ................................................................ 33

4.5.2 Dispenser Construction and Attachments .................................................. 33

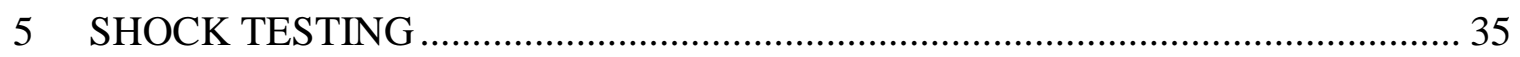

$5.1 \quad$ Test Overview and Equipment Description …………………….................... 35

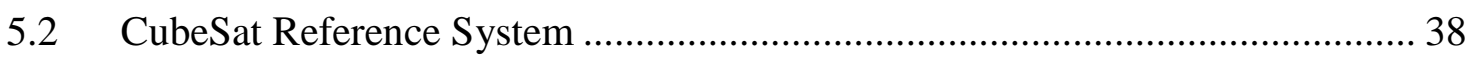

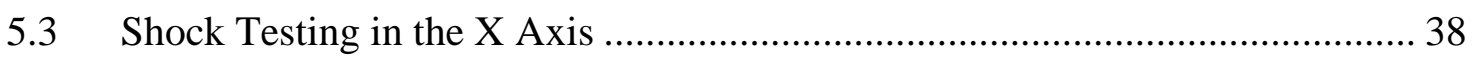

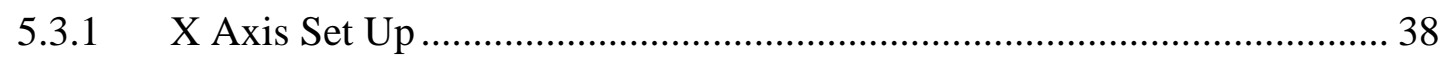

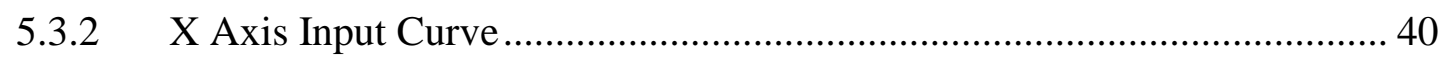

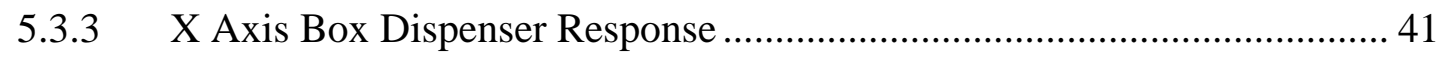

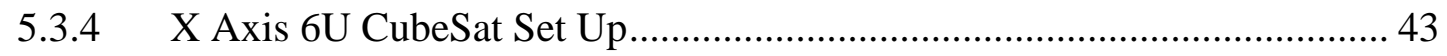

5.3.4.1 X Axis Output Curves Dispenser and 6 CubeSat: Run \#1 .................. 44

5.3.4.2 X Axis Output Curves Dispenser and 6 CubeSat: Run \#2 .................. 45

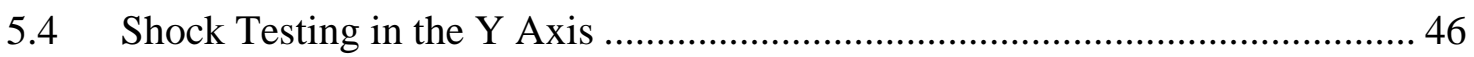

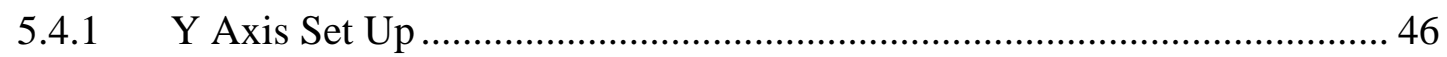

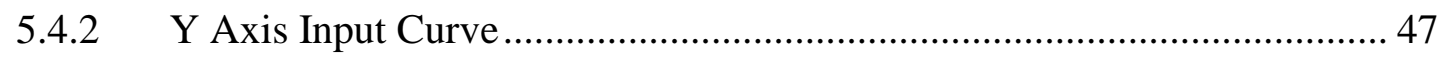

5.4.3 Y Axis Box/Dispenser Response ............................................................. 49

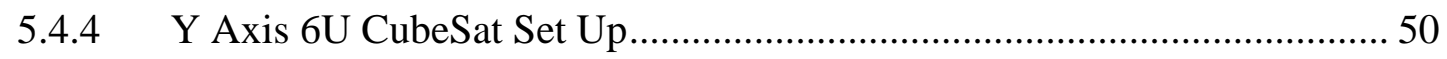

5.4.4.1 Y Axis Output Curves Dispenser and 6 CubeSat: Run 1 .................... 51

5.4.4.2 Y Axis Output Curves Dispenser and 6 CubeSat: Run 2 .................... 51

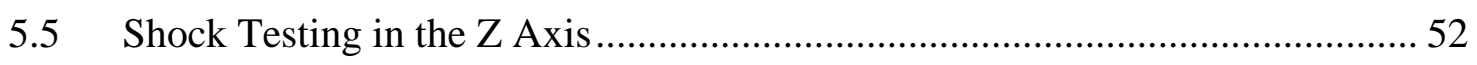

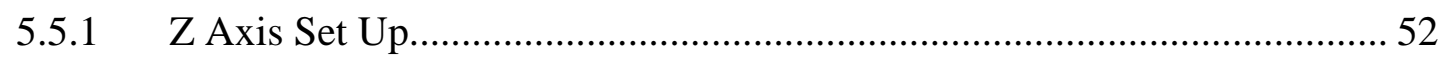

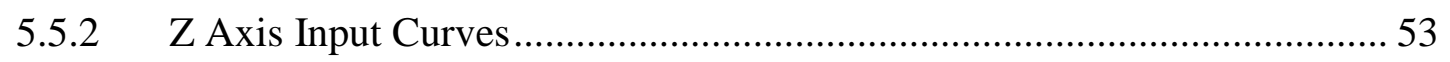

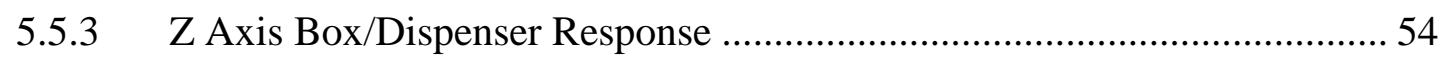

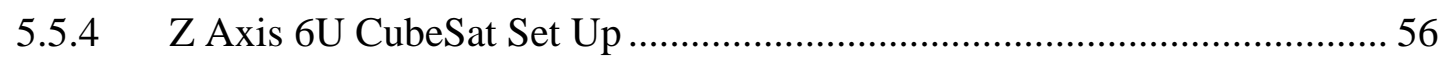

5.5.4.1 Z Axis Output Curves Dispenser and 6 CubeSat: Run 1..................... 57

5.5.4.2 Z Axis Output Curves Dispenser and 6 CubeSat: Run 2.................... 58

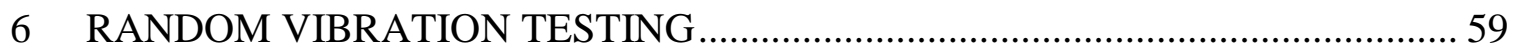

6.1 Test Overview and Equipment Description ………………............................. 59

6.2 NASA Random Vibration Levels .............................................................. 59

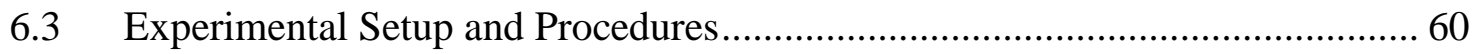

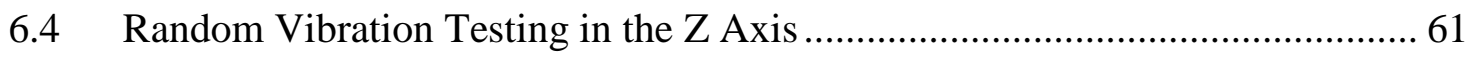

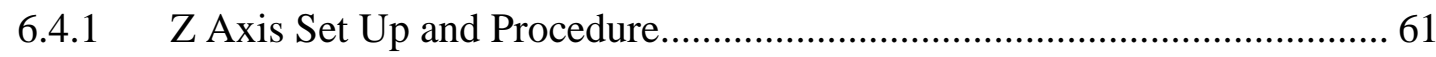

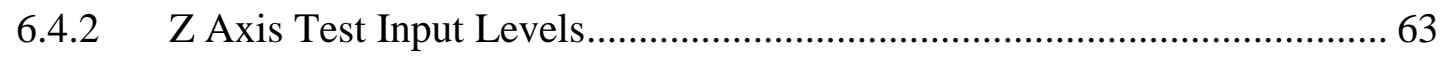




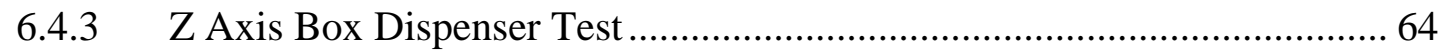

6.4.3.1 Z Axis Pre and Post Sine Sweep Response Curves: Box Dispenser ... 64

6.4.3.2 Z Axis Random Vibration Response Curves: Box Dispenser............. 64

6.4.4 Z Axis Box Dispenser with Satellite Test.................................................. 65

6.4.4.1 Z Axis Pre-Sine Sweep Curves: Box Dispenser and Satellite.............. 66

6.4.4.2 Z Axis Random Vibration Curves: Box Dispenser and Satellite ........ 67

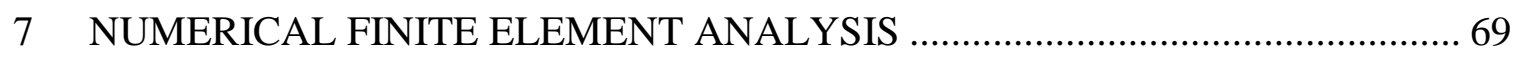

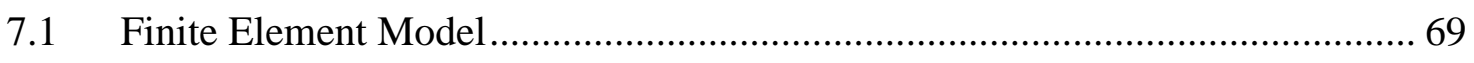

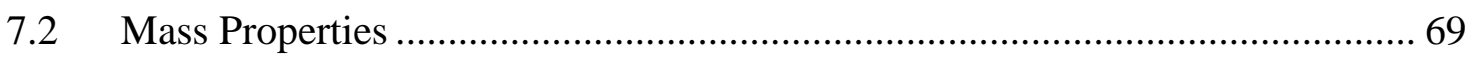

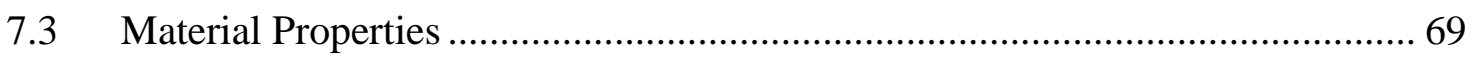

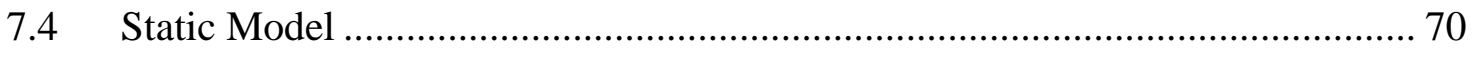

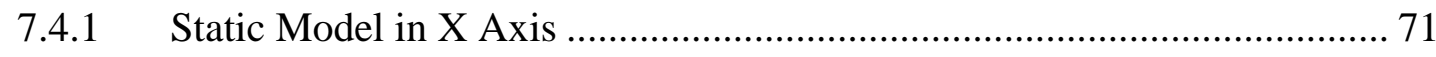

7.4.1.1 Static Model Boundary Conditions ..................................................... 71

7.4.1.2 Static Model Loads ............................................................................ 71

7.4.1.3 Static Model Results in X Axis ....................................................... 72

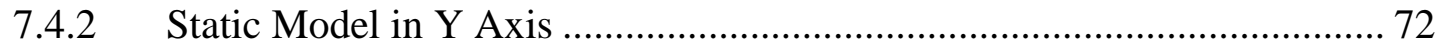

7.4.2.1 Static Model Boundary Conditions …………................................... 72

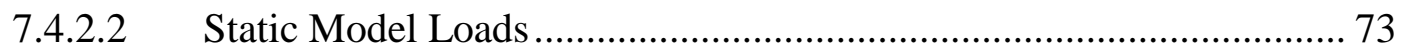

7.4.2.3 Static Model Results in Y Axis ........................................................ 74

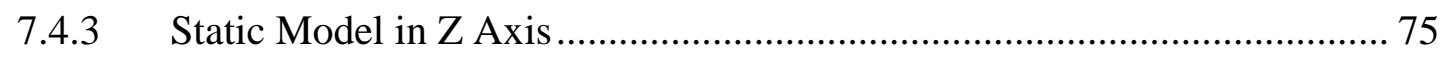

7.4.3.1 Z Axis Static Model Boundary Conditions .......................................... 75

7.4.3.2 Z Axis Static Model Load ............................................................. 75

7.4.3.3 Static Model Results in Z Axis........................................................ 76

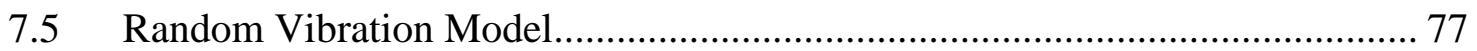

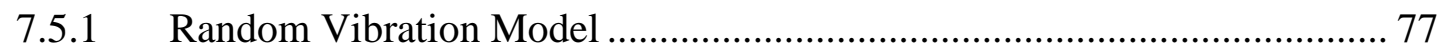

7.5.2 Random Vibration Input Function Loads ……………................................ 77

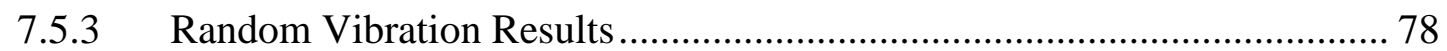

7.6 Error percentage between the Numerical and Experimental Results .................. 80

8 COMPARISON BETWEEN CUBESATS COMMERCIALLY AVAILABLE ...... 81

8.1 6U Structures Overview and Comparison........................................................ 81

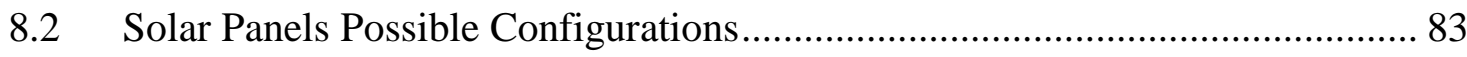

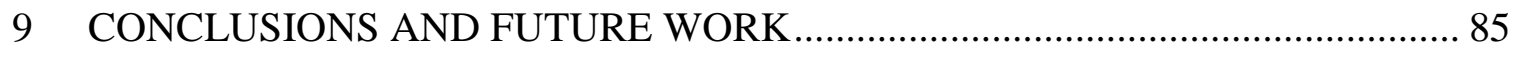

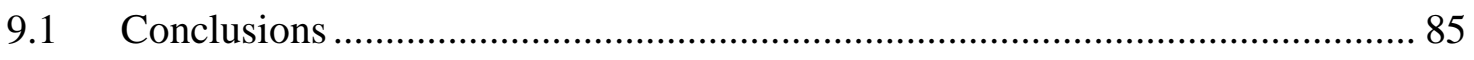




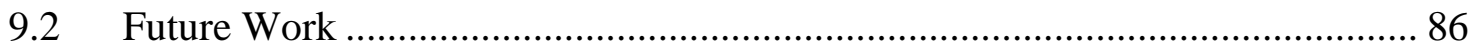

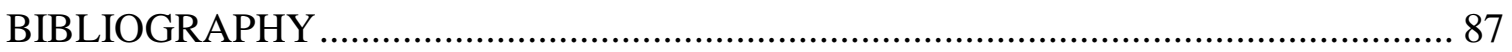

APPENDICES

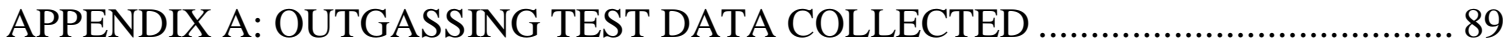

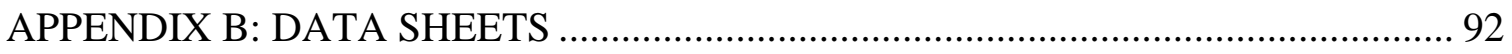

APPENDIX C: 6U CUBESAT STANDARD DRAWINGS ..................................... 93 


\section{LIST OF TABLES}

Table

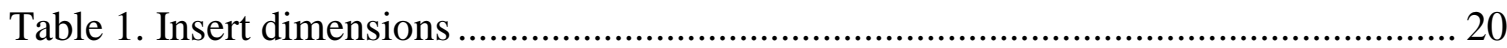

Table 2. NASA GEVS Qualification and Acceptance Levels ..................................... 60

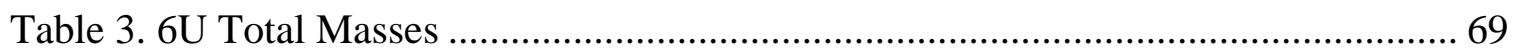

Table 4. Finite Element Model Material Properties for Aluminum 6061....................... 70

Table 5. Finite Element Model Material Properties for Composites Materials ............... 70

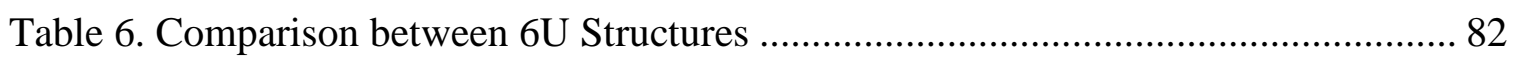

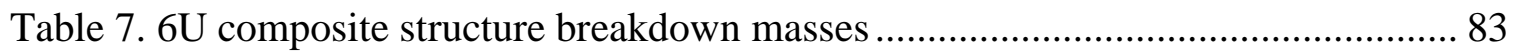

Table 8. Solar Panels Information Credit/ DHV Technology ...................................... 84 


\section{LIST OF FIGURES}

Figure $\quad$ Page

Figure 1. 1U CubeSat structure. Image credit/cubesatkit.com ................................... 1

Figure 2. Different CubeSat Aluminum Structures up to 12U Credit/Radius Space ......... 2

Figure 3. Pumpkin 6U Supernova TM. Image Credit/Pumpkin Space Systems ............... 6

Figure 4. NASA Outgassing Online Database. Image Credit/NASA GSFC .................. 10

Figure 5. Vacuum Chamber Equipment at Space Environment Lab............................. 12

Figure 6. Carbon Fiber LTM45/CF1803 Outgassing Samples .................................... 12

Figure 7. Weighing of Carbon Fiber Sample before the Outgassing Test ...................... 13

Figure 8. Carbon Fiber Samples inside the vacuum chamber ..................................... 13

Figure 9. 6U CubeSat-B Specification Drawing. Image Credit/Tyvak ......................... 14

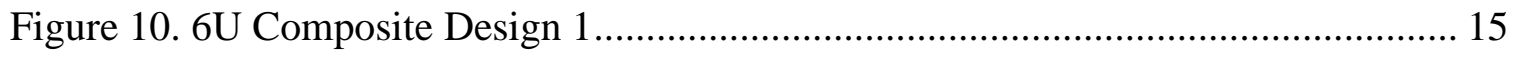

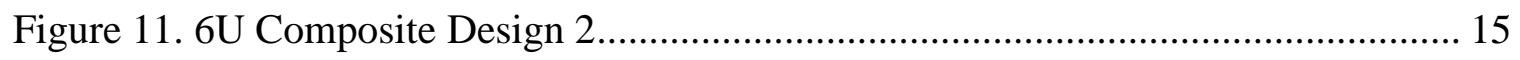

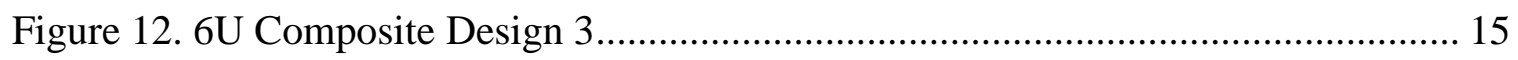

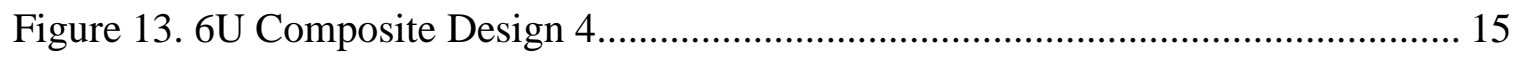

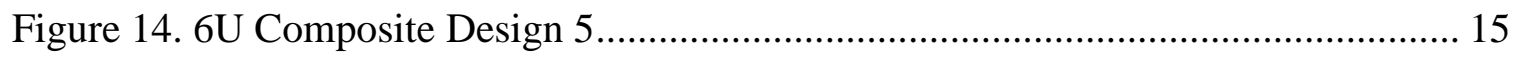

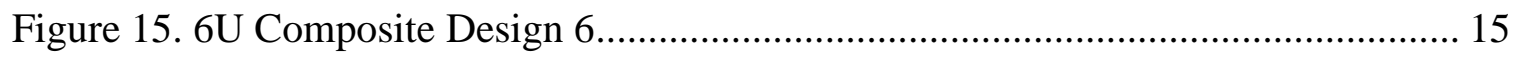

Figure 16. 6U CubeSat Structure Designed ......................................................... 16

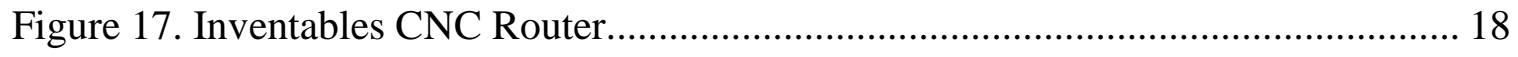

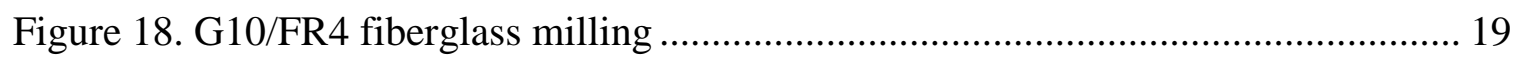

Figure 19. Drawing of the Press in place inserts . Image credit/EZ-Lok........................ 19

Figure 20. G10/FR4 Dividers finished. Press Inserts placed ................................... 20

Figure 21. Holes and inserts made on one of the laterals of the G10/FR4 panels ........... 21 
Figure 22. Cutting out the dimension of the LTM45/CF1803 Carbon Fiber used 22

Figure 23. LTM45/CF1803 Carbon Fiber Lay Ups in between non porous material ...... 22

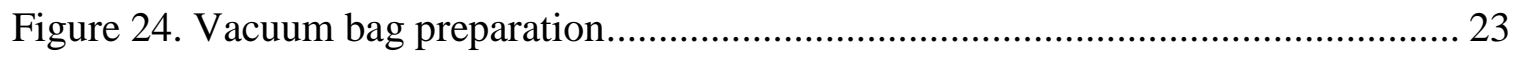

Figure 25. American Autoclave Co. at Aerostructures and Composites Lab (Cal Poly) . 24

Figure 26. Vacuum bag after taking it out from the Autoclave .................................. 24

Figure 27. LTM45/ Carbon Fiber Shear Panels .......................................................... 25

Figure 28. Example of one of the GCodes written for the CNC milling process ............ 25

Figure 29. Milling of the cut outs of the carbon fiber shear panels .............................. 26

Figure 30. Aluminum 6061 bars 3/8" x 3/8" x 14.5" before being machined ................. 27

Figure 31. 6U CubeSat aluminum 6061 rails machining process ............................... 27

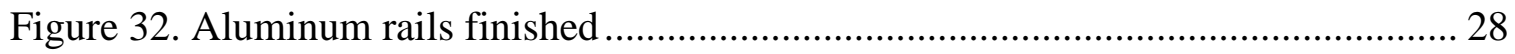

Figure 33. PC104 Standard. Image credit/PC104.org ............................................. 28

Figure 34. Dummie printed board circuit (PBC) machining .................................... 29

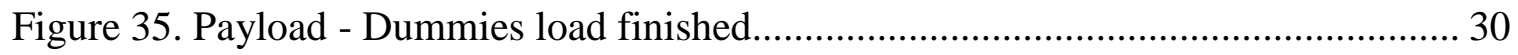

Figure 36. Two payload stacks assembled to the fiberglass panels ............................. 31

Figure 37. Inserts placed in the corners of the G10/FR4 panels ................................ 31

Figure 38. Equally distributed grooves in Aluminum rails...................................... 31

Figure 39. Structure semi- assembled with payloads and G10/FR4 panels .................... 32

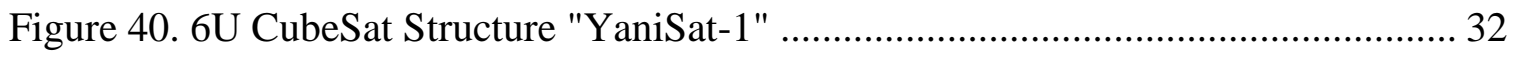

Figure 41. 6U Dispenser with payload. Image Credit/Planetary Systems Corporation.... 33

Figure 42. 6U Dispenser. Image Credit/Planetary Systems Corporation ........................ 33

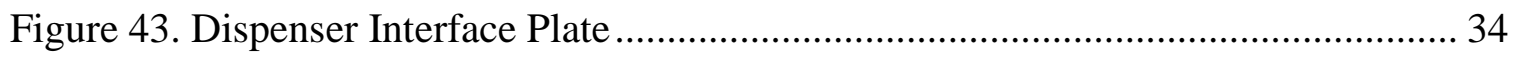

Figure 44. Dispenser Interface Plate mounted on the Shock Table ............................... 34 
Figure 45. Test Dispenser with the satellite mounted............................................. 34

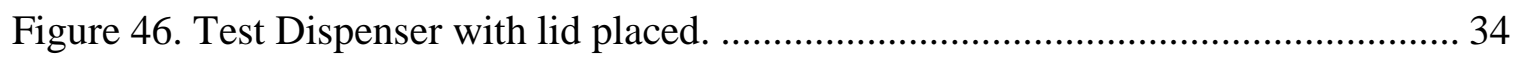

Figure 47. Shock Response Spectrum for assessing Component Test Requirements ...... 36

Figure 48. Random vibration levels for different Launch Vehicles. Image/SMAD........ 36

Figure 49. Shock Table at the Space Environment Lab, Cal Poly................................ 37

Figure 50. Wood plate representing different angles on top of the hammer ................... 37

Figure 51. CubeSat Reference System Axis. Credit/CDS ....................................... 38

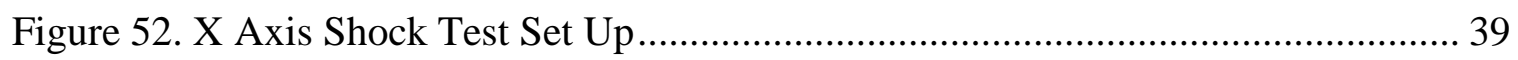

Figure 53. X and Z Axis Shock Test Set Up - Hammer ............................................ 39

Figure 54. X Axis Input Curve. Velocity Time History ........................................... 40

Figure 55. X Axis Input Curve. Acceleration Time History........................................ 41

Figure 56. X Axis Dispenser Shock Response Spectrum ......................................... 42

Figure 57. X Axis Acceleration Pseudo Velocity Shock Spectrum............................... 43

Figure 58. X Axis Shock Test Set Up. Box Dispenser with 6U CubeSat....................... 43

Figure 59. X Axis, Dispenser with 6U CubeSat - SRS - Test $1 \ldots \ldots \ldots \ldots \ldots \ldots \ldots \ldots \ldots \ldots \ldots . . . . . . . \ldots 4$

Figure 60. X Axis, Dispenser with 6U CubeSat - APVSS - Test 1 ............................ 44

Figure 61. X Axis, Dispenser with 6U CubeSat - SRS - Test 2 ................................ 45

Figure 62. X Axis, Dispenser with 6U CubeSat - APVSS - Test 2 ........................... 45

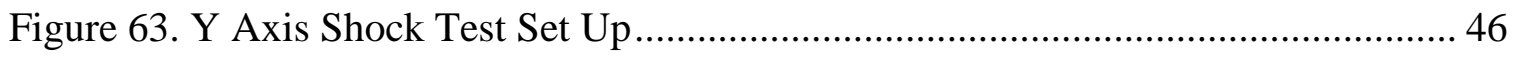

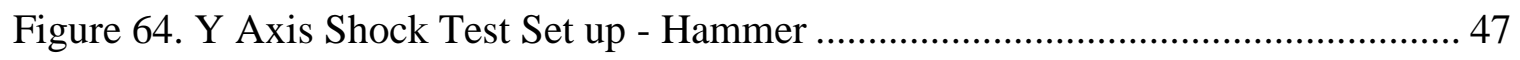

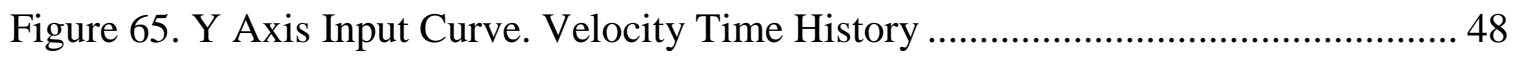

Figure 66. Y Axis Input Curve. Acceleration Time History ...................................... 48

Figure 67. Y Axis Dispenser Shock Response Spectrum .......................................... 49 
Figure 68. Y Axis Dispenser - Pseudo Velocity Shock Spectrum..................................... 50

Figure 69. Y Axis Shock Test Set Up. Box Dispenser with 6U CubeSat.......................... 50

Figure 70. Y Axis, Dispenser with 6U CubeSat - Shock Response Spectrum - Run 1 ... 51

Figure 71. Y Axis, Dispenser with 6U CubeSat - APVSS - Run 1 ………………….... 51

Figure 72. Y Axis, Dispenser with 6U CubeSat - SRS - Run 2 …………………….... 52

Figure 73. Y Axis, Dispenser with 6U CubeSat - APVSS - Run 2............................... 52

Figure 74. Z Axis Shock Test Set Up ……………….............................................. 53

Figure 75. Z Axis Input Curve. Velocity Time History.................................................... 54

Figure 76. Z Axis Input Curve. Acceleration Time History ........................................... 54

Figure 77. Z Axis Dispenser Shock Response Spectrum .............................................. 55

Figure 78. Z Axis Dispenser - Pseudo Velocity Shock Spectrum .................................... 56

Figure 79. Z Axis Shock Test Set Up. Box Dispenser with 6U CubeSat ......................... 56

Figure 80. Z Axis, Dispenser with 6U CubeSat - SRS - Run 1 ..................................... 57

Figure 81. Z Axis, Dispenser with 6U CubeSat - APVSS - Run 1 ............................... 57

Figure 82. Z Axis, Dispenser with 6U CubeSat - SRS - Run 2 …………………….... 58

Figure 83. Z Axis, Dispenser with 6U CubeSat - APVSS - Run 2 ................................ 58

Figure 84. Random vibration levels for different Launch Vehicles. Image/SMAD......... 60

Figure 85. Shake Table at Cal Poly Aerostructures and Composites Lab ......................... 61

Figure 86. Box Dispenser Test Set Up in the Shake Table - Z Axis ................................ 62

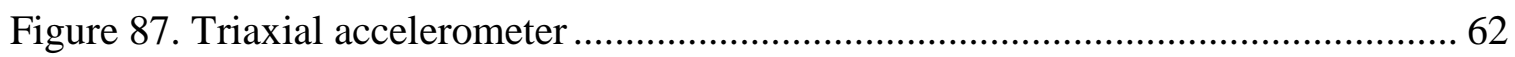

Figure 88. Accelorometers placement …………………............................................. 62

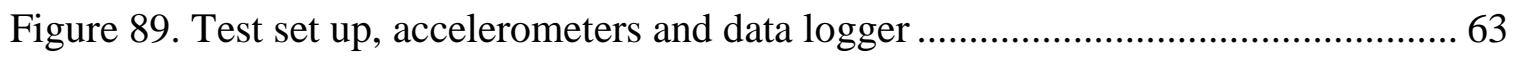

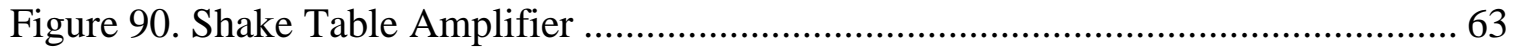




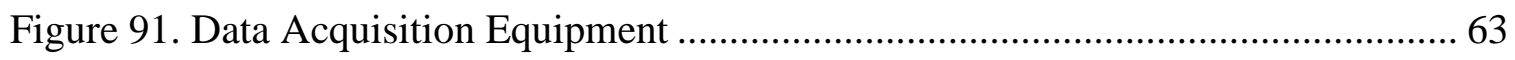

Figure 92. Pre and Post Sine Sweep - Z Axis - Dispenser................................................ 64

Figure 93. Random Vibration Response of the Dispenser............................................. 65

Figure 94. Box Dispenser and Satellite Test Set Up in the Shake Table.......................... 66

Figure 95. Pre and Post Sine Sweep - Z Axis - Dispenser with Satellite ......................... 66

Figure 96. Random vibration Response dispenser with Satellite ................................... 67

Figure 97. Dispenser and Dispenser + Structure Random Vibration response................. 68

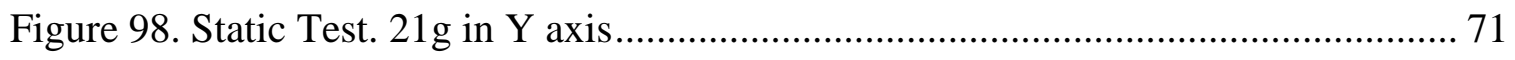

Figure 99. Static Test. Chart: Boundaries Conditions in X Axis ..................................... 71

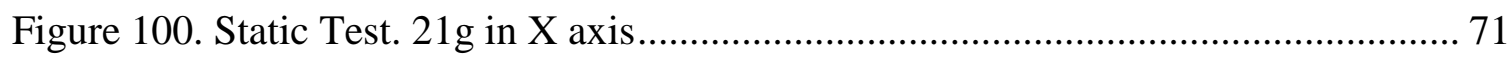

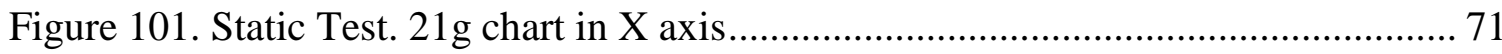

Figure 102. Stresses and deflections in the X Axis, after applying 21G ........................ 72

Figure 103. Stresses and deflections in the X Axis, after applying 21G ........................ 72

Figure 104. Static Test. Boundaries Conditions in Y Axis............................................. 73

Figure 105. Static Test. Chart: Boundaries Conditions in Y Axis.................................... 73

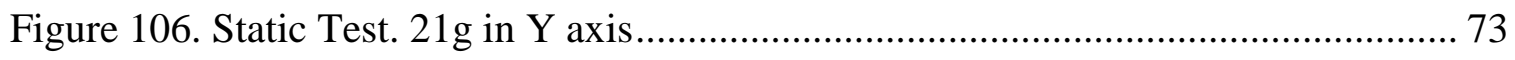

Figure 107. Static Test. 21g chart in Y axis................................................................. 73

Figure 108. Stresses and deflections in the Y Axis, after applying 21G ........................ 74

Figure 109. Stresses and deflections in the Y Axis, after applying 21G ......................... 74

Figure 110. Static Test. Boundaries Conditions in $\mathrm{Z}$ axis .............................................. 75

Figure 111. Static Test. Chart: Boundaries Conditions in Z Axis ................................... 75

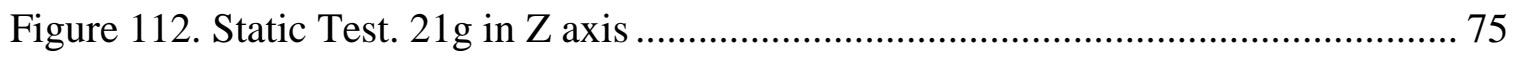

Figure 113. Static Test. 21g chart in $\mathrm{Z}$ axis .................................................................. 75 


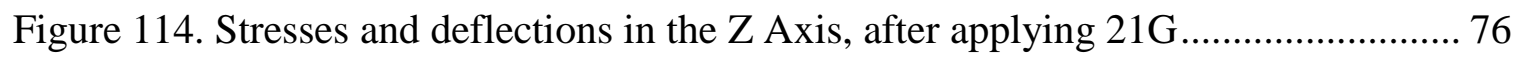

Figure 115. Stresses and deflections in the Z Axis, after applying $21 \mathrm{G} \ldots \ldots \ldots \ldots \ldots \ldots \ldots \ldots . . . . . . . . . . . .6 \%$

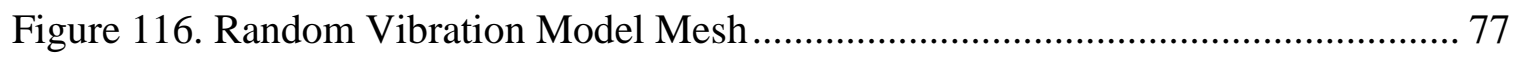

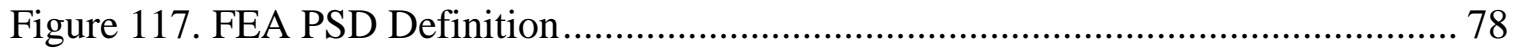

Figure 118. Frequency Curve for Random Vibration Analysis .................................. 78

Figure 119. Random Vibration Response. Scale Factor 30 times ................................ 79

Figure 120. Random Vibration Displacements ..................................................... 79

Figure 121. Random Vibration Response Graph. ASD vs Frequency (Z Axis) .............. 79

Figure 122. Supernova Credit/ Pumpkin Space ..................................................... 81

Figure 123. YaniSat-1 - First Composite 6U ….................................................. 81

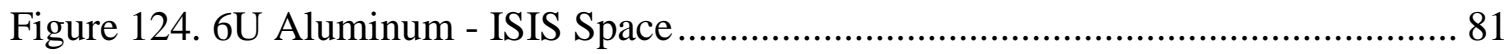

Figure 125. Possible Solar Panels Configurations Credit/Pumpkin Space..................... 84 


\section{ABBREVIATIONS AND ACRONYMS}

\begin{tabular}{|c|c|}
\hline CAL POLY & California Polytechnic State University \\
\hline GEVS & General Environmental Verification Specification \\
\hline GEO & Geostationary Earth Orbit \\
\hline LEO & Low Earth Orbit \\
\hline NASA & National Aeronautical and Space Administration \\
\hline $\mathrm{MEO}$ & Middle Earth Orbit \\
\hline SRS & Shock Response Spectrum \\
\hline APVSS & Acceleration Pseudo Velocity Shock Spectrum \\
\hline PCB & Printed Circuit Boards \\
\hline ASD & Acceleration Spectral Density \\
\hline TML & Total Mass Loss \\
\hline FEA & Finite Element Analysis \\
\hline G-10 FR4 & Grade 10 - Flame Retardant 4 - Fiberglass Epoxy \\
\hline $\mathrm{CVCM}$ & Collected Volatile Condensable Materials \\
\hline CDS & CubeSat Design Specification \\
\hline $\mathrm{NC}$ & Numerical Control \\
\hline CTE & Coefficient of Thermal Expansion \\
\hline
\end{tabular}




\section{INTRODUCTION}

\subsection{CubeSat Basics}

In 1999 Dr. Jordi Puig-Suari from California Polytechnic State University (hereafter referred to as Cal Poly) was the co-creator of the CubeSat standard.

The original CubeSat standard stipulates a single unit (1U) CubeSat is $10 \mathrm{~cm}$ in length, width and height and has a mass of $1 \mathrm{~kg}$ and no greater than $1.33 \mathrm{~kg}$. Figure 1 shown a picture of a $1 \mathrm{U}$ (one unit) CubeSat structure. The CubeSat concept has been expanded over the years, and what started as a university-focused satellite to make the students gain hands-on experience has been scaled up to unit of sizes even greater.

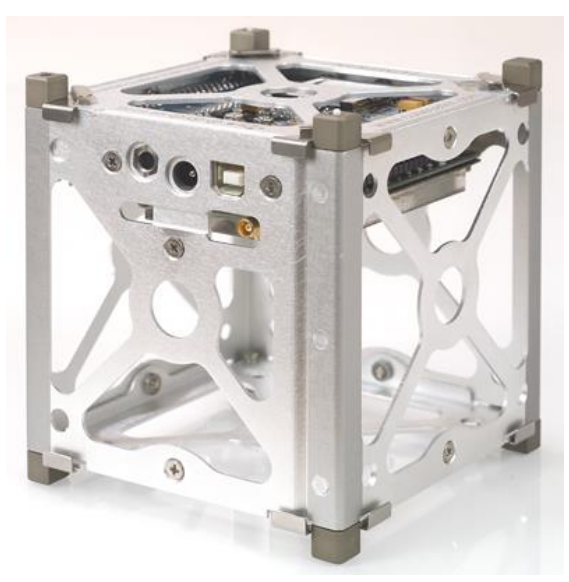

Figure 1. 1U CubeSat structure. Image credit/cubesatkit.com

The CubeSat standard has now been openly available for the last 17 years. During these years hundreds of companies have been created, as well as hundreds of high school and universities programs CubeSat-related. Nowadays, almost every Space mission, carry CubeSats as secondary payload to be deployed.

One Unit (1U), two unit (2U) and three unit (3U) CubeSat are the most common standards in the academic environment. But in the last 3 years the concept of six Unit (6U), 
twelve Unit (12U) and even twenty seven Unit (27U) has grown in the commercial CubeSat market. An example of the CubeSat standard evolution is shown in Figure 2.

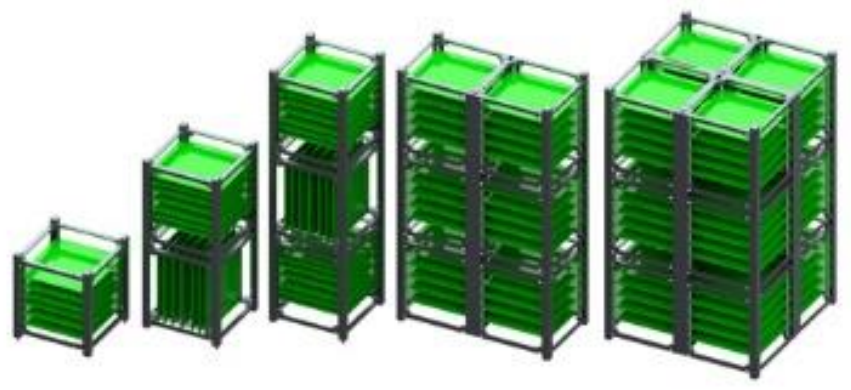

Figure 2. Different CubeSat Aluminum Structures up to 12U Credit/Radius Space

The standard has grown, and with it the dimensions of the satellites. For a $6 \mathrm{U}$ CubeSat the general dimensions are $226.3 \mathrm{~mm}$ in length, width of $100 \mathrm{~mm}$ and height of $366 \mathrm{~mm}$ and has a mass of $6 \mathrm{~kg}$ and no greater than $8 \mathrm{~kg}$. There is another version of the $6 \mathrm{U}$ standard that stipulates a height of $340.5 \mathrm{~mm}$ respecting the same dimensions for width and length.

\subsection{Composites Review}

Composites are basically constituted of two or more materials. The most common are fibers and a resin. However particles, balls, and rods can also be used as reinforcement. Laminated composites consist of layers of at least two different materials that are bonded together. Lamination is used to combine the best aspects of the constituent layers in order to achieve a more useful material. (Jones, 1975). Some designs could require high strength and high electrical conductivity. While alloys usually provide high strength and pure metals offer good conduction. Composites can have both properties at the same time with the 
combination of proper materials selection. Continuous fiber composites exhibit desirable physical and chemical properties that include lightweight properties with high stiffness and strength along the direction of the reinforcing fiber, dimensional stability, temperature and chemical resistance, and a wide range of performance.

Over the years, composites were subjected to a close scrutiny. As is stated in Mechanics of Composite Materials (Jones, 1975), first, “demonstration pieces” were built with the philosophy "let's see if we can build one". The second stage was "replacement pieces", where some primary structures of both aircraft and spacecraft were replaced.

Nowadays most of the space applications use composites as a weight-saving alternative instead of conventional aluminum alloys. An example of this is the Hubble Telescope, which used graphite/epoxy in its main structure. (NASA, Goddard Space Flight Center, 2009)

\subsection{Statement of the Problem}

The scaling up of the CubeSat units has contributed to the increasing of the structure mass, and therefore leaving less room and mass for payloads. Nowadays, the structures of all CubeSats are made of aluminum, since it is cheap and the machinability is easy compared to other metals.

As it was explained in the previous section, composites offer an unlimited possibility of applications, when the correct materials are combined together. (See 1.2 Composites Review). Something important to point out is that the stiffness to weight ratio is defined as the modulus of elasticity divided by the density. The higher this number, the stiffer and lighter the material. A simple calculation was done and leaving this number as 
unitless, for the aluminum the stiffness to weight ratio is 100 while for a generic carbon fiber/epoxy this number grows to 307.

"Spacecraft structures - small or large - must be made of materials that resist without failure or excessive distortion, the static, dynamic, and thermal stresses that occur during launch, deployment and service.

Moreover structural weight of spacecraft has historically been about 20 percent of the total dry mass. However, structural weight saving may assume accentuated importance for many small spacecraft missions, where each kilogram shaved from the structure is precious and may provide increase capacity for additional payload, autonomous control devices, or auxiliary equipment” (National Research Council, 1994, p. 42).

Therefore, a number of questions were brought the attention of the researcher. What if a CubeSat structure is built from composite materials? Will the stiffness to weight ratio be enough to pass a random vibration test? How would the response of a composite structure in a mechanical shock test be? Will the machinability of the composite materials be easy as is the case of aluminum? Is the conductivity of the composites good for spacecraft applications? Does the epoxy resin outgas in space? Some of this questions, are described in the objectives and motivation of this work presented in Section 1.5

\subsection{Literature Review}

After doing extensive research, it was found only two papers related to composite materials applied in CubeSats.

In the first paper found (University of Patras, 2014), a comparison between a 1U CubeSat structure commercially available made out of aluminum and a $1 \mathrm{U}$ CubeSat made of carbon fiber, developed by the researchers, was studied. A sine sweep test was 
performed and the result found was that a $35 \%$ mass reduction was obtained with the composite structure. However, the structure had no rails, no internal payloads, and thermal effects and a random vibration study were not carried out in this paper, and were described as future work.

The second paper found was presented by the researcher (Nomme, 2013) to the Norwegian University of Science and Technology. This Master's Thesis was focused on the design and manufacturing of a $2 \mathrm{U}$ CubeSat structure made out of carbon fiber and polymers, a FEA and a thermal study for the NUTS-1, second Norwegian CubeSat, was conducted. The researcher had access to this Master thesis, and it was a great source of information since it has extensive and useful chapters. Equipment and resources were not available to do a random vibration testing and the thesis was supported with FEA. The NUTS-1 CubeSat (Norwegian University of Science and Technology, 2015) has still not been launched yet, but it was designed to occupy a Low Earth Orbit (LEO) in a $98^{\circ}$ Polar inclination.

\subsection{Motivation and Objective Overview}

The main motivation for doing this project was the idea that it was something that has not been tried before for a 6U CubeSat structure. Moreover, Cal Poly is the home of the CubeSat, and almost every paper published, cites the CDS (California Polytechnic State University, 2013) and the Cal Poly University, the researcher wanted to take advantage of being a student of this university and study the possibility of doing improvements to the CubeSat Program. Thus, a set of objectives were stipulated for this thesis. 
First, Chapter 2 INTRODUCTION of this thesis will be dedicated to explain the outgassing issues that surround the composite materials. A preliminary research study about thermal effects will be developed.

Second, after understanding the properties of the carbon fiber and composites and its implications when they are use in space applications, the design, manufacture and testing of a 6 Unit composite structure will be developed. The tests carried out are a mechanical shock test in a shock table and random vibration testing in an electrodynamic shaker. This two tests will try to answer some of the questions that were raised in Section

\subsection{Statement of the Problem.}

The correlation between the Finite Element Model with the experimental data is presented. The percentage of error between both is shown.

Last, with the results of the testing, a mass and performance comparison between the available $6 \mathrm{U}$ aluminum structures as it is shown in Figure 3 and the $6 \mathrm{U}$ CubeSat structure developed in the present study, will be presented.

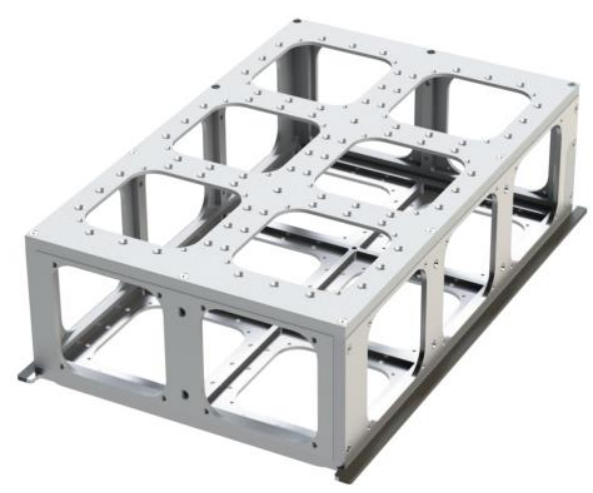

Figure 3. Pumpkin 6U Supernova TM. Image Credit/Pumpkin Space Systems 


\section{THERMAL EFFECTS}

The starting point of this thesis involves the answer of one of the questions that is surrounding the composite materials. Can a near-zero coefficient of thermal expansion material offer suitable conductivity in space? Does the carbon fiber outgas? Extensive research was done by the author and a compacted overview of that gathered information is presented below.

\subsection{Thermal Expansion and Thermal Conductivity}

\subsubsection{Expansion, Conductivity and Shielding}

There are two important properties: thermal conductivity and thermal expansion. The thermal conductivity will affect how the heat transfers through the structure. In space, there is radiation and heat generated from the electronics. There is also a minimal convection depending on orbit. On the ground, a vacuum chamber is used to test the thermal conductivity.

In addition to this information author Myer Kutz, (Spacecraft Applications of Advanced Composite Materials, 2002 ) explains in his book, that "for typical carbon fiber composites, the transverse and through-the-thickness thermal conductivity is three to four orders of magnitude less than the longitudinal thermal conductivity". The low conductivity of the composites is sometimes viewed as a disadvantage. However, this can be solved creating the proper thermal path within the components.

The thermal expansion is another important property. Composites, especially carbon fibers are well known for having high stiffness and low coefficient of thermal expansion (CTE). If these factors are added to the low density of the carbon fiber, this makes this material especially attractive for space applications. 
The author found that in a NASA publication "Thermal Expansion Properties of Composite Materials" (Robert R. Johnson, 1981) was stated that for space applications, a near-zero coefficient of thermal expansion (CTE) is often highly desirable to maintain the thermal dimensional stability of a structure on-orbit. In the same publication it was explained that even though the near-zero CTE properties can be achievable with composite materials, sometimes it as expenses of some structural efficiency.

On the other hand, the electromagnetic shielding interference (EMI) is a concern in every space flight. Shielding is important since its principal function is isolate instrument from one another.

Test results consistently indicate that the shielding characteristics of unaugmented carbon fiber composites are much more similar to metals than to plastics. One way to make the composite laminates more conductive is by adding solid metal laminations or coating, then the shielding effectiveness is roughly equivalent to that of solid aluminum. (Spacecraft Applications of Advanced Composite Materials, 2002 ). The author also mentioned that "highly conductive polymers have been investigated to increase the shielding effectiveness of composites and eliminate the need for metal coatings".

CubeSats, among other spacecraft use metallic structure for grounding purposes. In the Satellite NUTS-1 (Nomme, 2013) thesis, the shear panels used were made out of carbon fiber weave and the grounding was solved using the aluminum rails.

\subsubsection{Environmental Durability}

The impact of space environmental effects on materials is dependent on the type of mission and the environment in which the spacecraft operates. 
The orbital space is divided into three regions based on altitude. Low-Earth-Orbit (LEO up to $100 \mathrm{~km}$ ), Mid-Earth-Orbit (MEO 100-35,000 km) and geosynchronous Earth Orbit (GEO 35,000 km and higher).

Any concern related to thermal conductivity and thermal expansion can be verified through a thermal test of the structure in an oven with minimum and maximum temperatures, depending on what time of resin is used. It was the intention of the researcher to test the structure but there was no equipment available.

\subsection{Outgassing}

Outgassing is the release of a gas that was dissolved, trapped, frozen, or absorbed in some material (Strong, 1938). In vacuum, Outgassing is a challenge to creating and maintaining clean high-vacuum environments. NASA and ESA maintains a list of lowoutgassing materials to be used for spacecraft, as outgassing products can condense onto optical elements, thermal radiators, or solar cells and obscure them. (Schläppi, 2010)

\subsubsection{NASA Outgassing Database}

An online tool from NASA has a broad database for a large range of materials outgassing (NASA GSFC, 2016) in form of tables. A screenshot of this tool is shown in Figure 4. The materials are divided in different categories, giving the option of selecting more than one at a time and it is also possible to filter with a percentage of Total Mass Loss (TML) and/or Collected Volatile Condensable Materials (CVCM) (\%) to indicate the outgassing properties of materials. The user can also type in the material name and check if the TML and CVCM percentage fulfill his/her application requirements. 


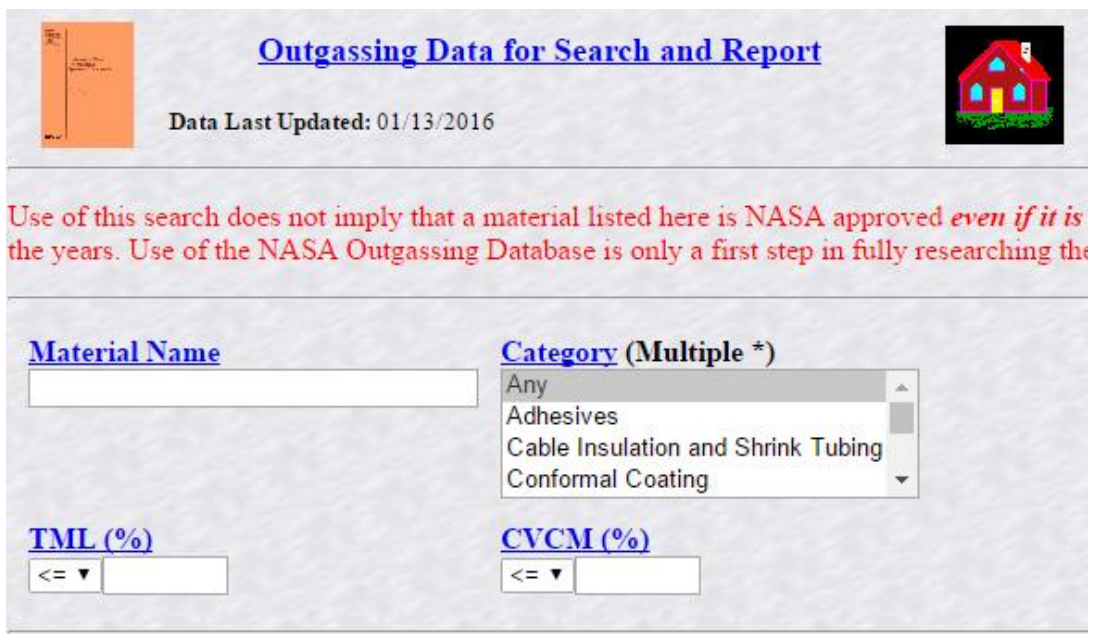

Figure 4. NASA Outgassing Online Database. Image Credit/NASA GSFC

\subsubsection{Material Selected}

Two composite materials were employed to manufacture the $6 \mathrm{U}$ CubeSat. The properties and the reason why this materials were selected are explained in Section 4.1 Materials Selection. However, after checking in the NASA Outgassing Database, the material selected for this study was not was found on the database and it was decided to test the carbon fiber weave LTM45/CF1803 (Advanced Composites Group, 2009) in the vacuum chamber to check the percentage of TML in order to use it as part of the $6 \mathrm{U}$ Structure. The carbon fiber weave LTM45/CF1803, among other different materials (unidirectional and weaves of different fibers) were donated by private companies to the Aerostructures and Composites Laboratory at Cal Poly.

\subsubsection{Outgassing Test Overview}

The industry standard test for measuring outgassing in adhesives and other materials is ASTM E595. (American Society for Testing and Materials, 2015)

Developed by NASA to screen low outgassing materials for use in space, the test determines the volatile content of material samples placed in a heated vacuum chamber. 
Samples to be tested are first preconditioned at 50\% relative humidity for 24 hours and then weighed. Following this, they go into the test chamber for another 24 hours with the temperature set at $125^{\circ} \mathrm{C}$ and the vacuum at a minimum of $5 \times 10^{-5}$ torr.

During the time in the test chamber, volatiles that outgas from the sample escape through a port in the test chamber and condense on a cooled $\left(25^{\circ} \mathrm{C}\right)$ collector plate. The sample and condensate on the collector plate are then weighed to determine the total mass lost (TML) by the sample. There are three criteria to decide if the material passes the outgassing test:

If $\mathrm{CVCM}<0.1 \%$ and $\mathrm{TM}<1 \%$, the material passes.

If $\mathrm{CVCM}<0.1 \%$ and $\mathrm{TM}>1 \%$, the material can pass if the TML-WV $<1 \%$.

If $\mathrm{CVCM}>0.1 \%$ or TML-WV $>1 \%$, the material fails.

If a material passes NASA low outgassing tests, it can be used in a multitude of applications including outer space, high vacuum, specialty optical and electro-optical applications, among others.

\subsubsection{Test Set up and Procedure}

Following the Procedure descripted in the previous Section 2.2.3 Outgassing Test Overview the test was performed in the Space Environment Laboratory from Cal Poly. The test was carried out by Dr. Kira Abercromby, who is the head of that Lab. The carbon fiber that was intended to be qualified was LTM45/CF1803 (Advanced Composites Group, 2009). The Vacuum chamber and equipment can be seen in Figure 5. 


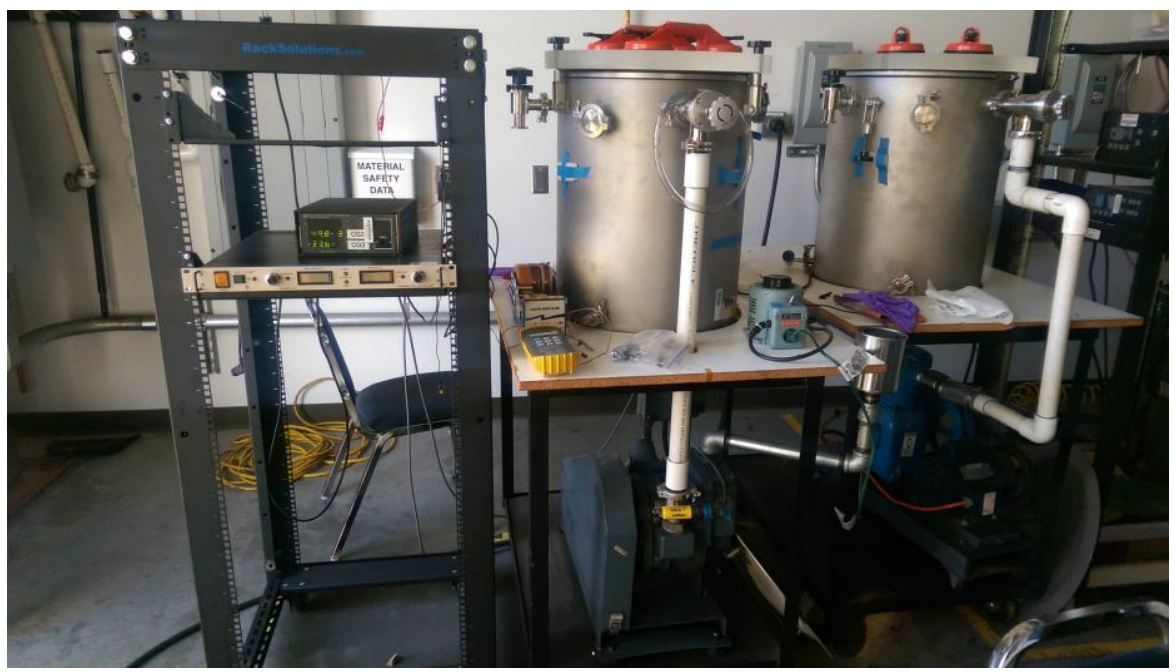

Figure 5. Vacuum Chamber Equipment at Space Environment Lab

The samples used for the test are shown in Figure 6. A total of 30 samples, of dimensions 1 inch x 1 inch x 0.1 inch of thickness, were tested.

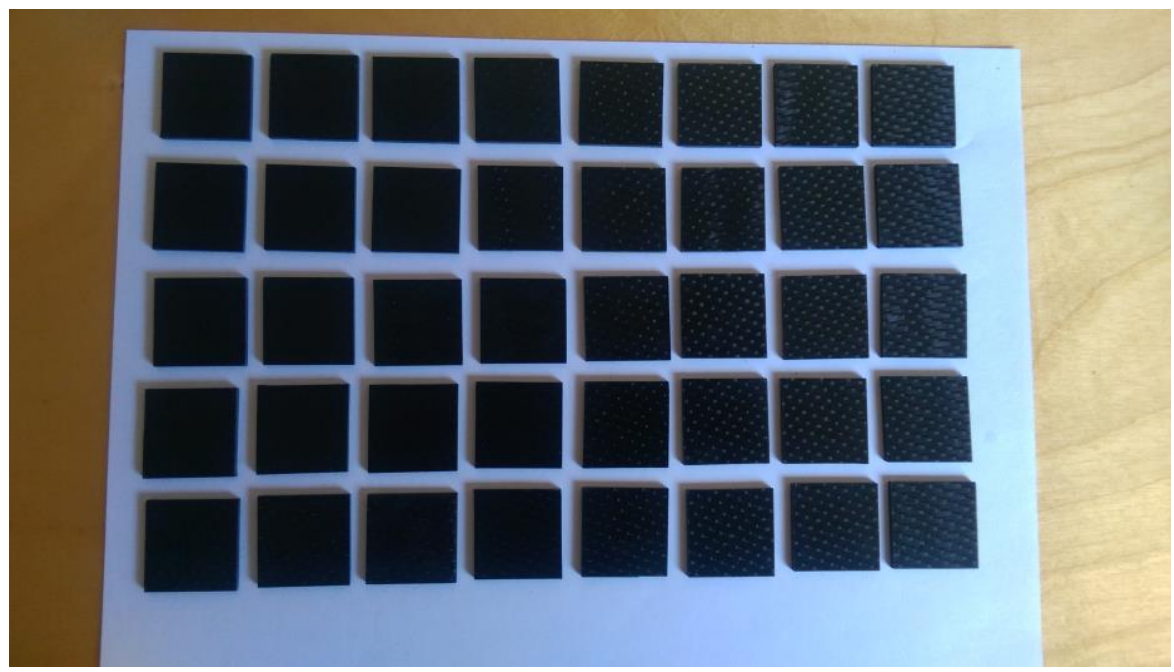

Figure 6. Carbon Fiber LTM45/CF1803 Outgassing Samples

As it was explained in the Section 2.2.3. The samples were first weighed (Figure

7) and then placed into the test chamber for 24 hours with the temperature set at $125^{\circ} \mathrm{C}$ and the vacuum at a minimum of $5 \times 10-5$ torr, as it shown in Figure 8 . A total of three tests were 
run, and 10 samples were tested per batch. When the tests were finished, the samples were weighed again.

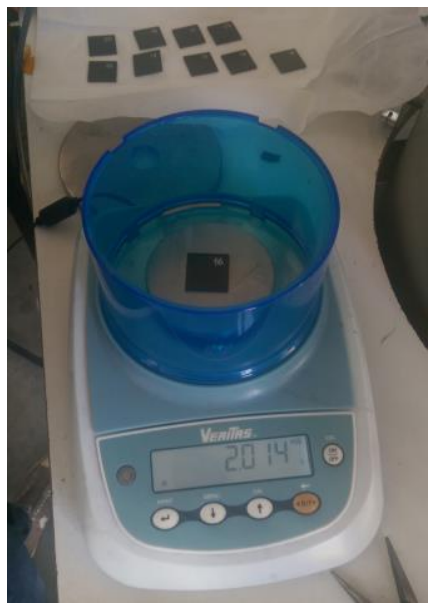

Figure 7. Weighing of Carbon Fiber Sample before the Outgassing Test

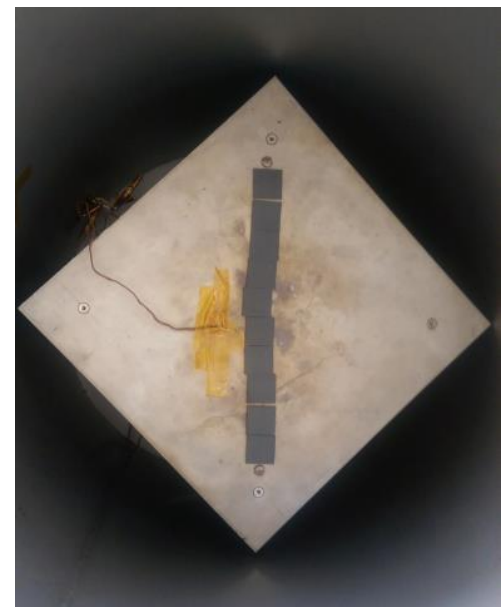

Figure 8. Carbon Fiber Samples inside the vacuum chamber

\subsubsection{Outgassing Test Results}

In Appendix A can be found, the spreadsheet with the initial and final masses, for the 30 samples that were tested, as well as the results obtained.

The results of the outgassing tests shown that the average TML percentage for test 1 was 0.97 and test 3 was 0.21 . Data from test 2 was not viable, and it was decided not to include it in the analysis.

Since the percentage of TML sought was $1 \%$ or less, Dr. Kira Abercromby recommended to move forward with the testing of the Carbon Fiber, even though results were preliminary and more testing was suggested to be conducted.

It was decided to continue with this material, since there is a broad list of materials that has been approved for space applications. 


\section{DESIGN}

\subsection{CubeSat Dimensional Requirements}

Designing a CubeSat involves the fulfillment of different types of requirements. Some of them, are based on the CubeSat Design Specification Document (hereafter referred to as CDS) (California Polytechnic State University, 2013) while others involve the use of specific drawings or additional information.

For the entire design of the structure of this thesis, the $6 \mathrm{U}$ specification drawing \#TK-6UDSB-01 (Tyvak Nano-Satellite Systems, 2014) Figure 9 (See appendix X) was used. As it was explained before, currently there are two specific standards to follow (See Section 1.1).

The CubeSat requirements listed in the CDS (California Polytechnic State University, 2013) are up to 3U CubeSat and are classified as general, mechanical, electrical and operational. For the purpose of this research, electrical and operational requirements were not considered. Some of the general requirements were not taken into account for this study.

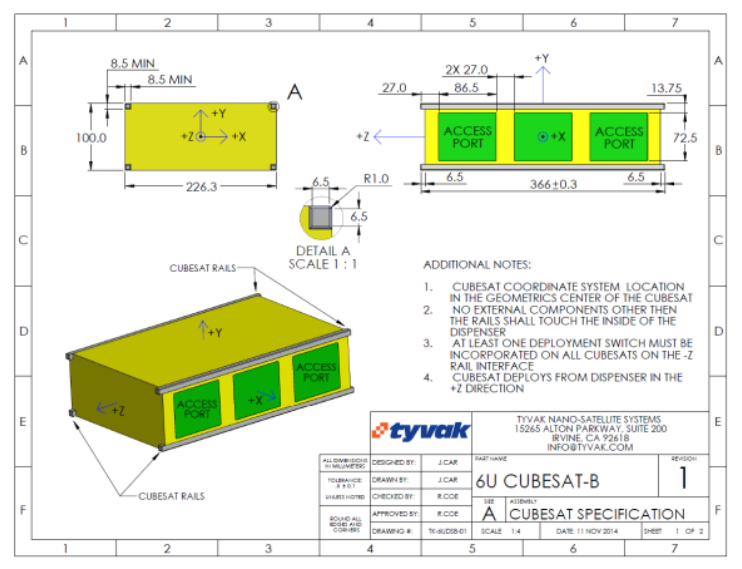

Figure 9. 6U CubeSat-B Specification Drawing. Image Credit/Tyvak 


\subsection{Design Evolution}

The researcher started the design of the $6 \mathrm{U}$ structure based on the requirements from the given standard (California Polytechnic State University, 2013). A series of iterations were performed before actually deciding on the design that was built. Example of the Design Evolution can be seen from Figure 10 to Figure 15.

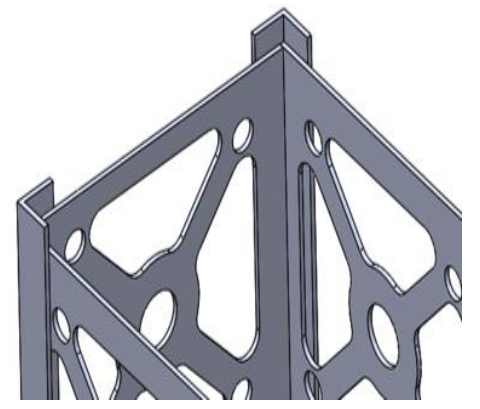

Figure 10. 6U Composite Design 1

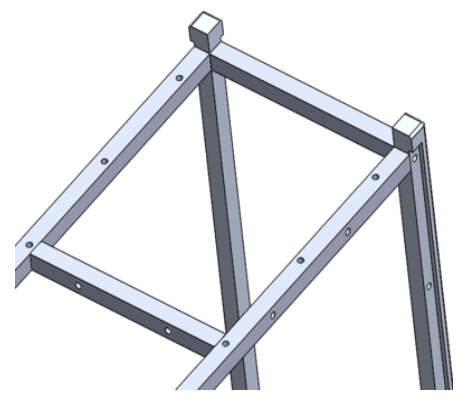

Figure 13. 6U Composite Design 4

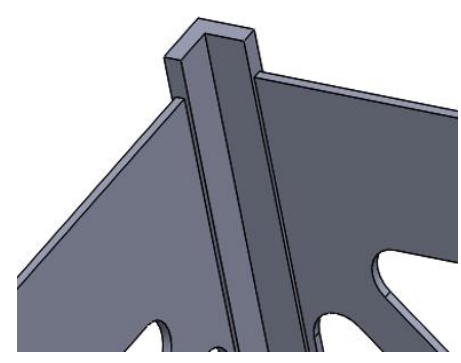

Figure 11. 6U Composite Design 2

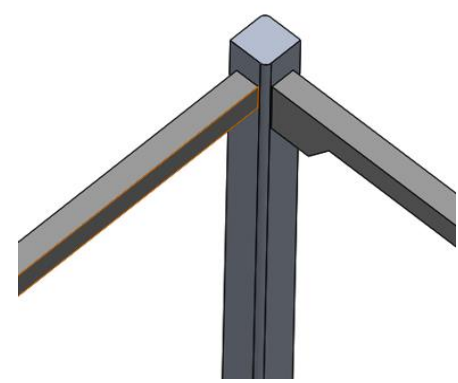

Figure 14. 6U Composite Design 5

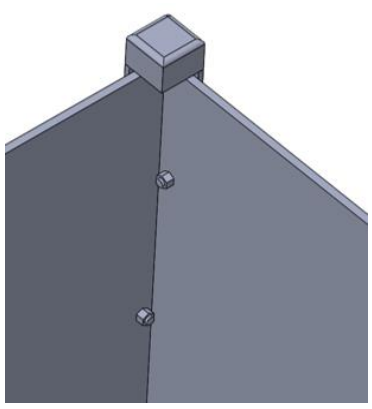

Figure 12. 6U Composite Design 3

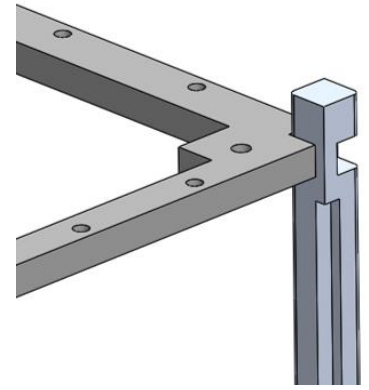

Figure 15. 6U Composite Design 6

The main reason why the first three models were discarded (Figure 10 to Figure 12) is that from a spacecraft point of view, these designs did not have good accessibility. The designs presented were difficult to access once the payload was already mounted. Moreover, the use of screws from outside of the rails, was complicated at the moment of the assembly. Also, an internal structure was needed to hold the payloads. This would have increased the total mass of the structure. Another reason why Design 2 and 3 (See Figure 
10 and Figure 11) were desestimated is because the use of a space-rated resin would have been needed.

The researcher thought about having a structure that was more accessible as well as more suitable and easier to handle for a potential operator. In addition, having a structure that is easy to assemble with a limited number of parts would help to reduce mass and make the design simpler.

Figure 13 and Figure 14 show other designs that later were discarded, because they did not fulfill all of the requirements. In addition, the researcher found that those designs, were too complicated to manufacture and assemble.

The final design was the best option of the most affordable trade-off made. It was thought to not only fulfill the requirements but also, to stabilize the structure without the need of an internal structure. Moreover, it has only 16 components and wide open spaces to access. It is composed of 4 aluminum rails, 6 panels and 6 dividers. A picture of the design proposed can be seen in Figure 16.

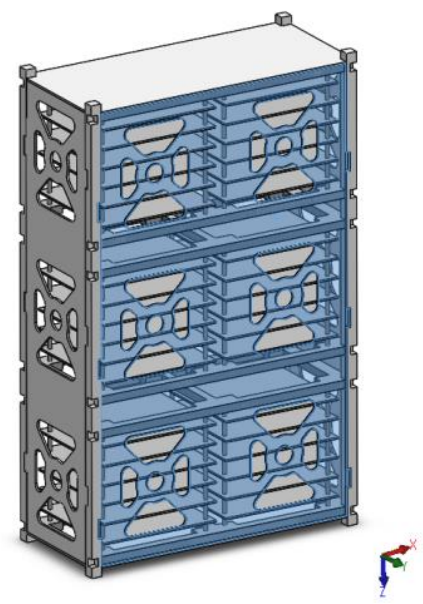

Figure 16. 6U CubeSat Structure Designed 


\section{MANUFACTURING PROCESS}

\subsection{Materials Selection}

According to the CDS (California Polytechnic State University, 2013), the material for the rails and the structure shall be, aluminum 7075, 6061, 5005, and/or 5052. If other materials are used the developer will have to submit a Deviation Approval Request (DAR) and adhere to a waiver process. Since one of the goals of this thesis was to design, build and test a composite structure, fiberglass and carbon fiber were chosen as primary materials for the structure itself while aluminum 6061 was chosen as the primary component of the rails. The researcher decided not to build rails made of composite materials, because it was thought that friction, generation of dust and finishing of the surface might affect the interaction with the dispenser. However, the researcher envisioned the possibility of continuing with this study as a future work.

\subsection{Structure Manufacturing Process}

\subsubsection{CNC Router}

For the entire manufacturing process, the researcher has used a CNC Router as can be seen in Figure 17. In order to get the equipment to run, different GCode were implemented. GCode is the common name for the most widely used numerical control (NC) programming language. It is used mainly in computer-aided manufacturing to control automated machine tools.

For the different manufacturing processes explained in the following section, a specific GCode was imported into two software: Easel and Chilipeppr. Both software are open source and have helped in the process of creating the toolpath for the carving process 
of the carbon fiber and fiberglass as well as the manufacturing process of the aluminum 6061 rails, as it is explained in the following sections.

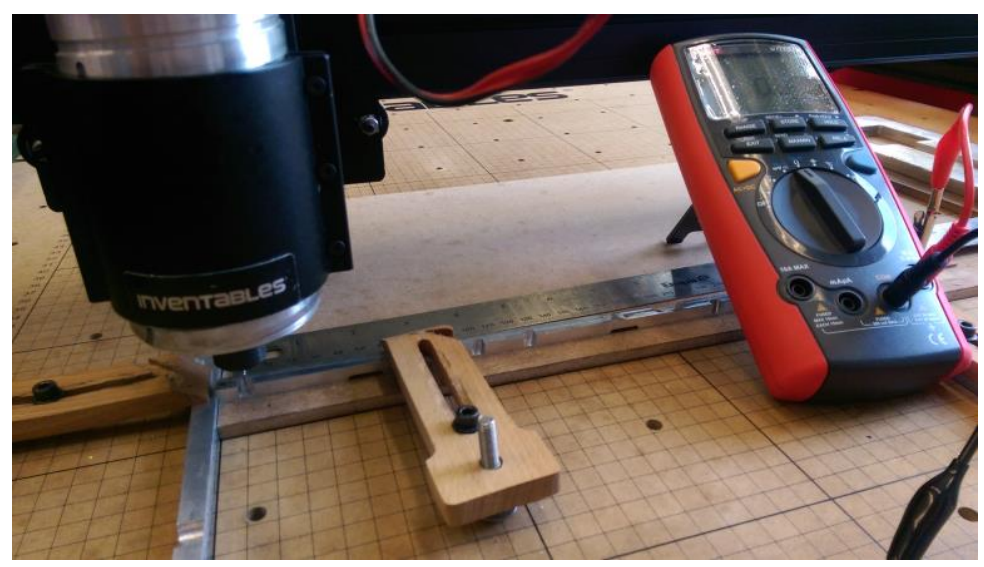

Figure 17. Inventables CNC Router

\subsubsection{Fiber Glass Reinforced Plastic Internal Panels}

For the internal part of structure of the 6U CubeSat, G10-FR4 material was selected. The G10-FR4 is a popular glass epoxy and versatile high-pressure thermoset plastic laminate grade with good strength to weight ratios. With near zero water absorption, FR-4 is most commonly used as an electrical insulator that possesses considerable mechanical strength. The main reason why this material was selected is because it is known to retain its high mechanical values and electrical insulating qualities in different environments. These attributes, along with good fabrication characteristics, lend utility to this grade for a wide variety of electrical and mechanical applications. The other option would be G11 which is even stiffer and with same low density.

A $1 / 4$ inch G10-FR4 plate was bought to use as part of the internal structure. The mechanical properties of this material were sent by the manufacturing (G-10 Mechanical Properties, n.d.). A customized GCode was created in order to carve the fiberglass (See 
Section 4.2.1). Figure 18 illustrates the milling process on the fiberglass panels. A total of 6 panels were milled in the same fashion.

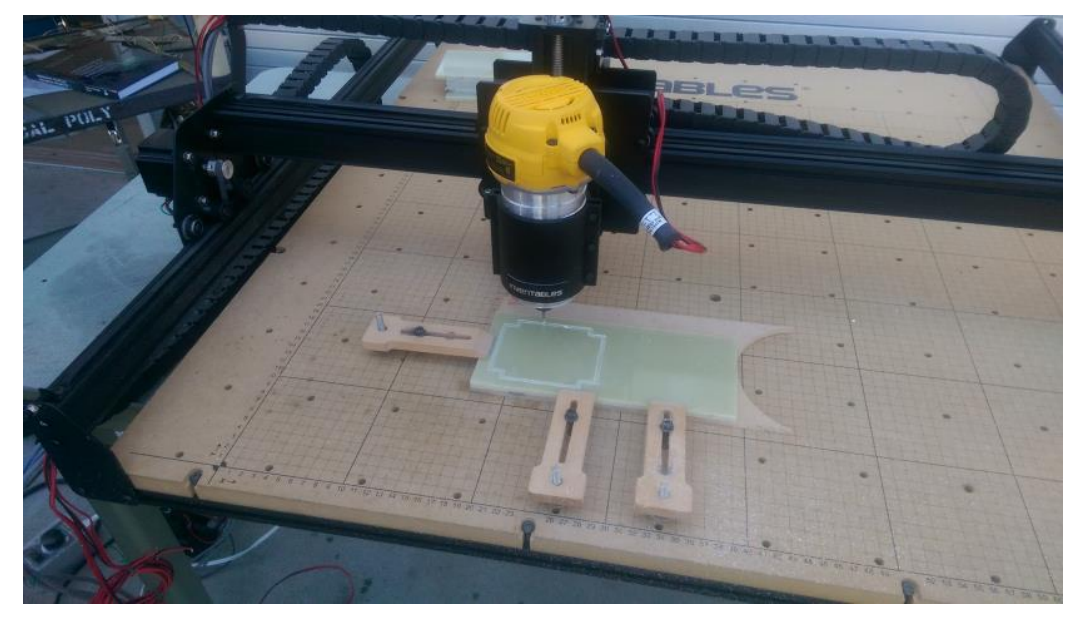

Figure 18. G10/FR4 fiberglass milling

Once the milling process of the G10/FR4 panels was completed, a total of 8 holes were made in the corners of the plates. The objective of these holes was to leave room for the inserts (EZ-Lok, 2016), that helped to attach the aluminum rails (See Section 4.2.4). A drawing of the inserts used during the assembling process can be seen in Figure 19. Table 1 shows the dimensions of the inserts that were chosen. For Data Sheet and Mechanical Properties. See Appendix B.

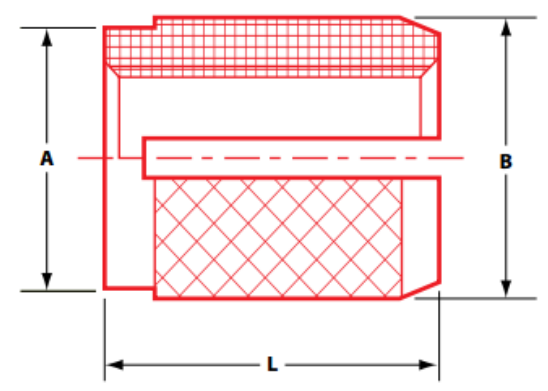

Figure 19. Drawing of the Press in place inserts . Image credit/EZ-Lok 
Table 1. Insert dimensions

\begin{tabular}{|c|c|c|c|c|c|c|}
\hline $\begin{array}{c}\text { Part } \\
\text { Number }\end{array}$ & Thread Size & $\begin{array}{c}\mathbf{L} \\
\mathbf{i n}(\mathbf{m m})\end{array}$ & $\begin{array}{c}\mathbf{A} \\
\mathbf{i n}(\mathbf{m m})\end{array}$ & $\begin{array}{c}\mathbf{B} \\
\mathbf{i n}(\mathbf{m m})\end{array}$ & $\begin{array}{c}\text { Hole } \\
\text { Size } \\
\mathbf{i n}(\mathbf{m m})\end{array}$ & $\begin{array}{c}\text { Minimum } \\
\text { Depth } \\
\mathbf{i n}(\mathbf{m m})\end{array}$ \\
\hline 240-000-BR & $0-80$ & $\begin{array}{c}0.125 \\
(3.175)\end{array}$ & $\begin{array}{c}0.094 \\
(2.3876)\end{array}$ & $\begin{array}{c}0.104 \\
(2.6416)\end{array}$ & $\begin{array}{c}0.094 \\
(2.3876)\end{array}$ & $\begin{array}{c}0.130 \\
(3.302)\end{array}$ \\
\hline
\end{tabular}

Figure 20 illustrates the fiberglass panels with the inserts placed in the corners of them.

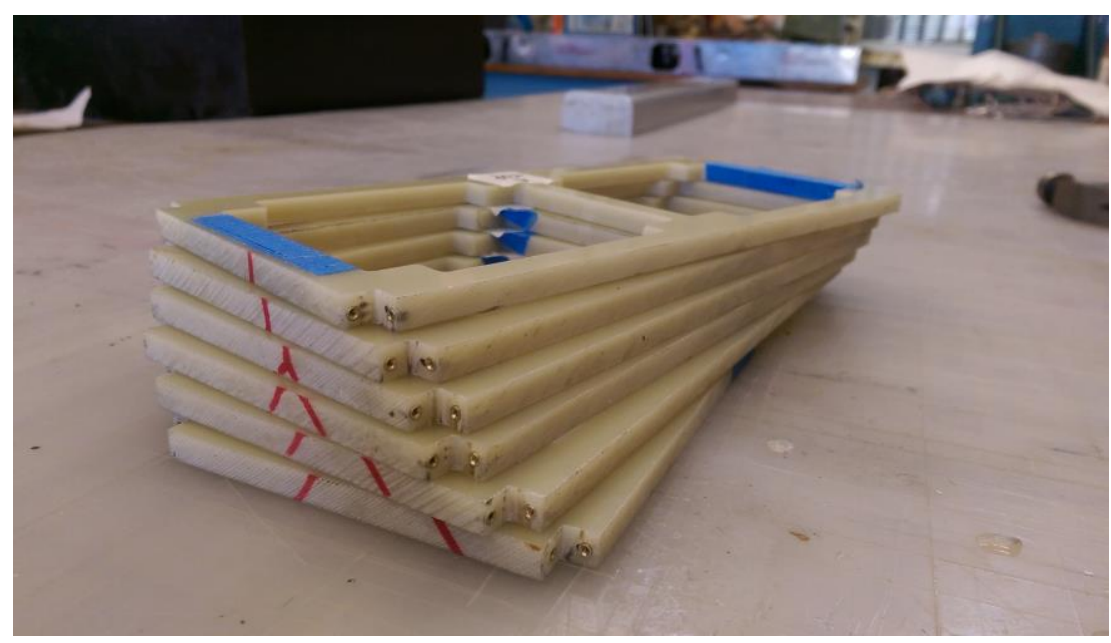

Figure 20. G10/FR4 Dividers finished. Press Inserts placed

More holes were made on the short and long laterals of the fiberglass panels as well as on the top and bottom faces of them. Inserts were placed here, helping to connect the fiberglass panels with the carbon fiber shear panels. A picture of this process can be seen in Figure 21. 


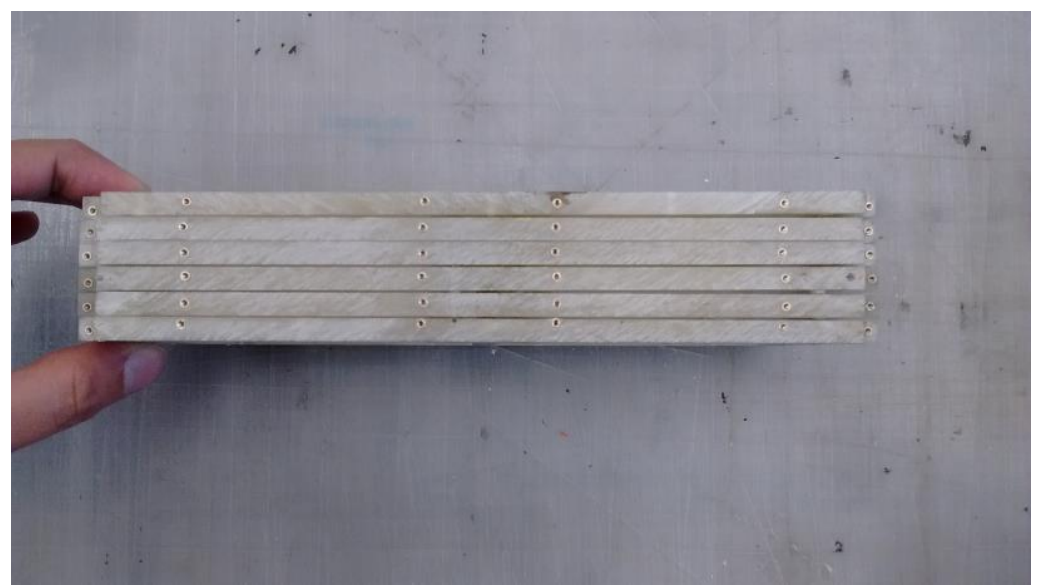

Figure 21. Holes and inserts made on one of the laterals of the G10/FR4 panels

\subsubsection{Carbon Fiber Shear Panels Fabrication}

The material selected was LTM45/CF1803. This material, a pre-impregnated (hereafter referred to as pre-preg) carbon fiber weave, was used to manufacture the shear panels of the structure. A total of four plies were stacked together applying the hand layup technique. The first step in the process is shown in Figure 22, which consisted of cutting the carbon fiber. In order to make the manufacturing process and the secondary process more convenient, four layers of LTM45/CF1803 were cut for each of the six panels. Each of the layers had the dimensions of the final components. 


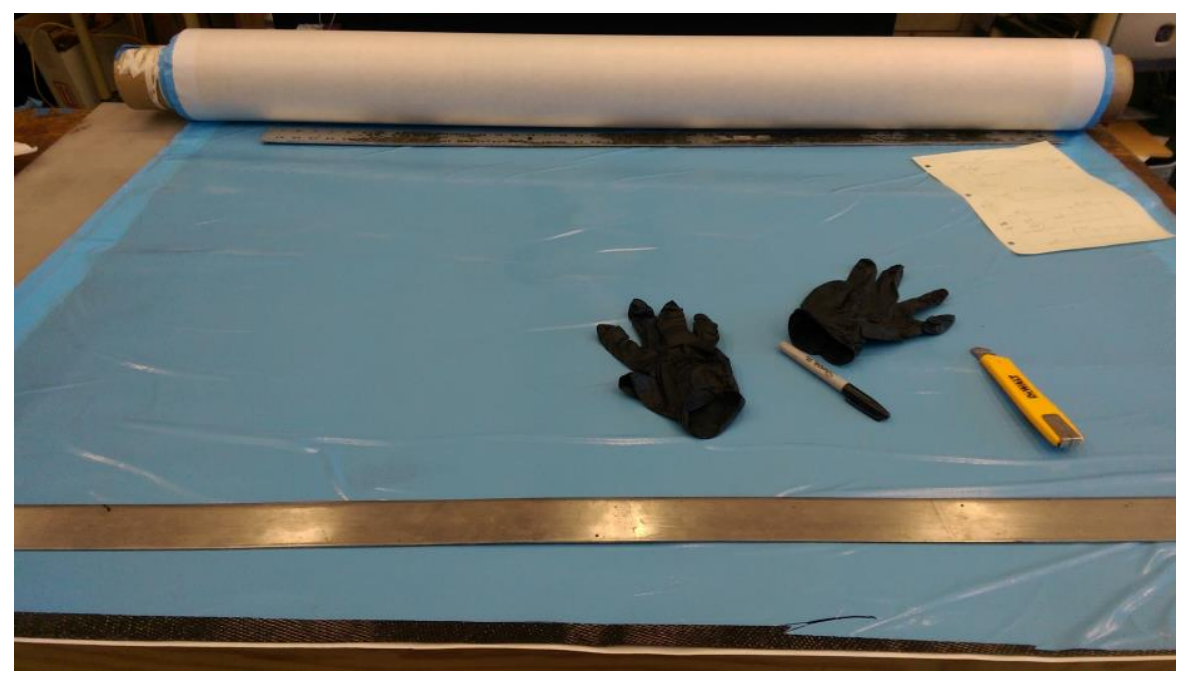

Figure 22. Cutting out the dimension of the LTM45/CF1803 Carbon Fiber used

In addition to the four carbon fiber layers, a series of different materials were used in the stack, in order to prepare the vacuum bag that was used to cure the carbon fiber inside the Autoclave. The stack is shown in Figure 23.

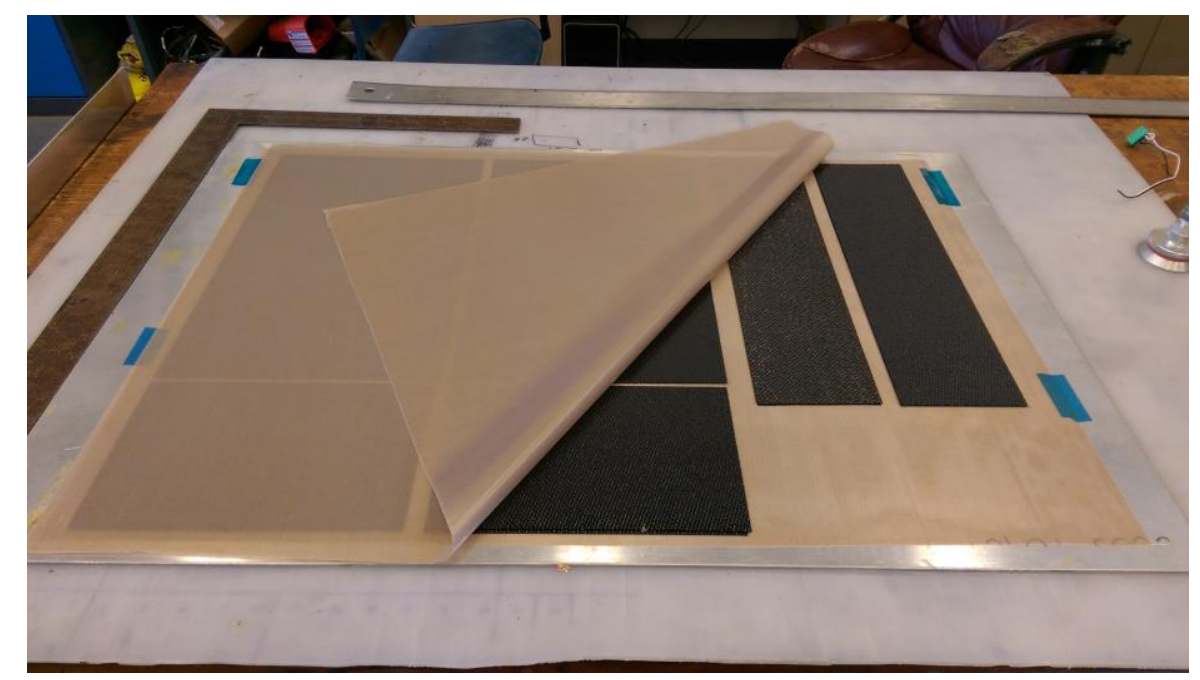

Figure 23. LTM45/CF1803 Carbon Fiber Lay Ups in between non porous material

The sequence was composed by a non-porous material, four layers of bidirectional LTM45/CF1803 pre-preg carbon fiber, non-porous material again, cotton sheet (breather), 
sealant tape and vacuum bag material. The non-porous material was essential to use because it allows for resin to flow through its layer and fully saturate the pre-preg carbon fiber. The cotton sheet or breather was used at the base of each vacuum pump which also covered the non-porous material and carbon fiber lay-up. The cotton sheets were used as precautionary material in case any resin escaped from the carbon fiber and into the vacuum pumps. The goal was to prevent resin from clogging the pipes.

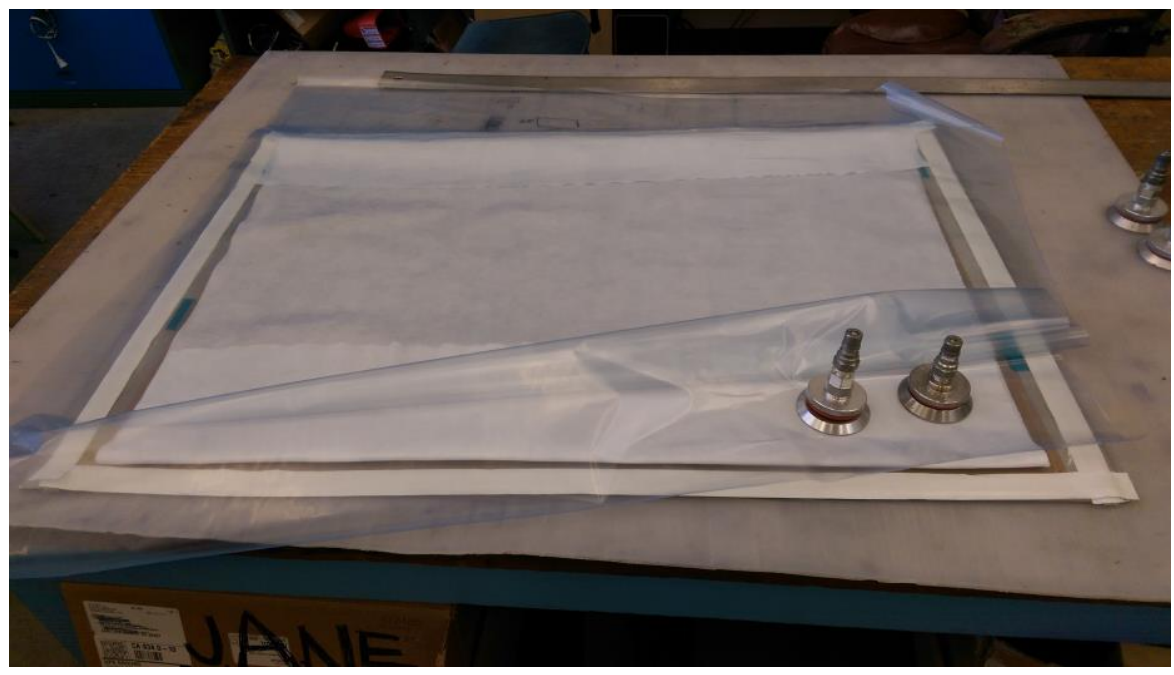

Figure 24. Vacuum bag preparation

Once the lay-up was completed, and after applying pressure with a pump, it was placed inside the autoclave at the Aerostructures and Composites Laboratory, which is property of the Aerospace Department from Cal Poly. Once inside the autoclave the vacuum pump valves were connected to the vacuum pump hoses. The hoses were then connected to the two connections on the tool surface to apply vacuum on the specimen. 


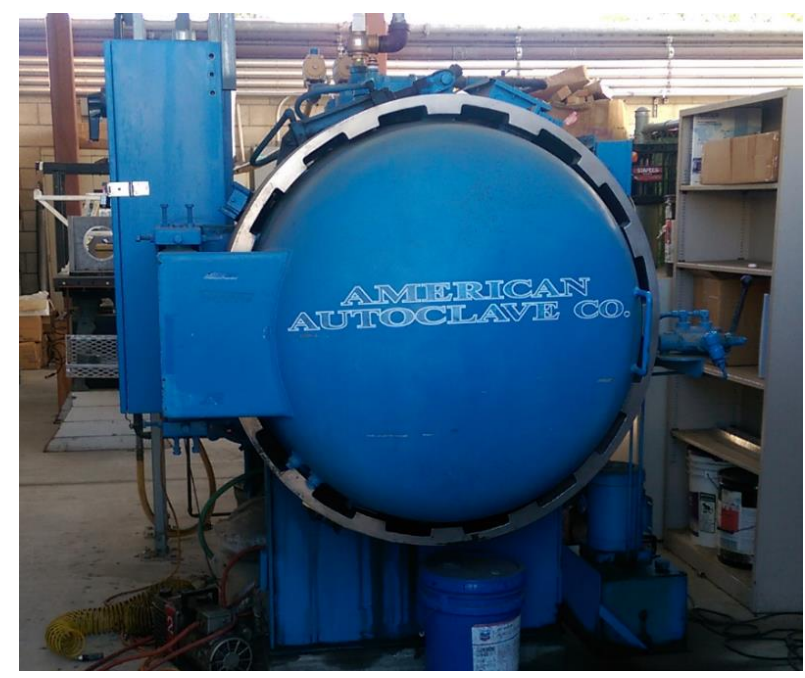

Figure 25. American Autoclave Co. at Aerostructures and Composites Lab (Cal Poly)

The vacuum bag stack can be seen in Figure 26 after it was removed from the autoclave, and in Figure 27 the carbon fiber plates were ready to pass on to the next stage.

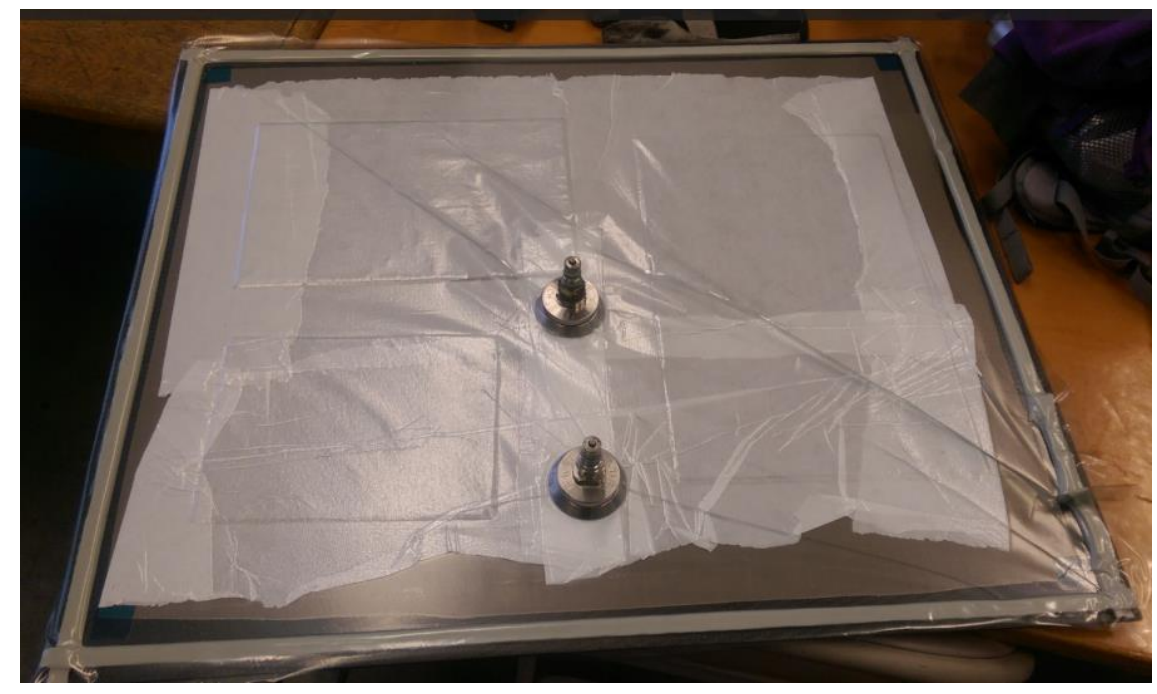

Figure 26. Vacuum bag after taking it out from the Autoclave 


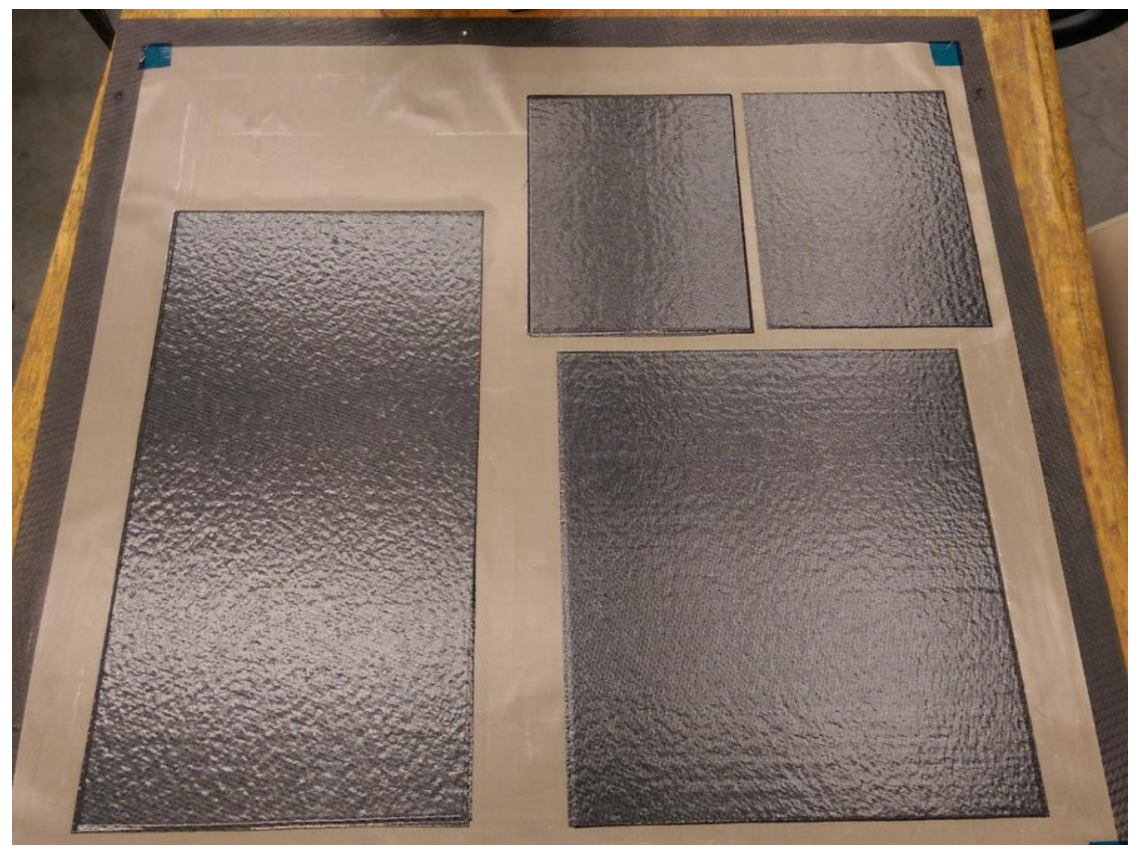

Figure 27. LTM45/ Carbon Fiber Shear Panels

A secondary process was carried out on the carbon fiber panels. The six panels, required a cut-out were needed on the carbon fiber panels and the CNC router was used to perform this operation. In the same fashion as for the fiberglass (See previous section 4.2.2), a GCode was created and the cut outs were performed. An example of the GCode is illustrated in Figure 28 and a picture of this process is illustrated in Figure 29. The researcher had written a specific GCode for each of the milling processes.

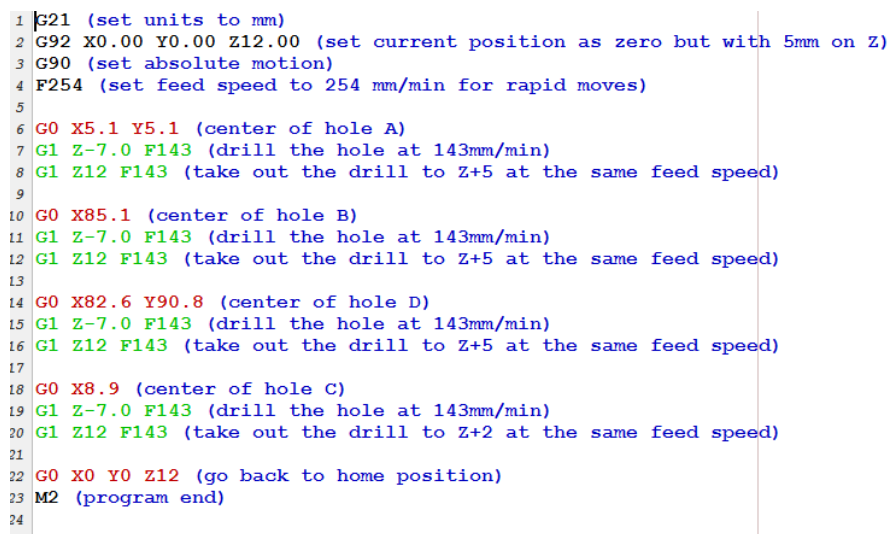

Figure 28. Example of one of the GCodes written for the CNC milling process 


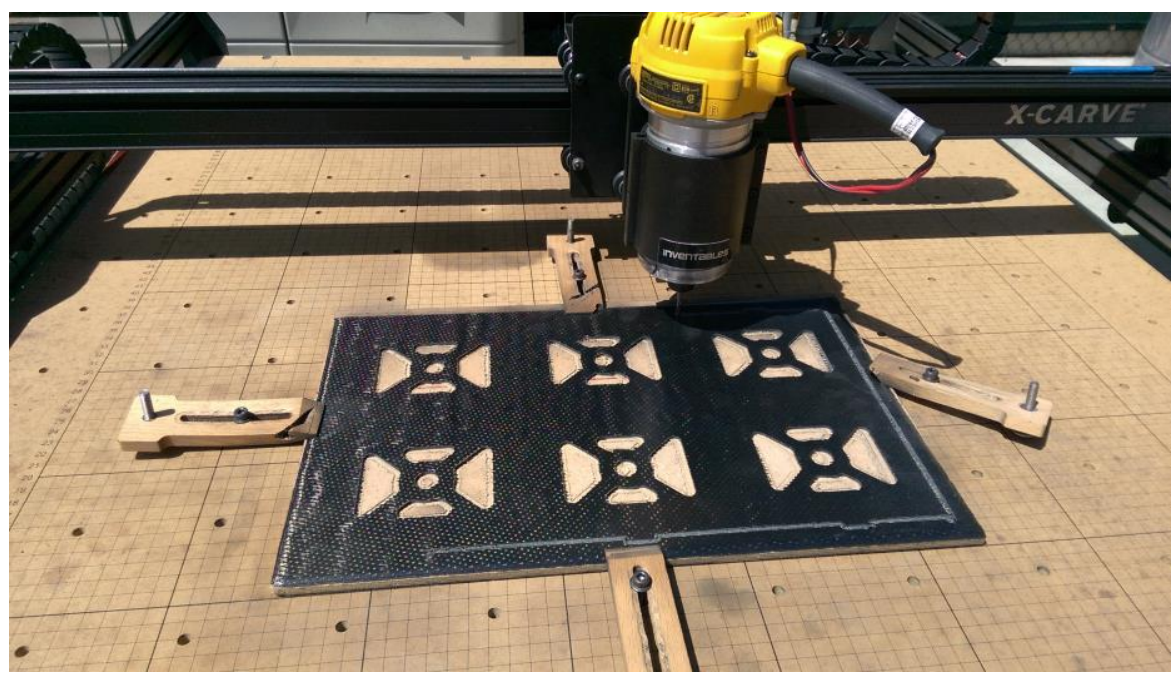

Figure 29. Milling of the cut outs of the carbon fiber shear panels

\subsubsection{Aluminum 6061 rails}

The researcher followed requirement 3.2.15 from the Cal Poly CDS (California Polytechnic State University, 2013), which states that the material for the rails shall be either aluminum 7075 or 6061 . For the purpose of this Thesis aluminum 6061 was selected.

For the manufacturing of the rails, the researcher started with an aluminum $3 / 8$ inch x 12 inch x 24 inch plate. Then, four bars of dimensions 3/8 inch x 3/8 inch x 14.5 inch of this plate were cut in order to make the machining process easier (Figure 30). Figure 31 shows the set up and machining of the aluminum rails. The machining time for each of the four rails was two hours. 


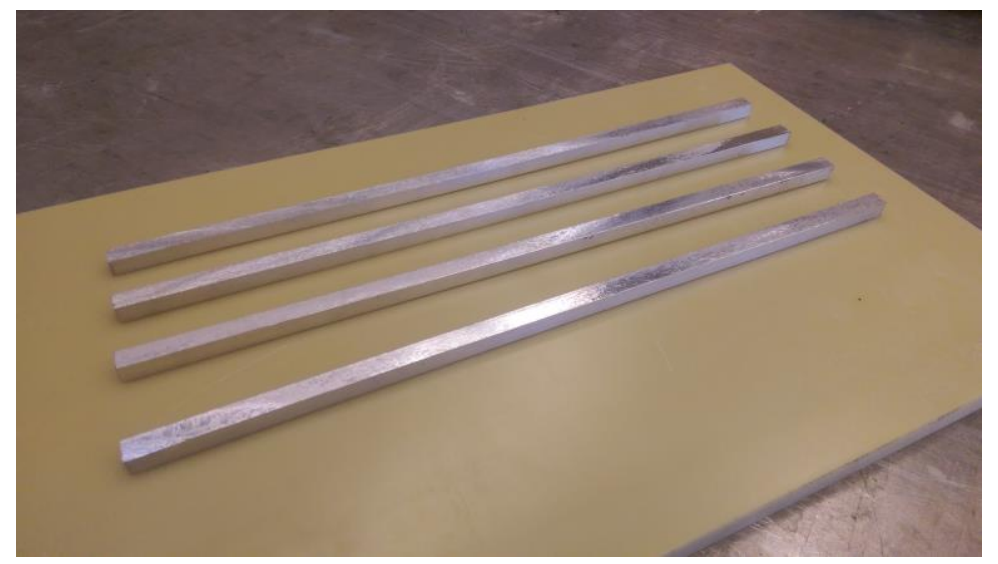

Figure 30. Aluminum 6061 bars 3/8" x 3/8" x 14.5" before being machined

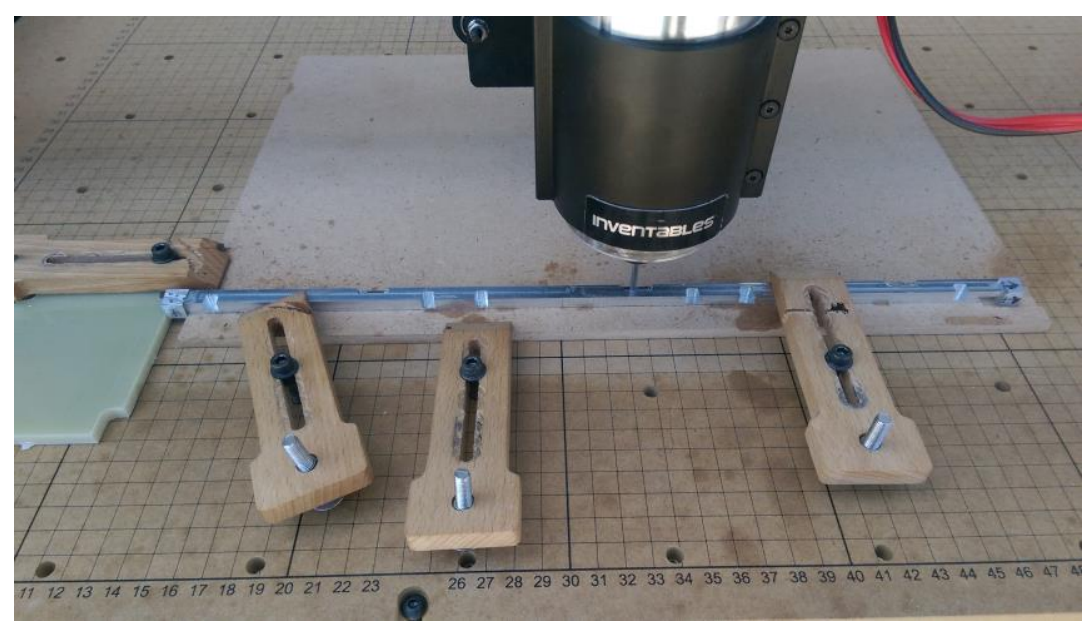

Figure 31. 6U CubeSat aluminum 6061 rails machining process

Since this $6 \mathrm{U}$ CubeSat was a research study and was not intended to be launched, and it was a research study, the anodized coating requirement for the rails (Requirement 3.2.16) according to the CDS (California Polytechnic State University, 2013) was not taken into account. Figure 32 shows the four CubeSat rails finished. 


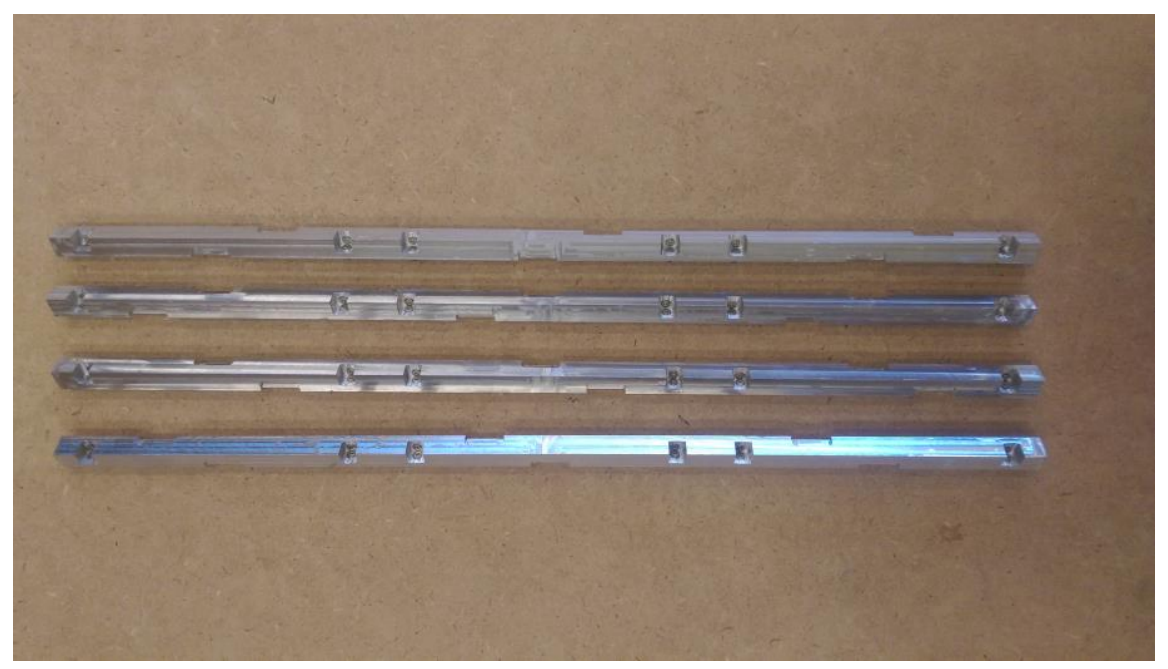

Figure 32. Aluminum rails finished

\subsection{Payload Manufacturing Process}

Since one of the main goals of this Thesis was to test the structure under random vibrations (NASA Goddard Space Flight Center, 2013), the manufacturing of dummie loads was needed. The design of the payload (dummie loads) was done following the PC104 standard (PC/104, 2008). This standard establishes general dimensions of $90.2 \mathrm{~mm}$ x $95.9 \mathrm{~mm}$ (3.55 inch x 3.77 inch) as shown Figure 33.

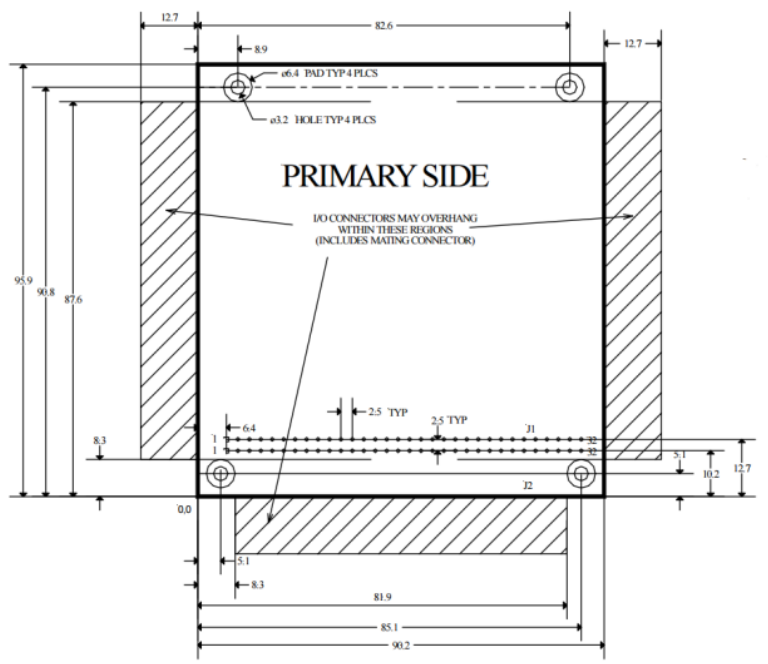

Figure 33. PC104 Standard. Image credit/PC104.org 
The primary materials used to build the dummie loads were two different types of structural fiberglass. Figure 34 shows one of the dummie load plates being manufactured. In each of the plates a total of four holes were made. The dimensions of the holes, tolerances, and locations were determined according to the PC104 reference document (PC/104, 2008).

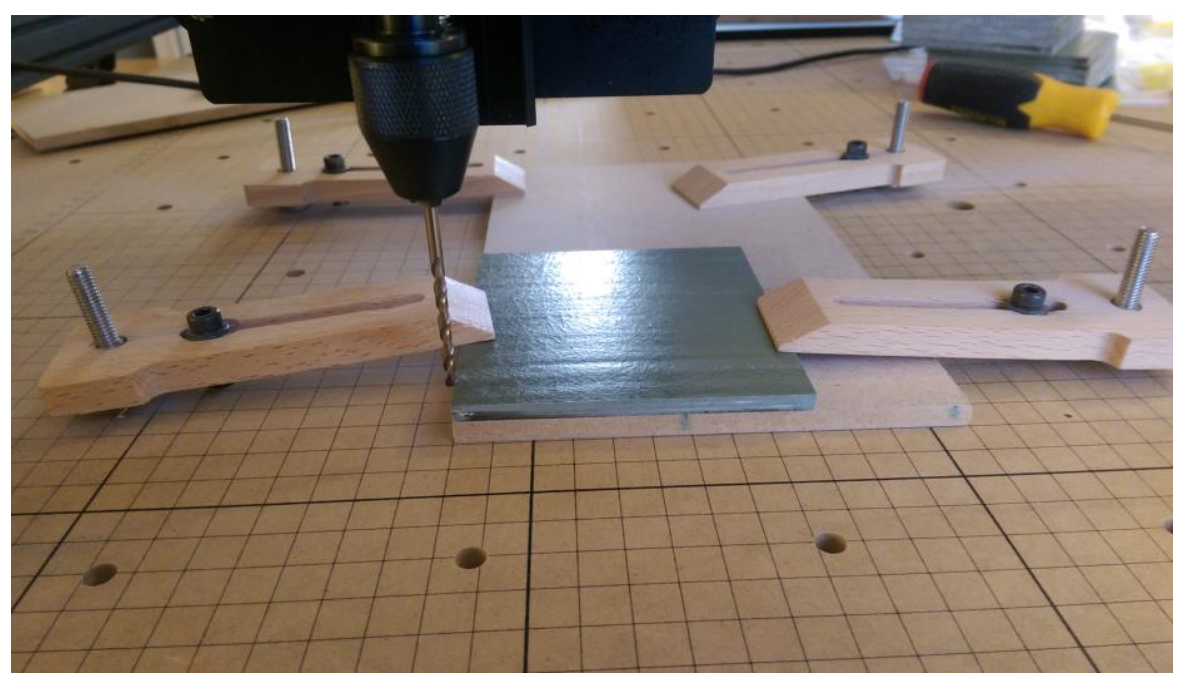

Figure 34. Dummie printed board circuit (PBC) machining

Each stack was composed of five PC104 dummie load plates. In order to connect the plates, four standoff spacers Hex M3 Male x M3 Female of 15mm length were used. In Figure 35, the six stacks of dummie loads are shown.

The mass of each stack was 400 grams. In order to make a more representative mass for the payload, it was decided to add more masses between each of the panels that represented the masses of batteries, wiring, and connectors. In order to do that, cast iron pieces were added to the stacks. Finally, the total mass for each stack was 950 grams. 


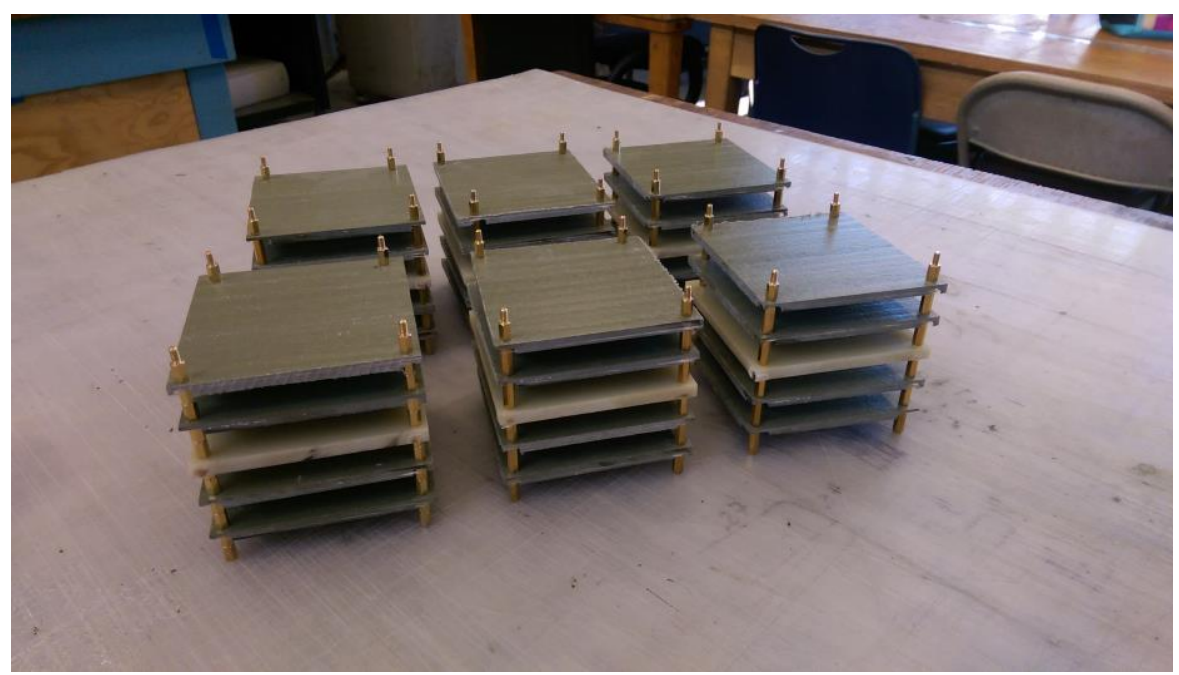

Figure 35. Payload - Dummies load finished

\subsection{Structure Assembly}

In order to put together the structure, an internal procedure was followed and different Ground Support Equipment (GSE) was built to help out during this process.

The first step was to mount the two payload stacks with two dividers. At the end of each stack, four hexagonal stand-offs male-female were placed. Each top divider had eight inserts, where the eight standoff were mounted from the male side. At the bottom part eight through holes were made and the female side of the stand-offs were connected to the fiberglass panels with a screw and a nut. A picture of this step is shown in Figure 36. 


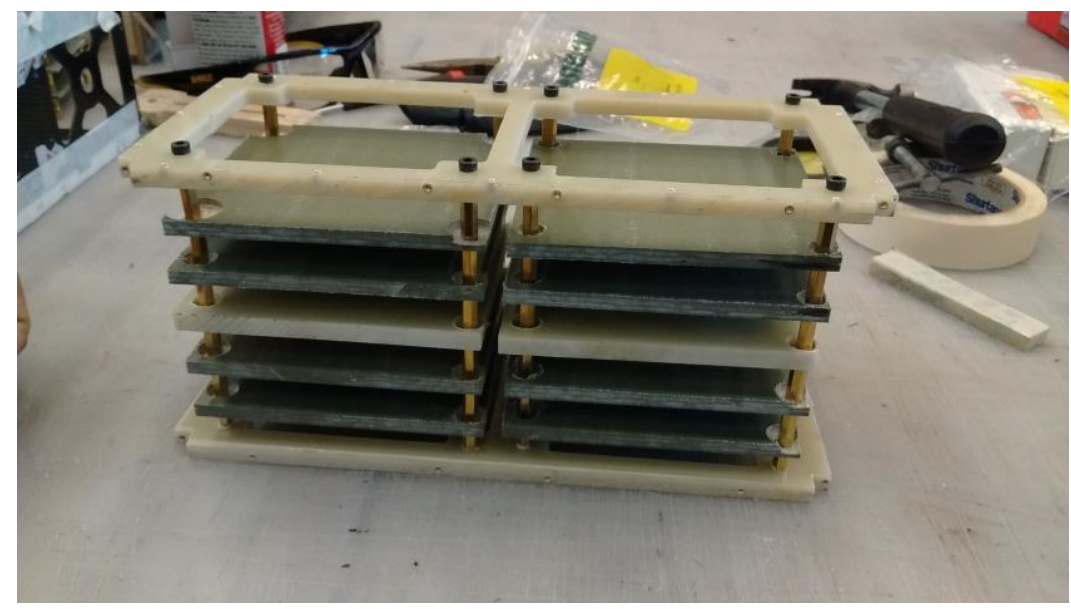

Figure 36. Two payload stacks assembled to the fiberglass panels

This process was repeated 3 times in order to get the six payloads attached. The second step in the assembly process was to mount the aluminum rails. The aluminum rails had equally distributed grooves that were made to connect them to the payload through the G10/FR4 panels.

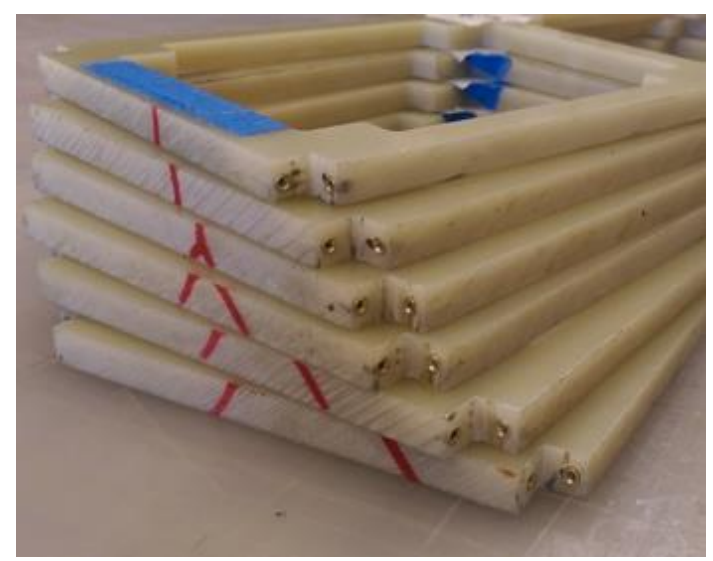

Figure 37. Inserts placed in the corners of the G10/FR4 panels

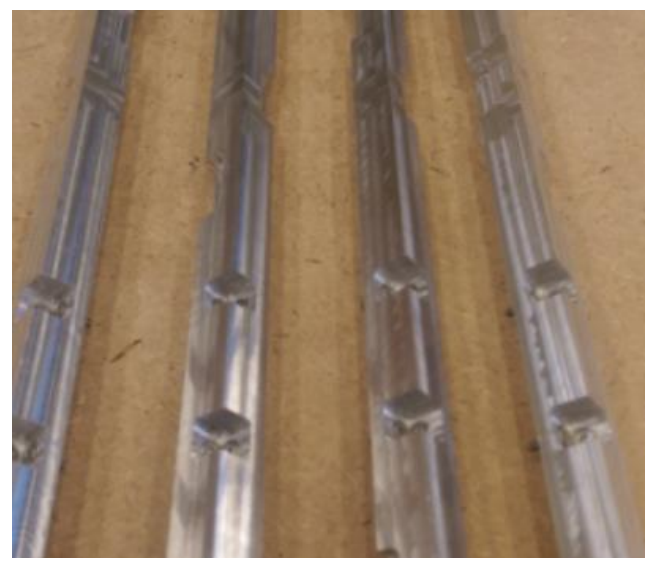

Figure 38. Equally distributed grooves in Aluminum rails

The partially assembled structure is shown in Figure 39. The four rails were connected to the G10/FR4 fiberglass dividers, and therefore attached to the payloads. 


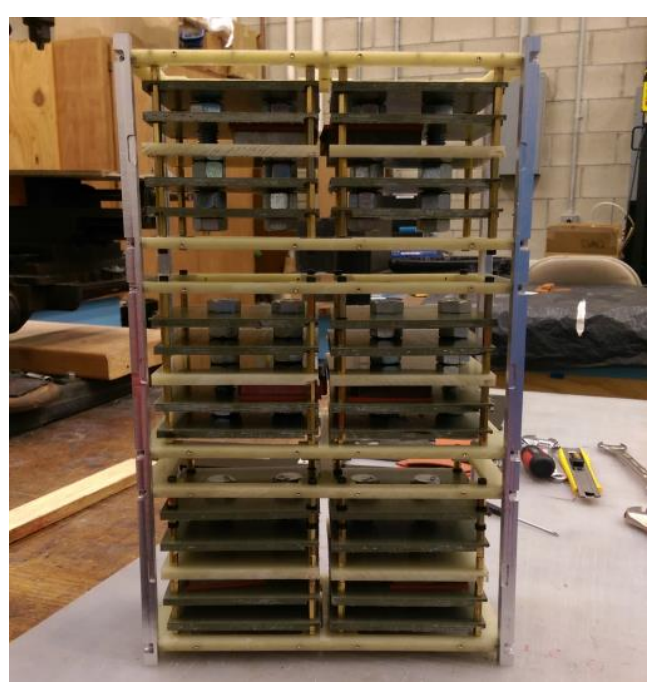

Figure 39. Structure semi- assembled with payloads and G10/FR4 panels

The last step in the assembly process was to mount the carbon fiber panels. Figure 21 was shown the inserts when they were placed in the laterals of the fiberglass plates. First the through holes were drilled on the carbon fiber panels, and later a countersunk process was done.

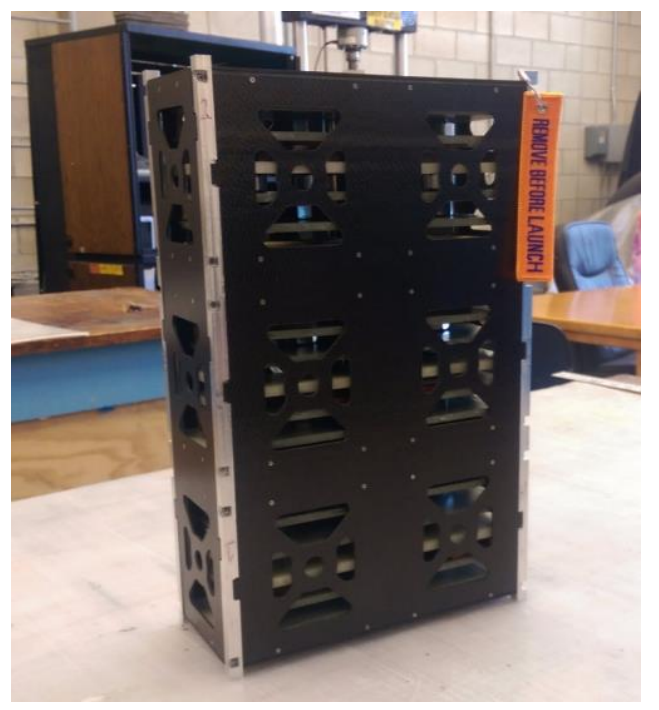

Figure 40. 6U CubeSat Structure "YaniSat-1" 


\subsection{U Satellite Box Dispenser}

\subsubsection{Satellite Dispenser Function}

A Satellite Dispenser is a reliable, testable, and cost-effective deployment mechanism for small secondary or tertiary payloads. It fully encapsulates the payload during launch and thus provides mission assurance for both the primary payload and launch vehicle. (Planetary Systems Corporation, 2016). The dispenser is also used during the testing phase. This is illustrated in Figure 41 and Figure 42 shown below.

At the beginning of this Thesis, a commercially available 6U Dispenser was planned to be used for the Testing phase. Due to that the impossibility at the moment of the tests, to use the dispenser and since no other alternative was encountered, a dispenser with similar characteristics was designed and built.

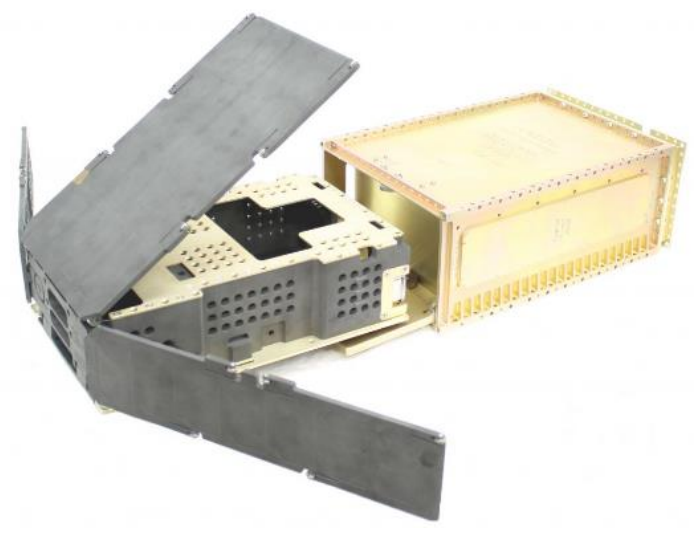

Figure 41. 6U Dispenser with payload. Image Credit/Planetary Systems Corporation

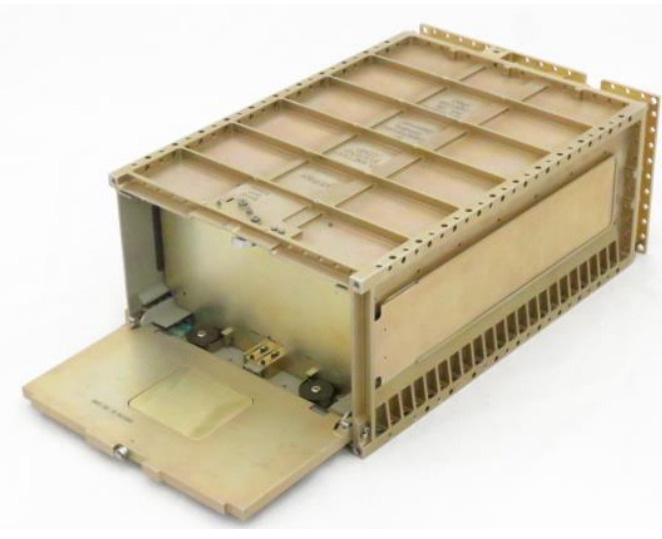

Figure 42. 6U Dispenser. Image Credit/Planetary Systems Corporation

\subsubsection{Dispenser Construction and Attachments}

In other to attach the dispenser to the shock table and to the shake table a dispenser was built. At the bottom part and in the bottom side, holes were drilled, to assist and facilitate the interaction with the shock table and shake table. Basically, in order to mount the dispenser to the apparatus, the same pattern of holes was drilled on it. 
The shock table (See Section 5. SHOCK TESTING) had equally spaced holes at 6 inches in each directions. The Shake table (See Section 6. RANDOM VIBRATION TESTING) instead, had equally spaced holes at 4 inches in each directions.

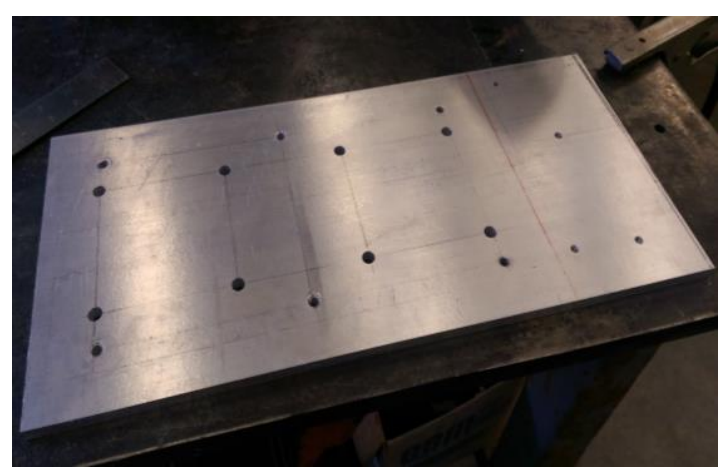

Figure 43. Dispenser Interface Plate

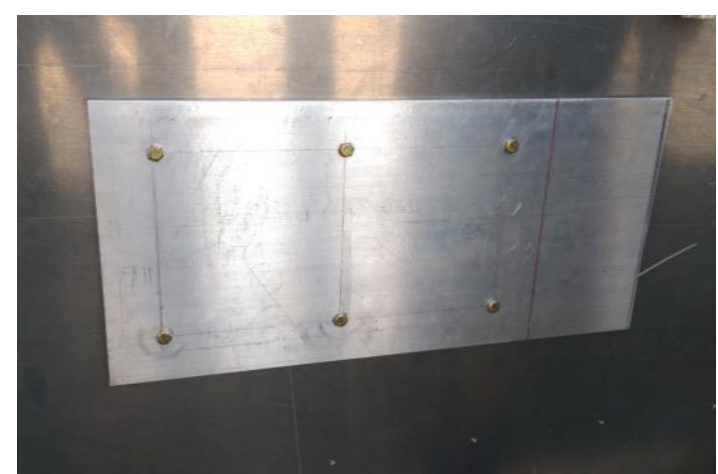

Figure 44. Dispenser Interface Plate mounted on the Shock Table

After checking that the holes were matching, plates with similar thickness at the ones the commercially available dispensers are made of, were welded and shaped in order to obtain a dispenser to use for the tests. Figure 45 and Figure 46 shown

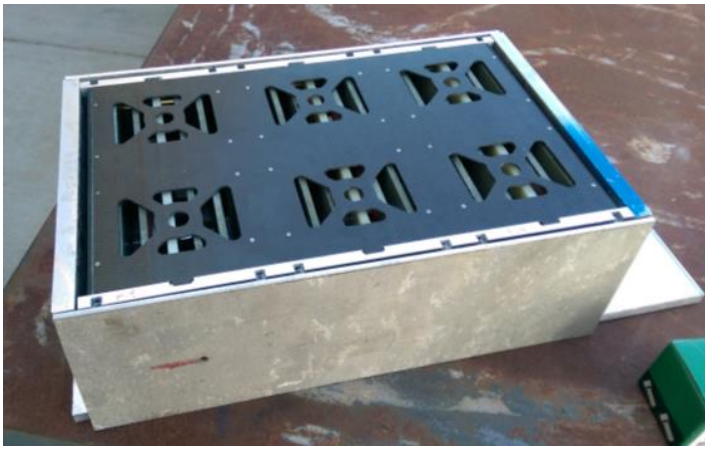

Figure 45. Test Dispenser with the satellite mounted.

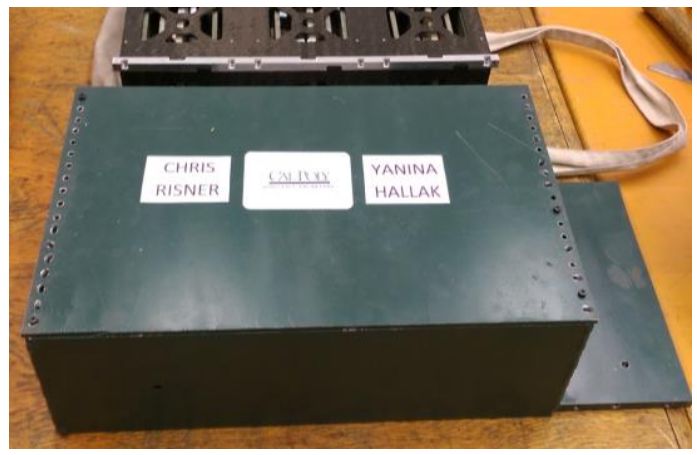

Figure 46. Test Dispenser with lid placed. 


\section{SHOCK TESTING}

\subsection{Test Overview and Equipment Description}

Pyrotechnic shock is a source of load that comes from explosive separation events involving the boosters, payload fairing, and spacecraft, as well as release mechanisms for solar panels and other deployable appendages. This shock causes high acceleration and high frequency over a very short time. (Larson J. R., 2010).

The shock wave goes from the launcher to the payload. The peak can be up to $10000 \mathrm{~g}$ depending on the natural frequency. The shocks happens with the pyrotechnics of the separation of the stages. The shock test creates a shock that it is transmitted through the structure. It is measured in orders of "g" and natural frequency (Hz) (Abercromby, 2015).

NASA has specific values for Shock Test that comprised a variety of launch vehicles. (NASA Goddard Space Flight Center, 2013). This curves have an upper limit and a lower limit that should be followed. Curves are shown in Figure 47.

The acoustic environment is a function of the physical configuration of the launch vehicle, its acceleration time history, and the configuration of the propulsion system. (Larson J. R., 2010). Figure 48 illustrates the acoustic environments of several launch vehicles. For the purposes of this test, the satellite was exposed at levels that tried to englobe as many launch vehicles as possible in order to make the study more conservative. 


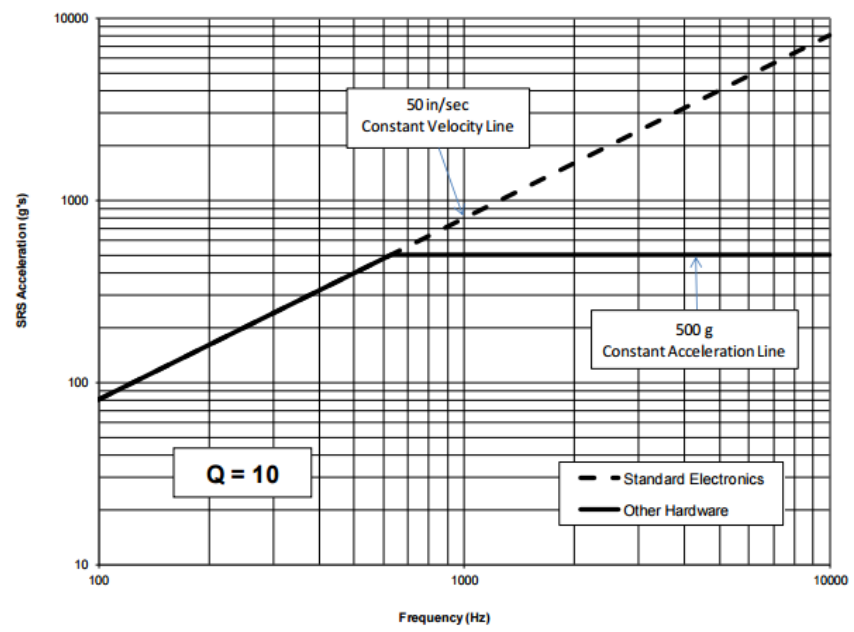

Figure 47. Shock Response Spectrum for assessing Component Test Requirements

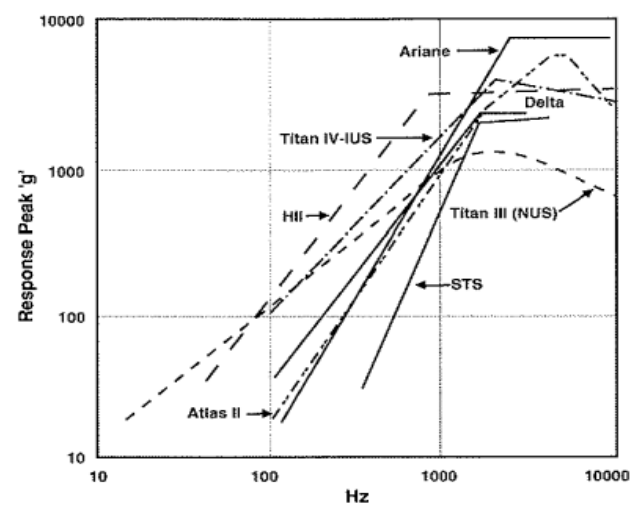

Figure 48. Random vibration levels for different Launch Vehicles. Image/SMAD

The test was performed at the Space Environment Lab at Cal Poly which is equipped with a Shock table (Figure 49). The shock table, which was fixed to the ground, was constituted by an aluminum 5052 plate 4 feet tall by 6 feet wide by $1 / 2$ inches thick and a hammer with a mass of 20 pounds. At the top part of the hammer, two wood plates with 20 holes each were mounted. Each of this holes, had a specific X and Y locations. In Figure 50 is shown the wood plates where each location represent a different angle. A rounded aluminum bar connected both wood plates. 


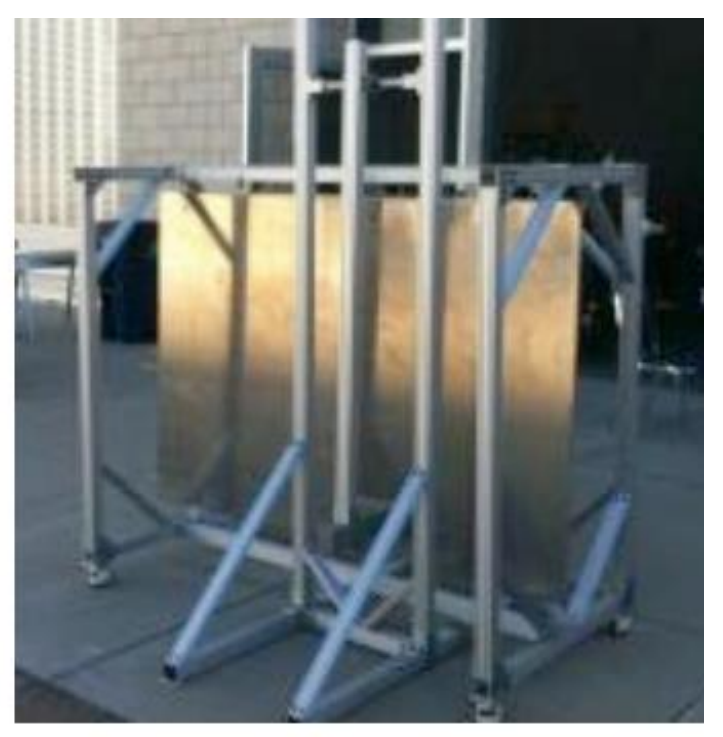

Figure 49. Shock Table at the Space Environment Lab, Cal Poly

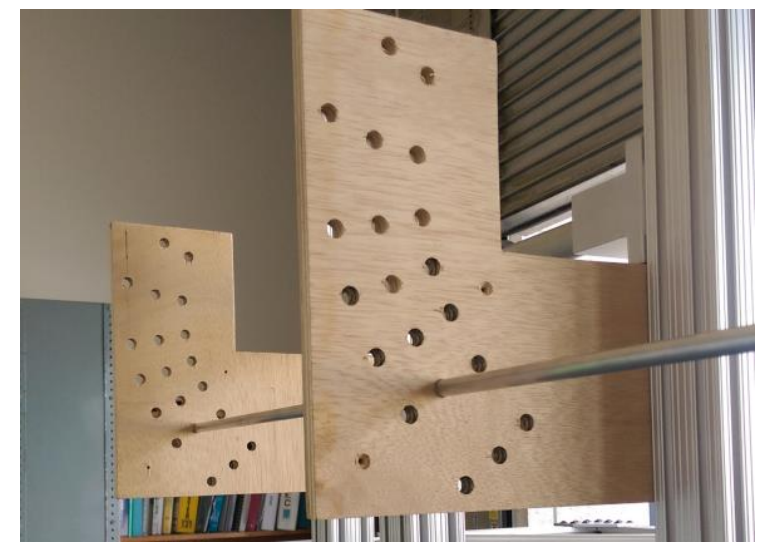

Figure 50. Wood plate representing different angles on top of the hammer

The tests that were performed, consisted on raising the hammer until the desired angles was reached. This occurred when the aluminum bar was touched. Once in that position, the hammer was dropped, causing an input curve to the shock table.

The response to the shock test in the 3 axis of the satellite were tested. In the case of The $\mathrm{X}$ and $\mathrm{Z}$ axes the hammer was placed aligned with the shock table plate and in the case of the Y axis, the hammer was placed behind the plate. 


\subsection{CubeSat Reference System}

The CubeSat reference system shall follow the configuration shown in Figure 51

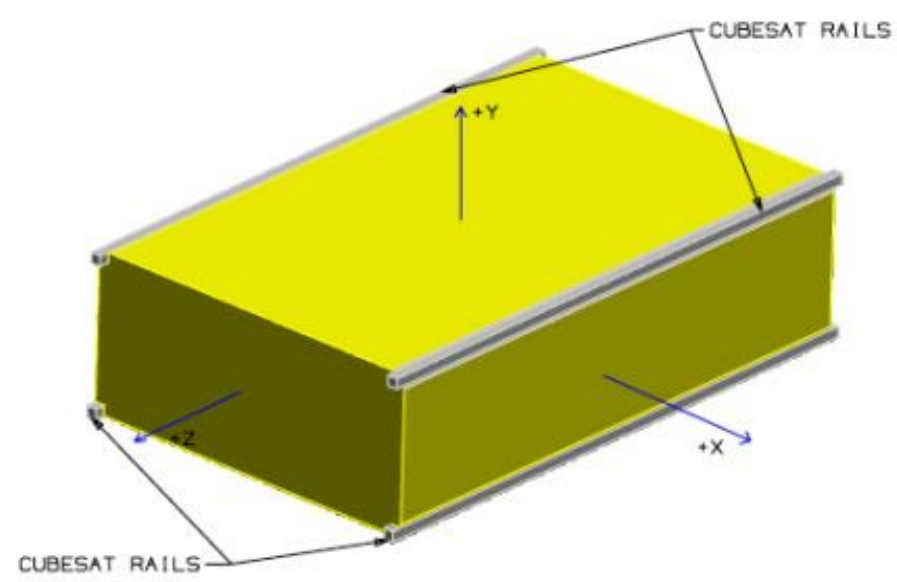

Figure 51. CubeSat Reference System Axis. Credit/CDS

\subsection{Shock Testing in the $X$ Axis}

\subsubsection{Axis Set Up}

The Box Dispenser was tested isolated, to measure the responses of it before introducing the $6 \mathrm{U}$ CubeSat. Three accelerometers were mounted in the direction of the impact, as it can be seen in Figure 52. 


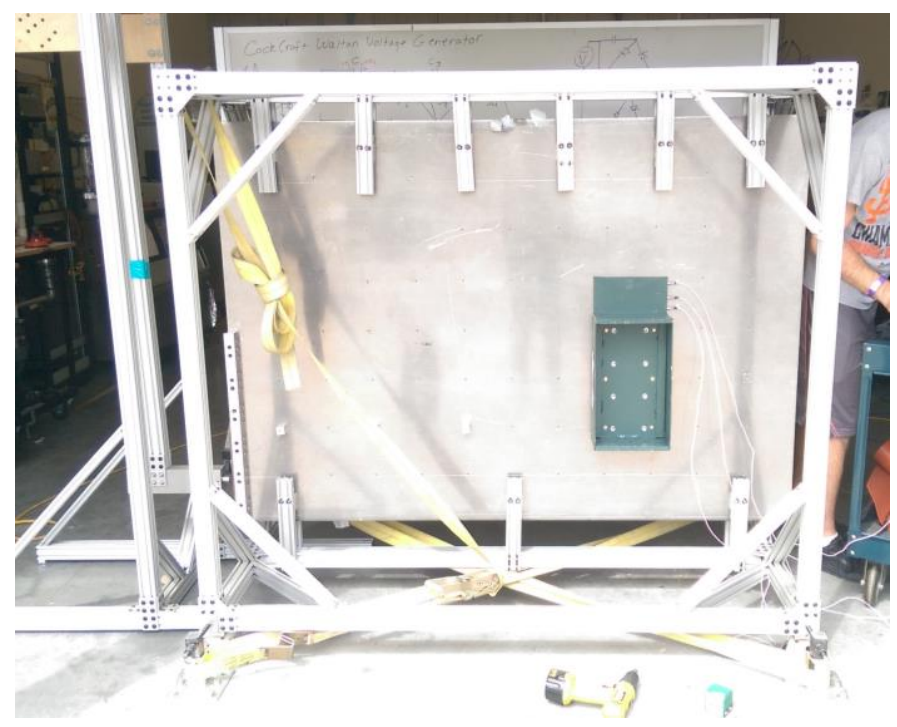

Figure 52. X Axis Shock Test Set Up

In Figure 53 the hammer set up used for the shock test in the Axis $\mathrm{X}$ and $\mathrm{Z}$ is shown.

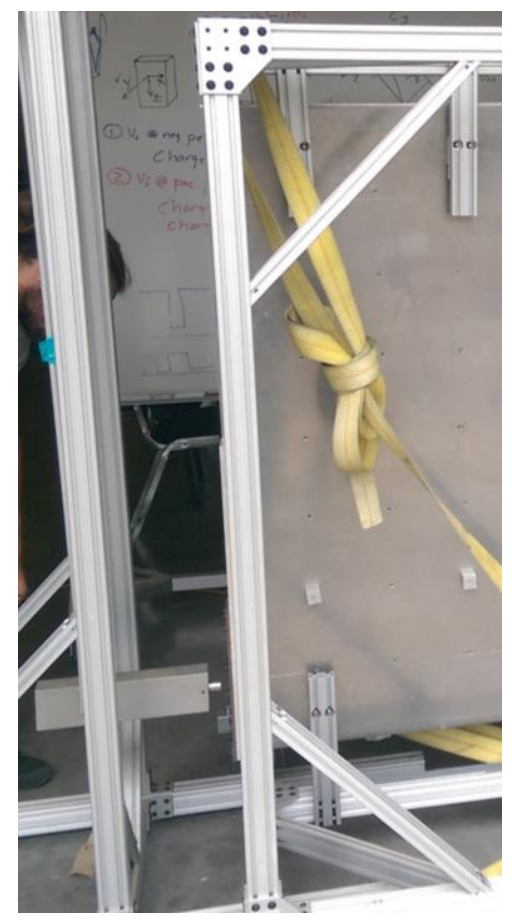

Figure 53. $X$ and $Z$ Axis Shock Test Set Up - Hammer 


\subsubsection{Axis Input Curve}

Once the hammer was dropped, it generated a shock impact to the table that was transmitted to the box dispenser in the $\mathrm{X}$ direction. A computer with a software input the shock and generated the velocity and acceleration time history. The maximum acceleration sensed by the accelerometers was $1500 \mathrm{G}$ for the $\mathrm{X}$ axis. Figure 54 and Figure 54Figure 55 are shown the input curves of the velocity time history and acceleration time history respectively for the $\mathrm{X}$ axis.

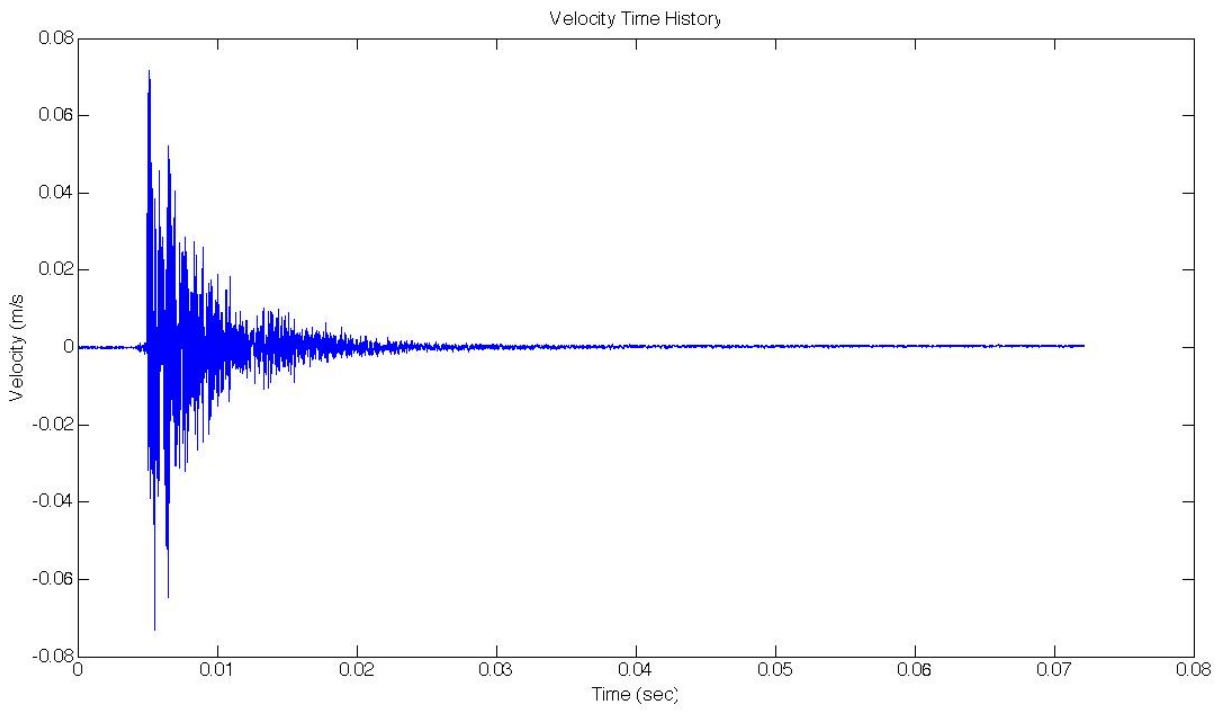

Figure 54. X Axis Input Curve. Velocity Time History 


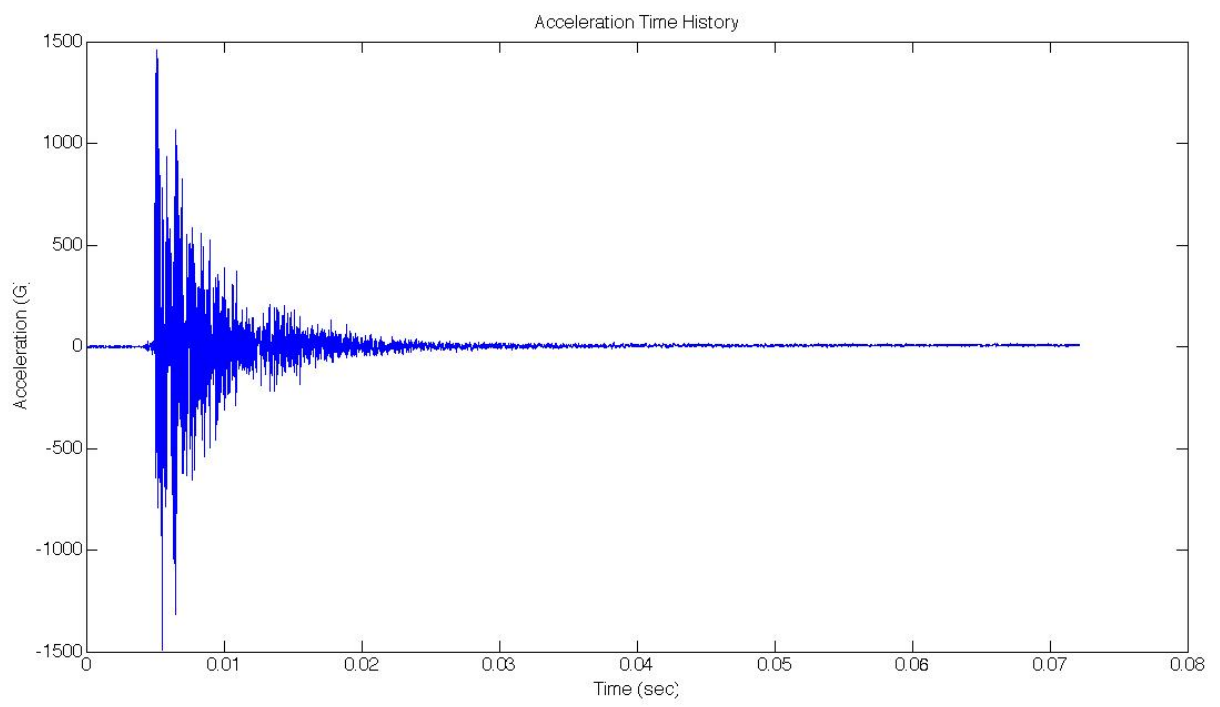

Figure 55. X Axis Input Curve. Acceleration Time History

\subsubsection{Axis Box Dispenser Response}

The software and controller of the computer was integrated with a code written that took the raw acceleration from the Cal Poly shock table and quickly converted this input into Shock Response Spectrum (SRS) Curves. In Figure 56 is shown in three different colors, (each color correspond to an accelerometer), the shock responses for the X Axis comparing to the NASA GEVS levels. It can be seen that the response of the box was acceptable and in some cases it was over tested. 


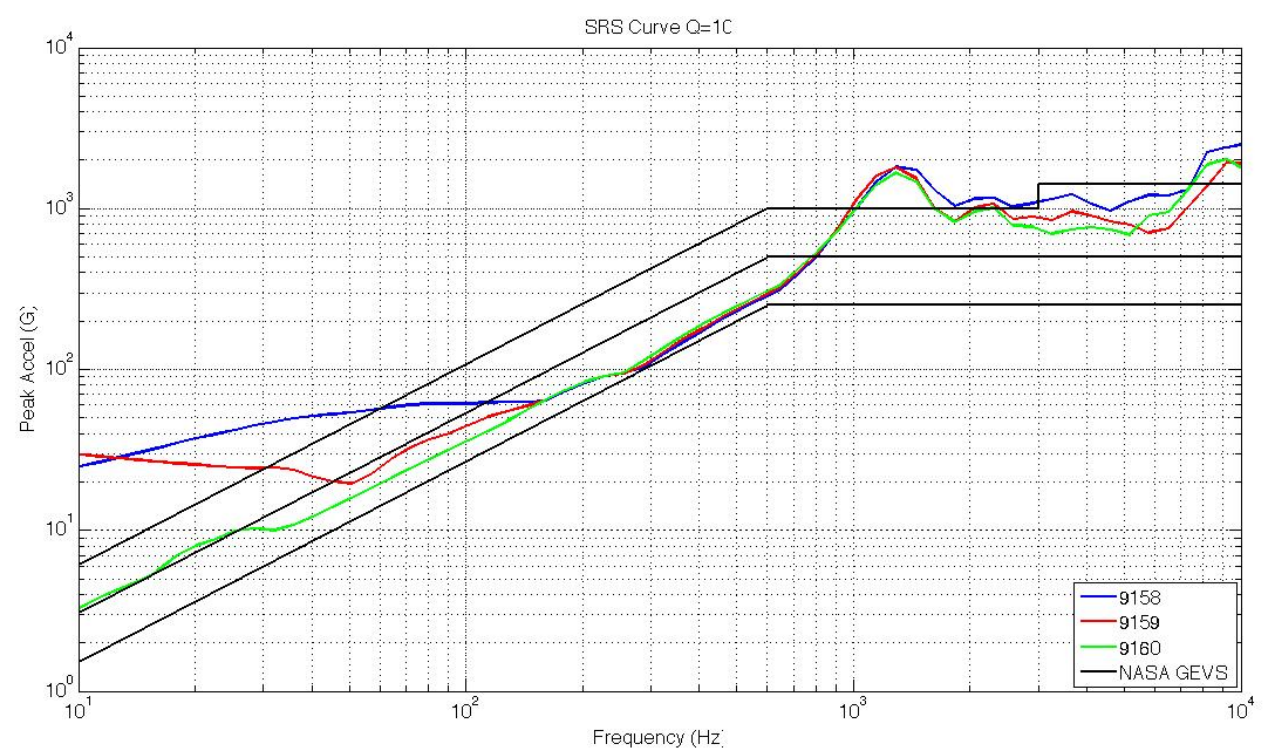

Figure 56. X Axis Dispenser Shock Response Spectrum

The Acceleration Pseudo Velocity Shock Spectrum (APVSS) for the Box dispenser in the X Axis can be found in Figure 57. The APVSS is a way of estimating the velocity response by dividing the acceleration frequency at each point of the Shock Response Spectrum Curve. For this set of tests the target was desired to reach $100 \mathrm{in} / \mathrm{sec}$ and be at least above $50 \mathrm{in} / \mathrm{sec}$. 


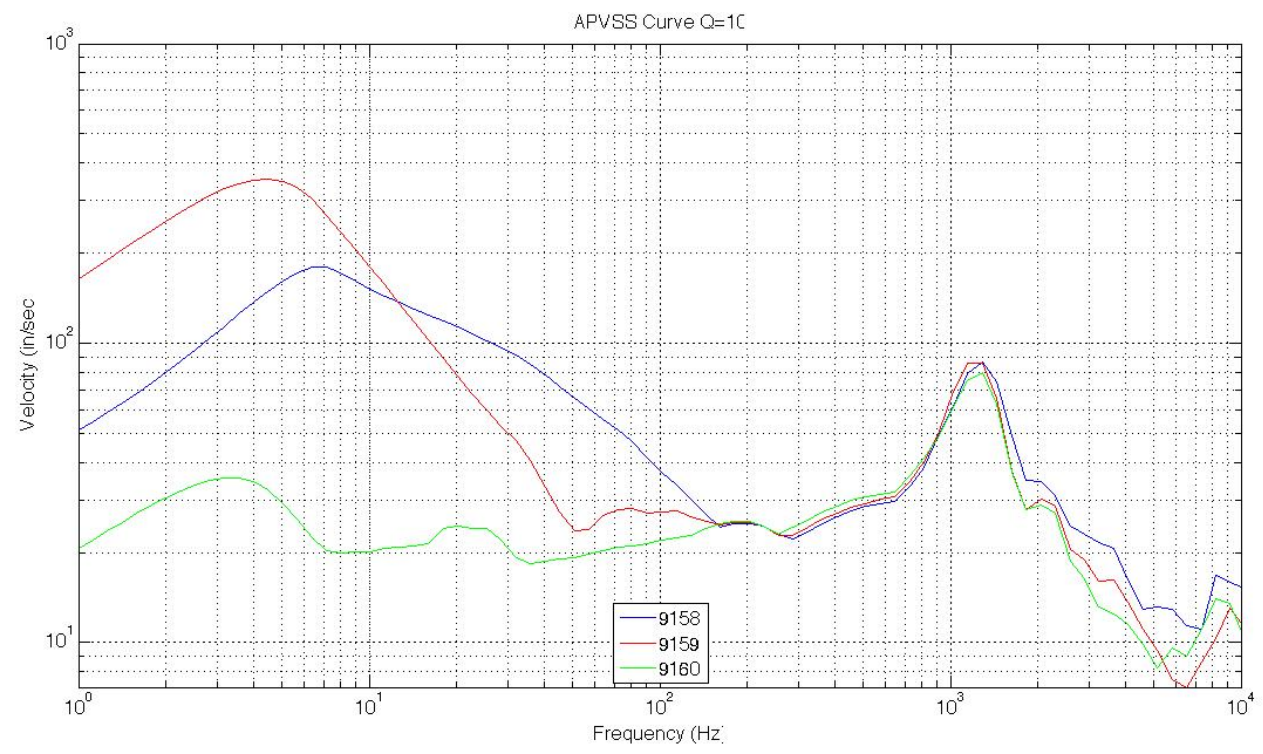

Figure 57. X Axis Acceleration Pseudo Velocity Shock Spectrum

\subsubsection{Axis 6U CubeSat Set Up}

After validating the results of the box dispenser in the $\mathrm{X}$ Axis, the $6 \mathrm{U}$ structure was placed inside the dispenser and the same test was conducted. Figure 58 shows the box dispenser with the lid mounted before the shock test.

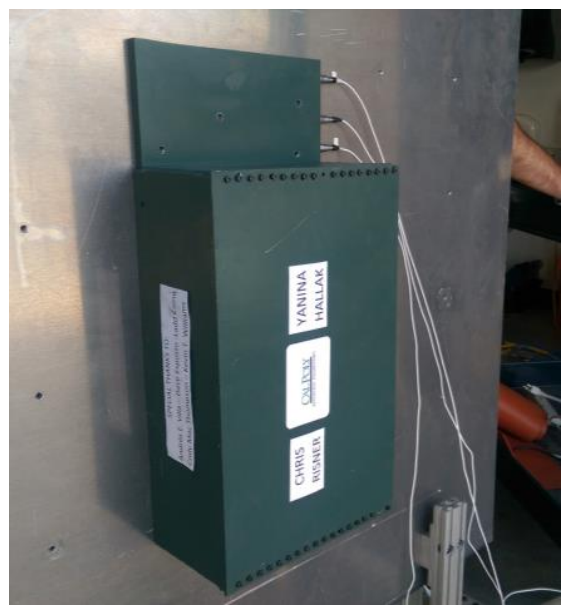

Figure 58. X Axis Shock Test Set Up. Box Dispenser with 6 U CubeSat 


\subsubsection{X Axis Output Curves Dispenser and 6 CubeSat: Run \#1}

Two tests were performed per axis and in order to obtain sustainable information.

Figure 59 and Figure 60 are shown the output curves for the test in the $\mathrm{X}$ axis of the dispenser with the satellite for the first test.

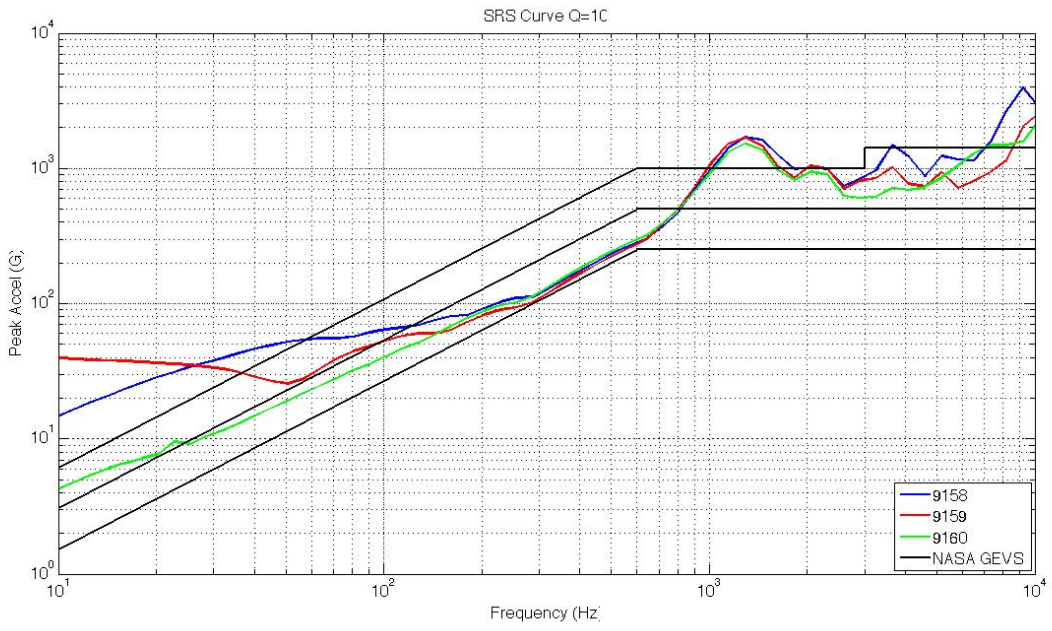

Figure 59. X Axis, Dispenser with 6U CubeSat - SRS - Test 1

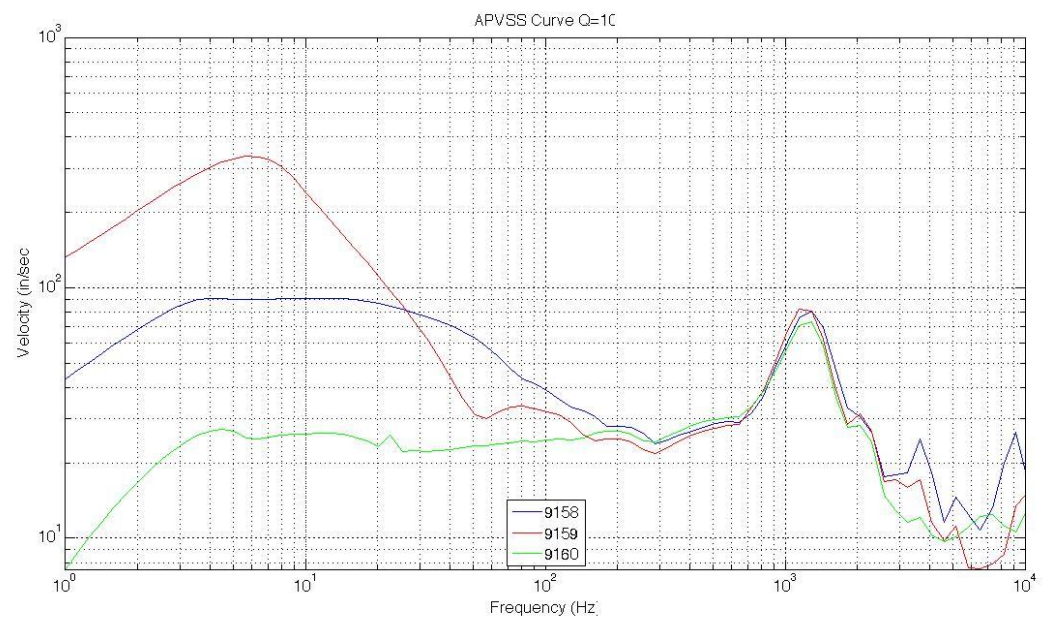

Figure 60. X Axis, Dispenser with 6U CubeSat - APVSS - Test 1 


\subsubsection{X Axis Output Curves Dispenser and 6 CubeSat: Run \#2}

Figure 61 and Figure 62 are shown the output curves for the second test in the $\mathrm{X}$ axis of the dispenser with the satellite.

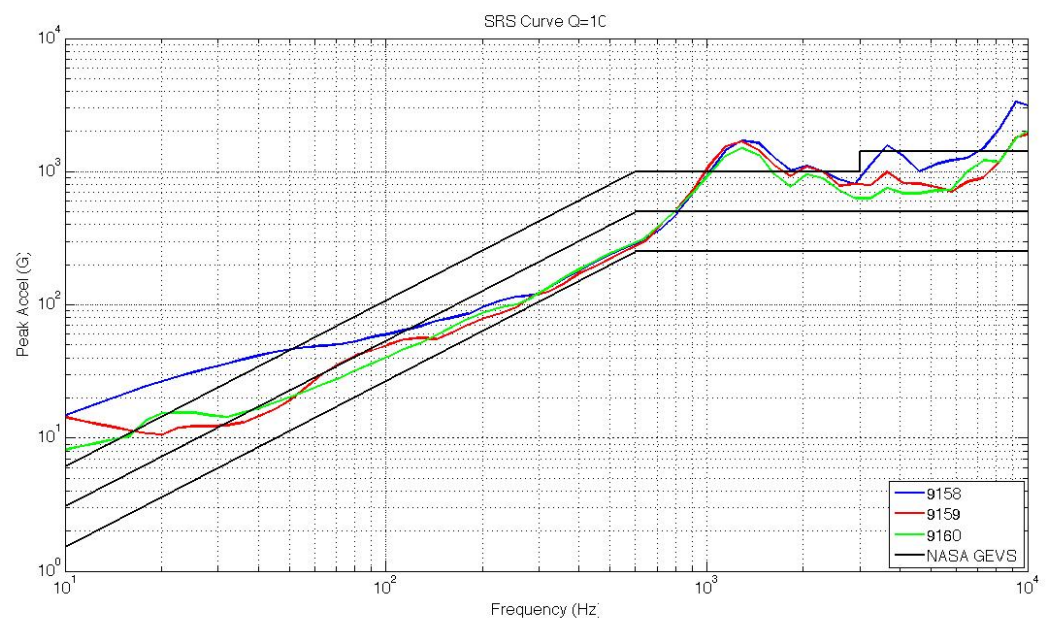

Figure 61. X Axis, Dispenser with 6U CubeSat - SRS - Test 2

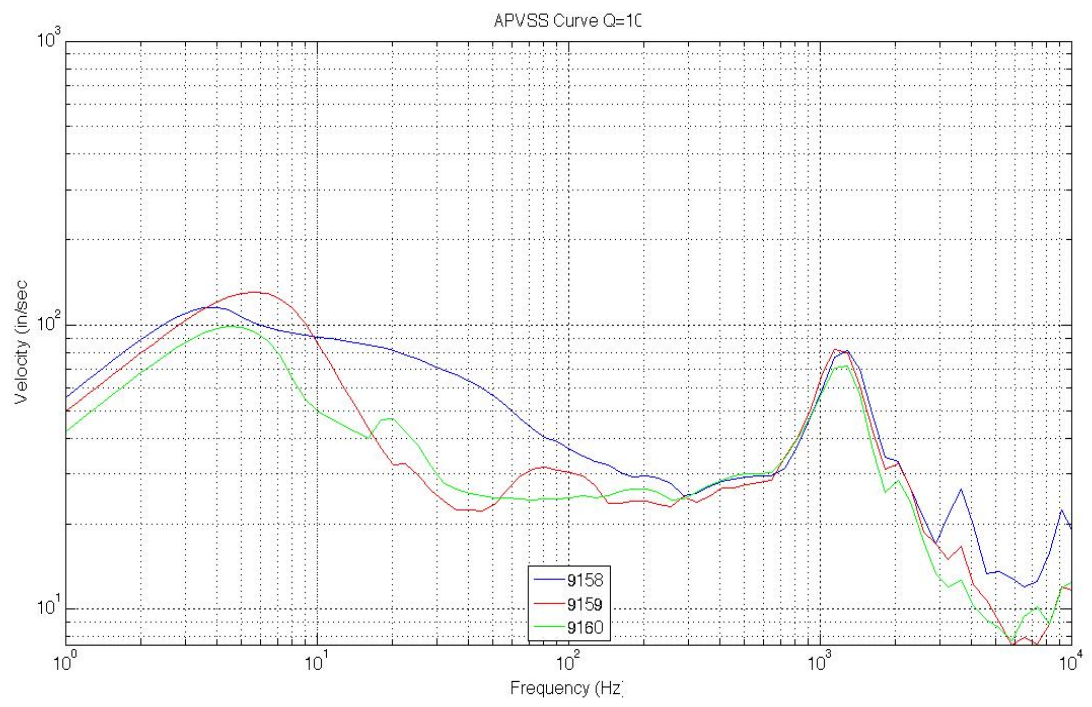

Figure 62. X Axis, Dispenser with 6U CubeSat - APVSS - Test 2 


\subsection{Shock Testing in the Y Axis}

\subsubsection{Y Axis Set Up}

In the same fashion that for the $\mathrm{X}$ axis, the Box Dispenser was tested isolated in the $\mathrm{Y}$ axis, to measure the responses of it before introducing the $6 \mathrm{U}$ CubeSat. Three accelerometers were mounted in the direction of the impact, as it can be seen in Figure 63.

For this axis, the hammer was placed behind the aluminum plate as it can it is shown in Figure 64. The accelerometers in order to measure in the direction of the $\mathrm{Y}$ axis, were placed perpendicularly to the shock table.

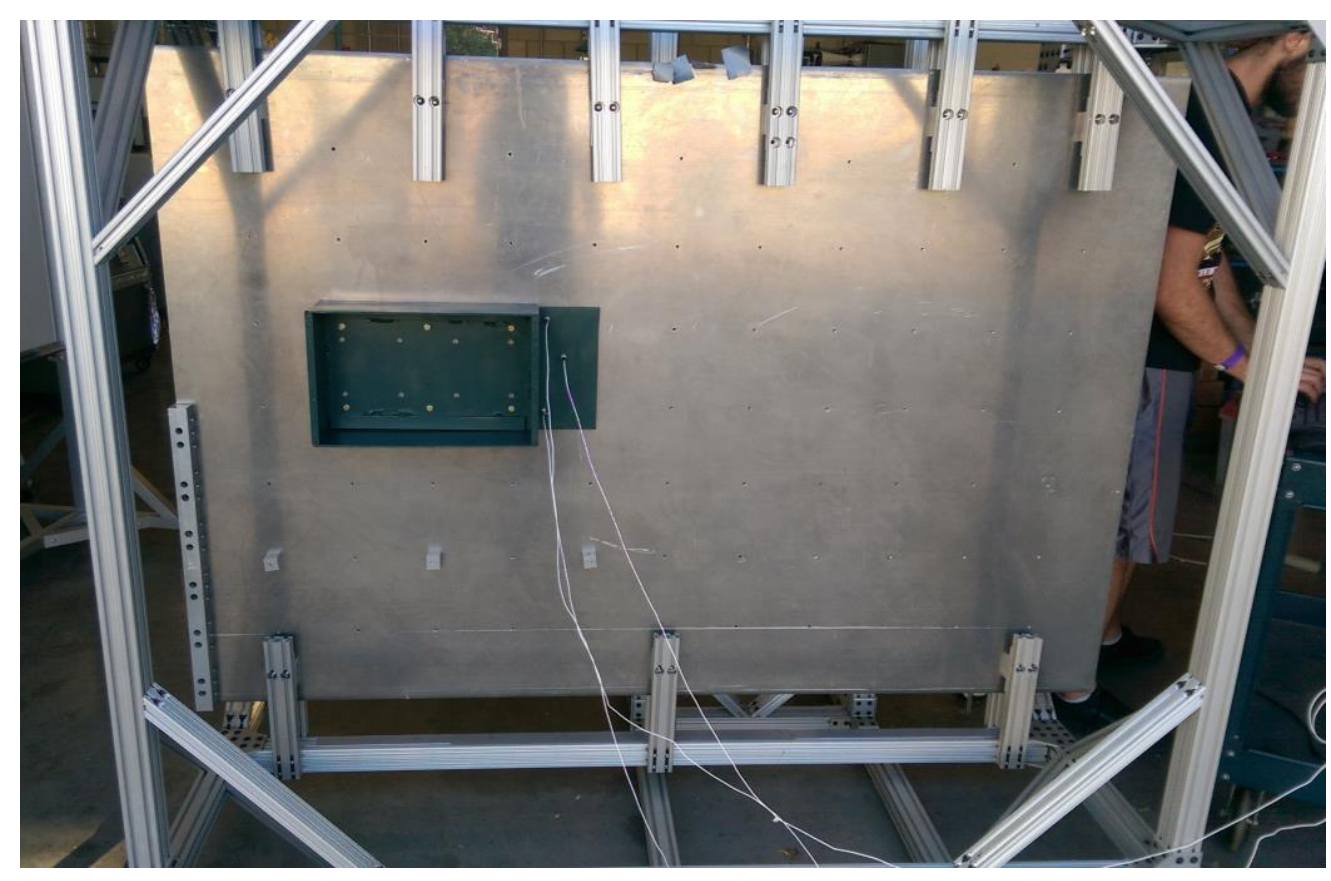

Figure 63. Y Axis Shock Test Set Up 


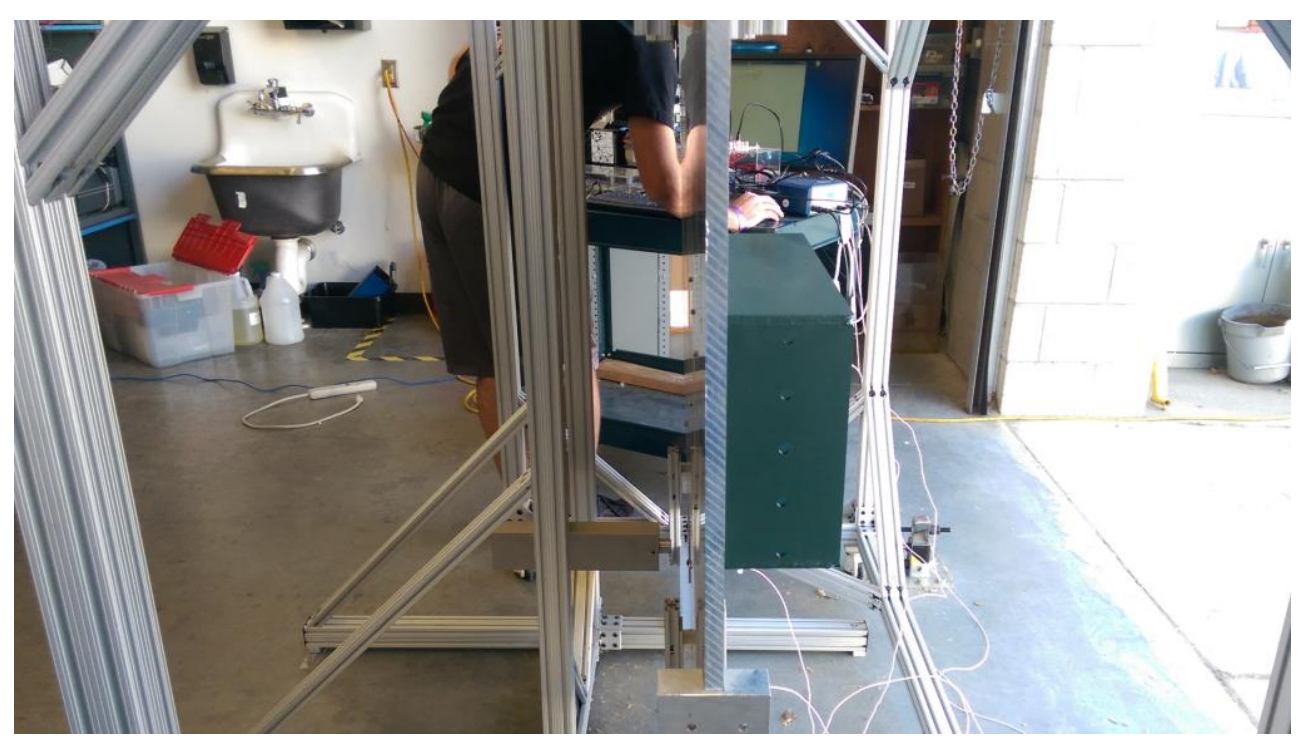

Figure 64. Y Axis Shock Test Set up - Hammer

\subsubsection{Y Axis Input Curve}

The test was conducted in the same way as for the $\mathrm{X}$ axis: the hammer was dropped, it generated a shock impact to the table that was transmitted to the box dispenser in the $\mathrm{Y}$ direction. The computer input the shock and generated the velocity and acceleration time history. The maximum acceleration sensed by the accelerometers was $470 \mathrm{G}$ for the $\mathrm{Y}$ axis. Figure 65 and Figure 66 are shown the input curves of the velocity time history and acceleration time history respectively for the $\mathrm{Y}$ axis. 


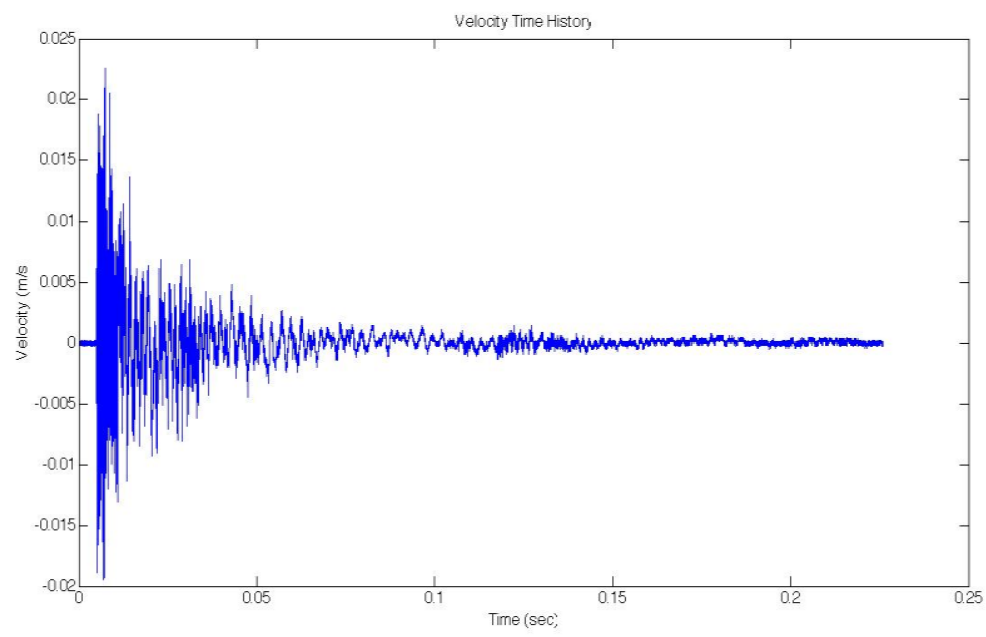

Figure 65. Y Axis Input Curve. Velocity Time History

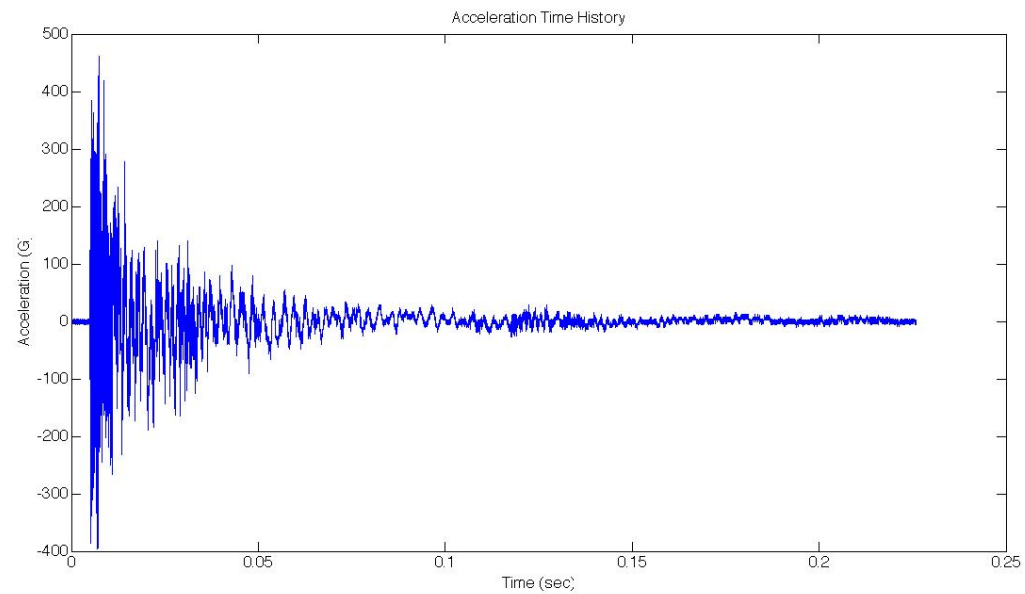

Figure 66. Y Axis Input Curve. Acceleration Time History

The software and controller of the computer was integrated with a code written that took the raw acceleration from the Cal Poly shock table and quickly converted this input into Shock Response Spectrum (SRS) Curves and Acceleration Pseudo Velocity Shock Spectrum. In Figure 67 is shown the three different responses of the accelerometers for the Y Axis comparing to the NASA GEVS levels. It can be seen that the response of the box was acceptable and more homogenous than in the previous axis. 


\subsubsection{Y Axis Box/Dispenser Response}

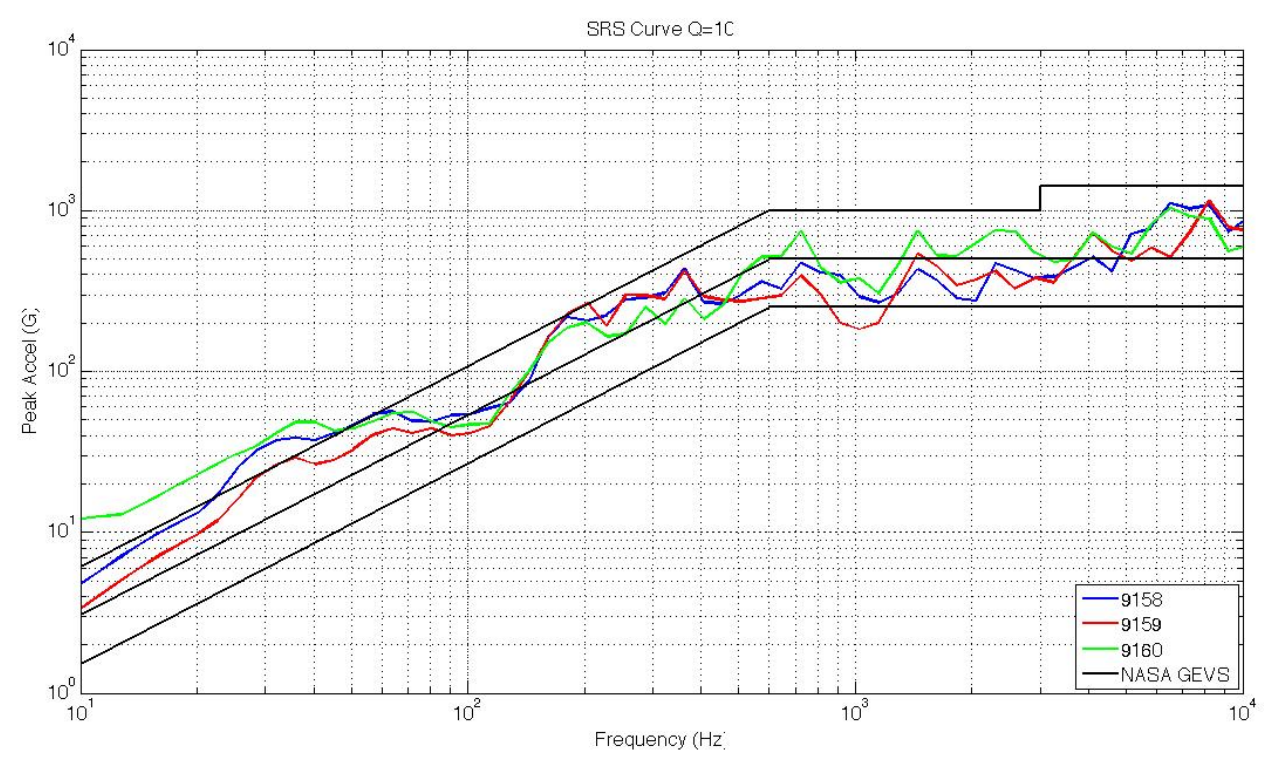

Figure 67. Y Axis Dispenser Shock Response Spectrum

The Acceleration Pseudo Velocity Shock Spectrum (APVSS) for the Box dispenser in the Y Axis is shown in Figure 68. The APVSS is a way of estimating the velocity response by dividing the acceleration frequency at each point of the Shock Response Spectrum Curve. For this set of tests the target was desired to reach $100 \mathrm{in} / \mathrm{sec}$ and be at least above $50 \mathrm{in} / \mathrm{sec}$. 


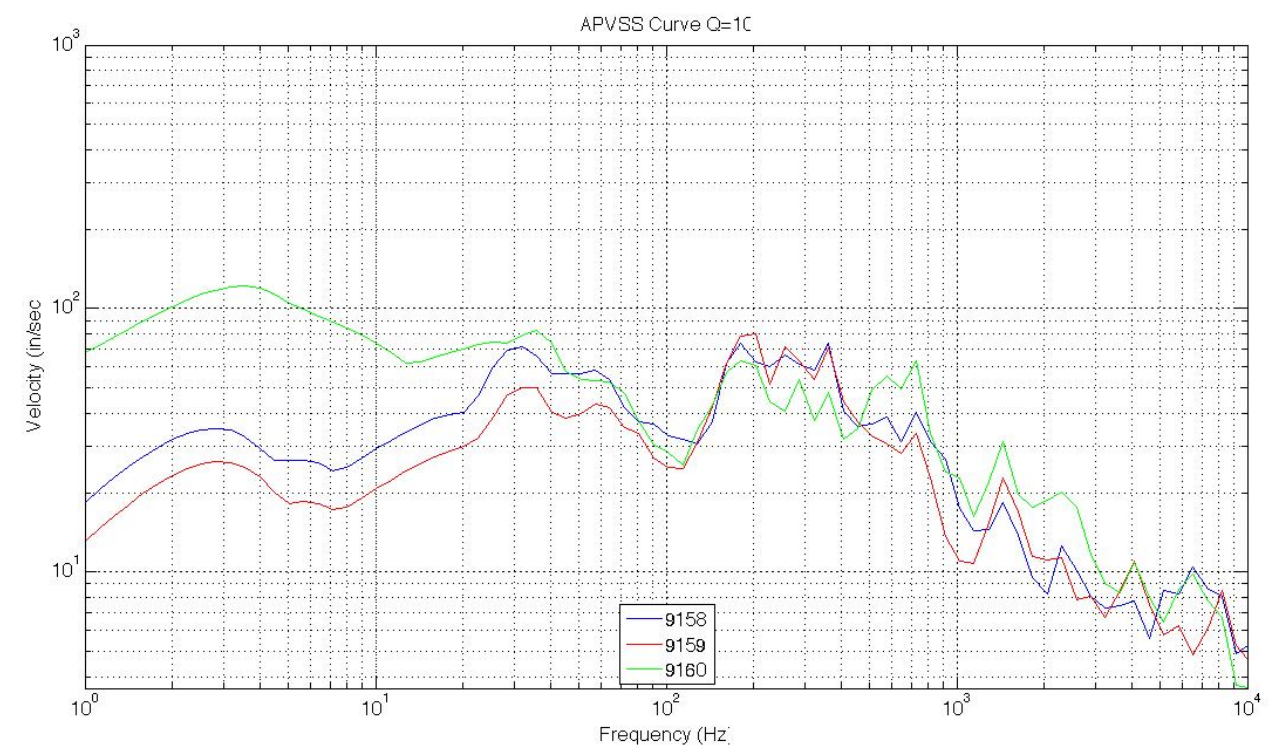

Figure 68. Y Axis Dispenser - Pseudo Velocity Shock Spectrum

\subsubsection{Y Axis 6U CubeSat Set Up}

After validating the results of the box dispenser in the Y Axis, the $6 \mathrm{U}$ structure was placed inside the dispenser and the same test was conducted. Figure 69 shows the box dispenser mounted before the shock test.

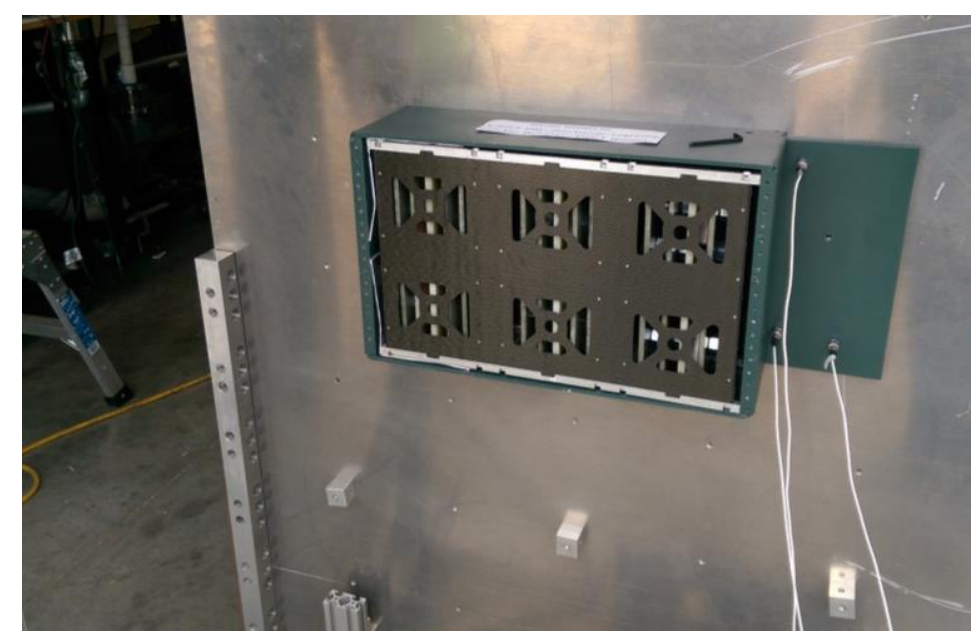

Figure 69. Y Axis Shock Test Set Up. Box Dispenser with 6U CubeSat 


\subsubsection{Y Axis Output Curves Dispenser and 6 CubeSat: Run 1}

Two tests were performed per axis in order to obtain sustainable information.

Figure 70 and Figure 71 are shown the output curves for the test in the $\mathrm{Y}$ axis of the dispenser with the satellite for the first test.

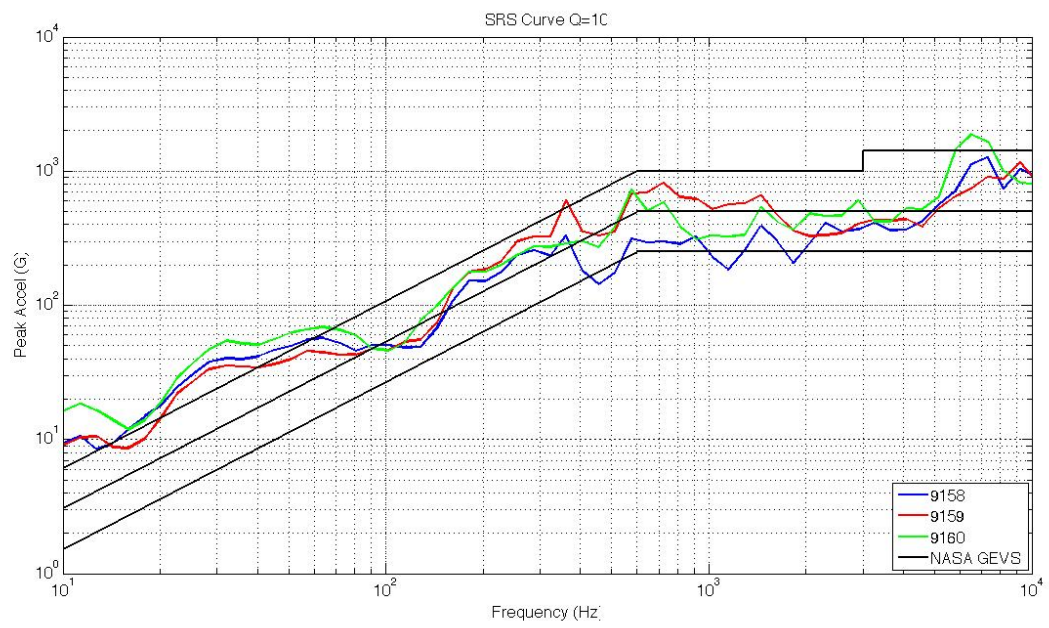

Figure 70. Y Axis, Dispenser with 6U CubeSat - Shock Response Spectrum - Run 1

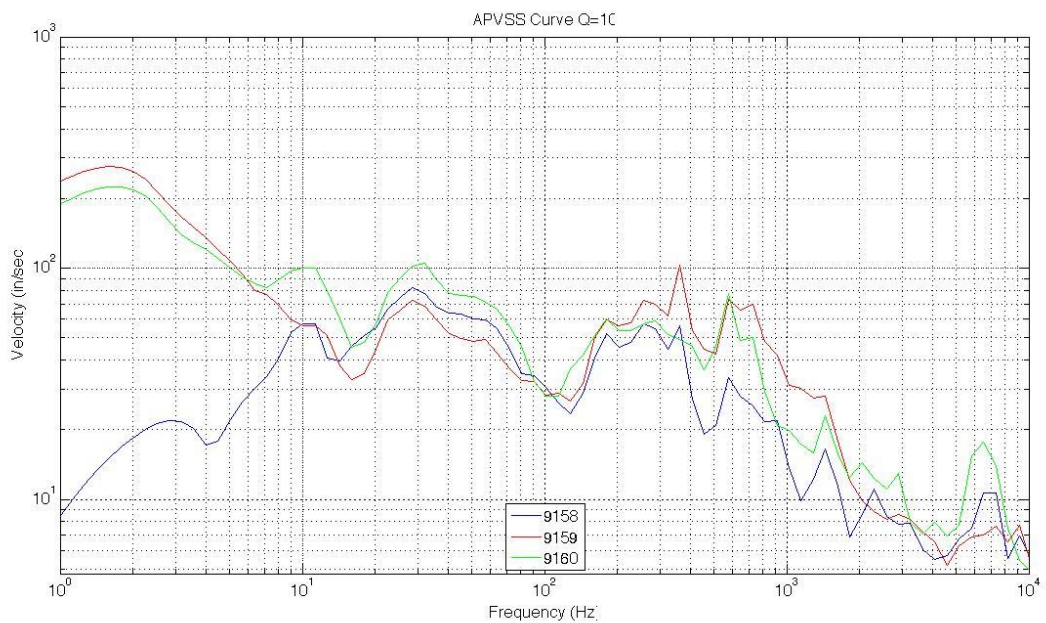

Figure 71. Y Axis, Dispenser with 6U CubeSat - APVSS - Run 1

\subsubsection{Y Axis Output Curves Dispenser and 6 CubeSat: Run 2}

Figure 72 and Figure 73 are shown the output curves for the second test in the $\mathrm{Y}$ axis of the dispenser with the satellite. 


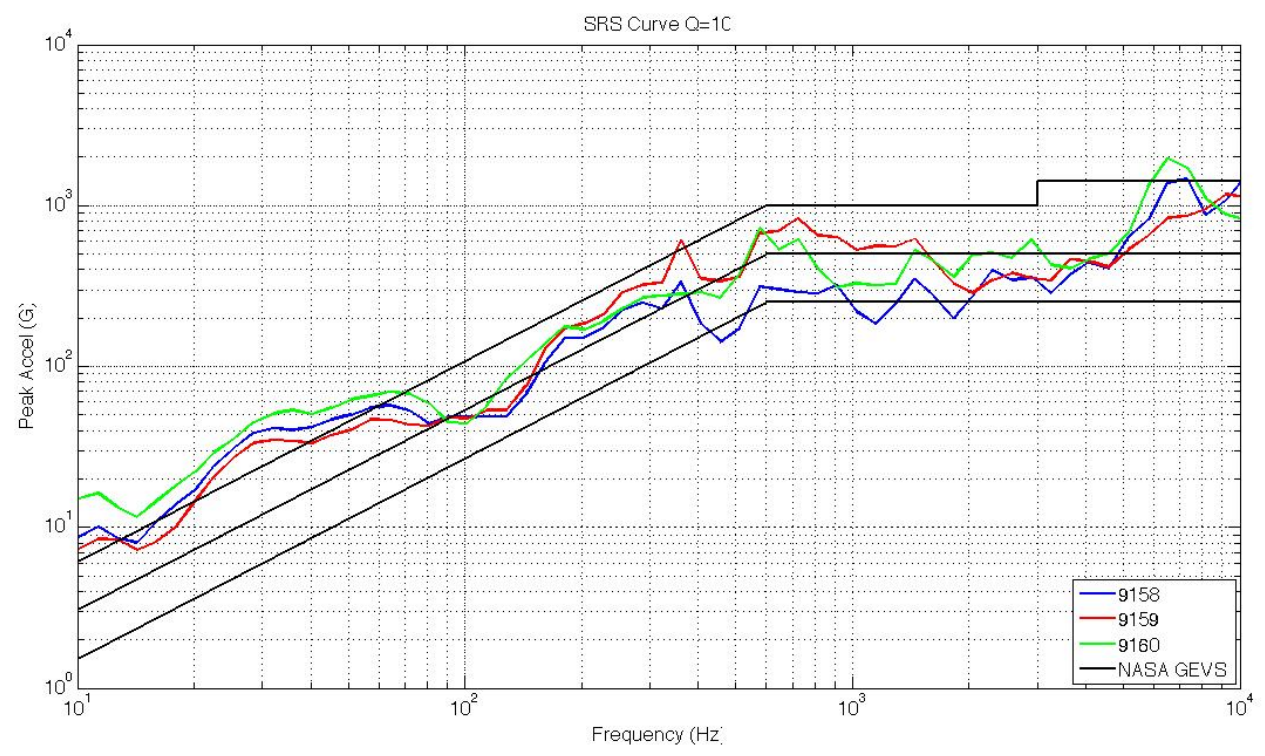

Figure 72. Y Axis, Dispenser with 6U CubeSat - SRS - Run 2

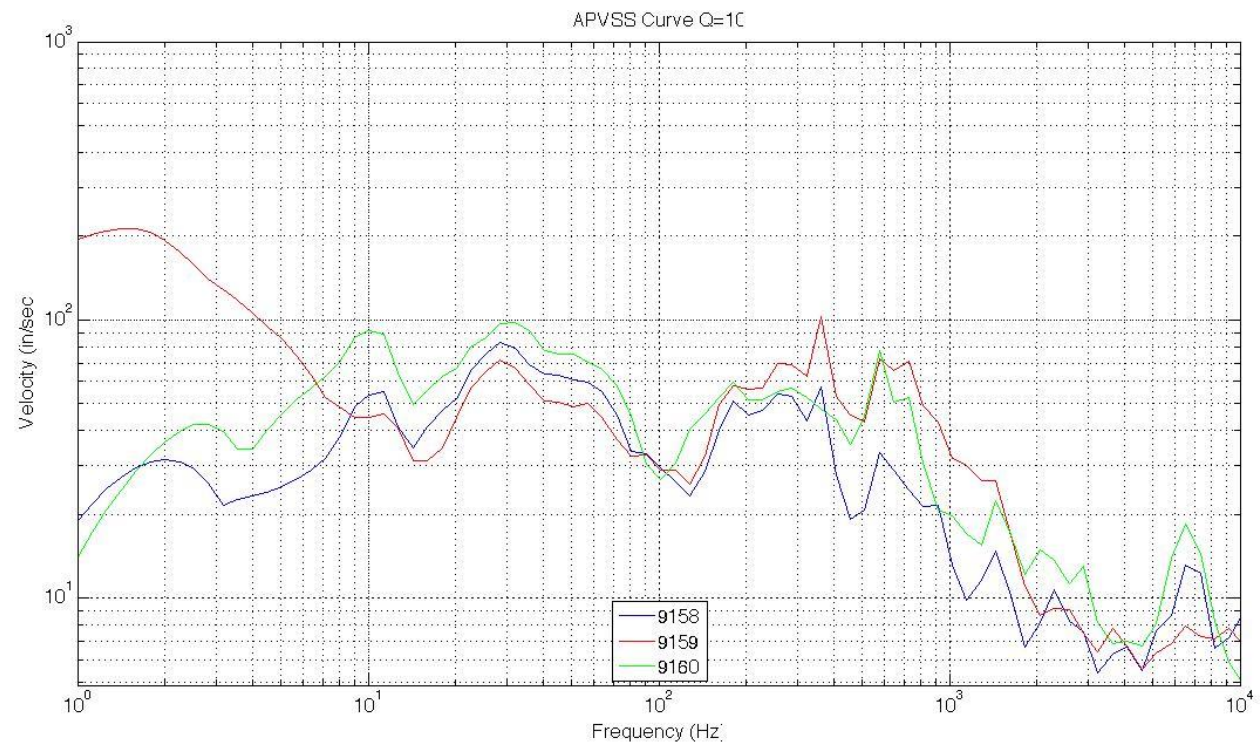

Figure 73. Y Axis, Dispenser with 6U CubeSat - APVSS - Run 2

\subsection{Shock Testing in the $Z$ Axis}

\subsubsection{Z Axis Set Up}

In the same way as for the $\mathrm{X}$ and $\mathrm{Y}$ Axis, the Box Dispenser was tested isolated, to measure the responses of it before introducing the $6 \mathrm{U}$ CubeSat. Three accelerometers were 
mounted in the direction of the impact, as it can be seen in Figure 74. As it was shown in the picture the hammer set up and the accelerometers are placed in the $\mathrm{Z}$ axis direction.

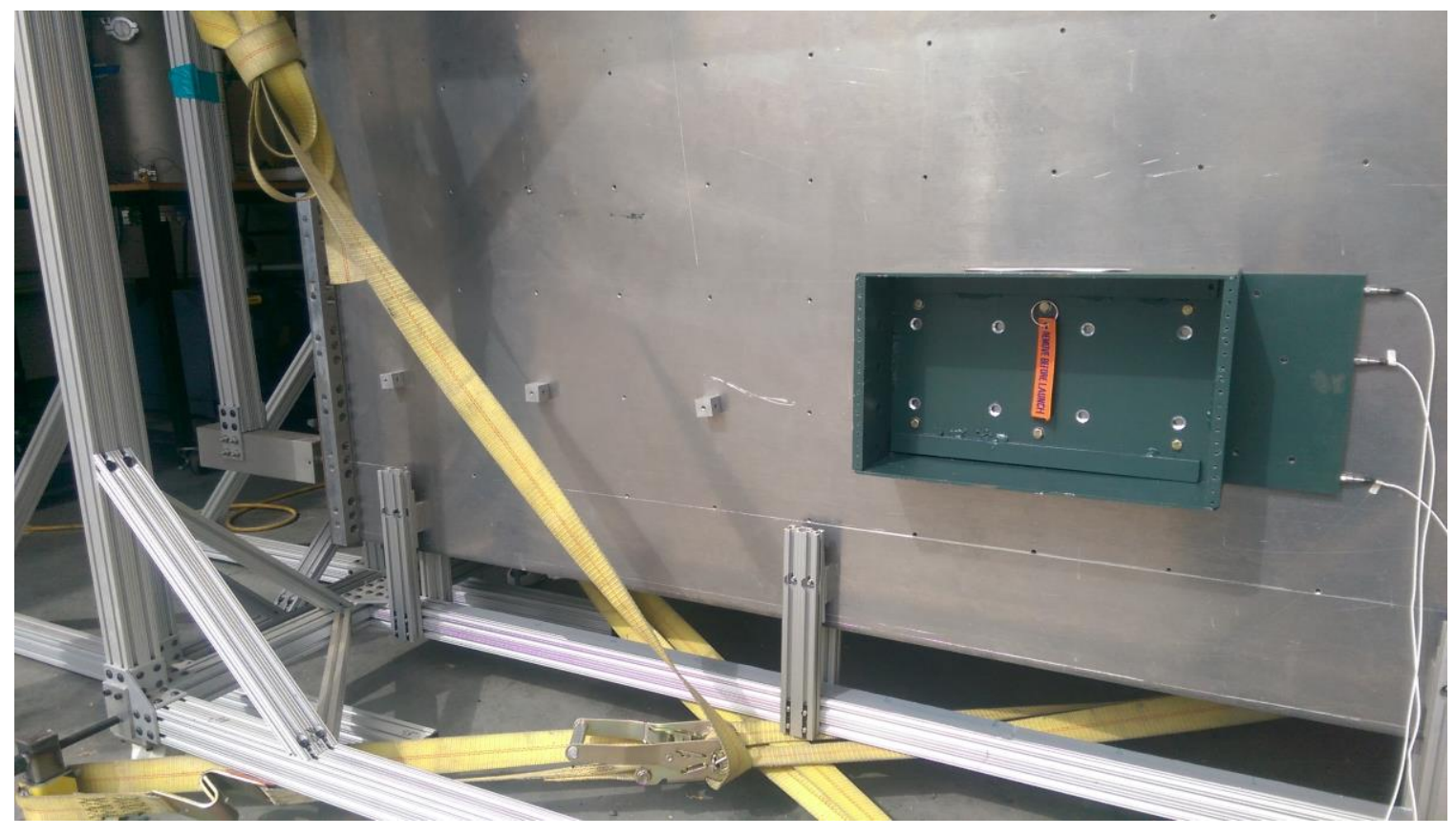

Figure 74. Z Axis Shock Test Set Up

\subsubsection{Z Axis Input Curves}

The test was conducted in the same way as for the other two axis: the hammer was dropped, it generated a shock impact to the table that was transmitted to the box dispenser in the $\mathrm{Z}$ direction. The computer input the shock and generated the velocity and acceleration time history. The maximum acceleration sensed by the accelerometers was 980G for the $\mathrm{Z}$ axis. Figure 75 and Figure 76 are shown the input curves of the velocity time history and acceleration time history respectively for the $\mathrm{Z}$ axis. 


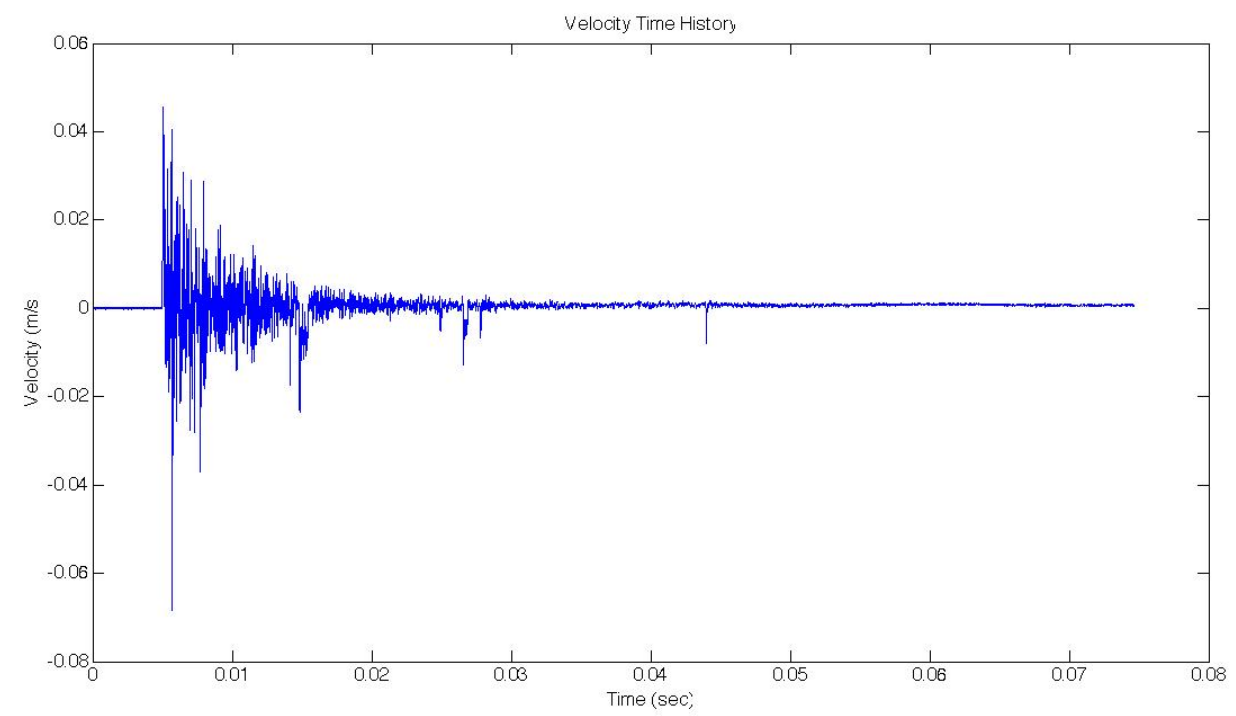

Figure 75. Z Axis Input Curve. Velocity Time History

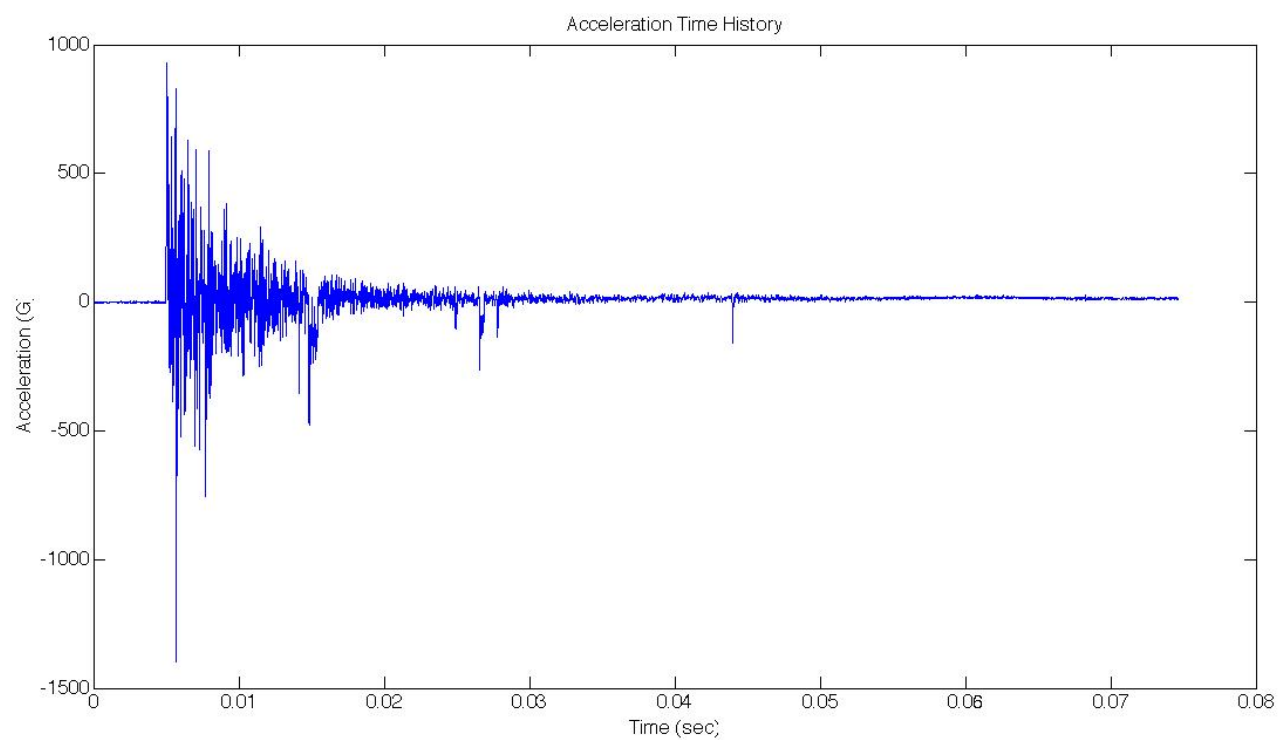

Figure 76. Z Axis Input Curve. Acceleration Time History

\subsubsection{Z Axis Box/Dispenser Response}

The software and controller of the computer was integrated with a code written that took the raw acceleration from the Cal Poly shock table and quickly converted this input into Shock Response Spectrum (SRS) Curves and Acceleration Pseudo Velocity Shock 
Spectrum. In Figure 77 is shown the three different responses of the accelerometers for the $\mathrm{Z}$ Axis comparing to the NASA GEVS levels. The response of the box dispenser was acceptable.

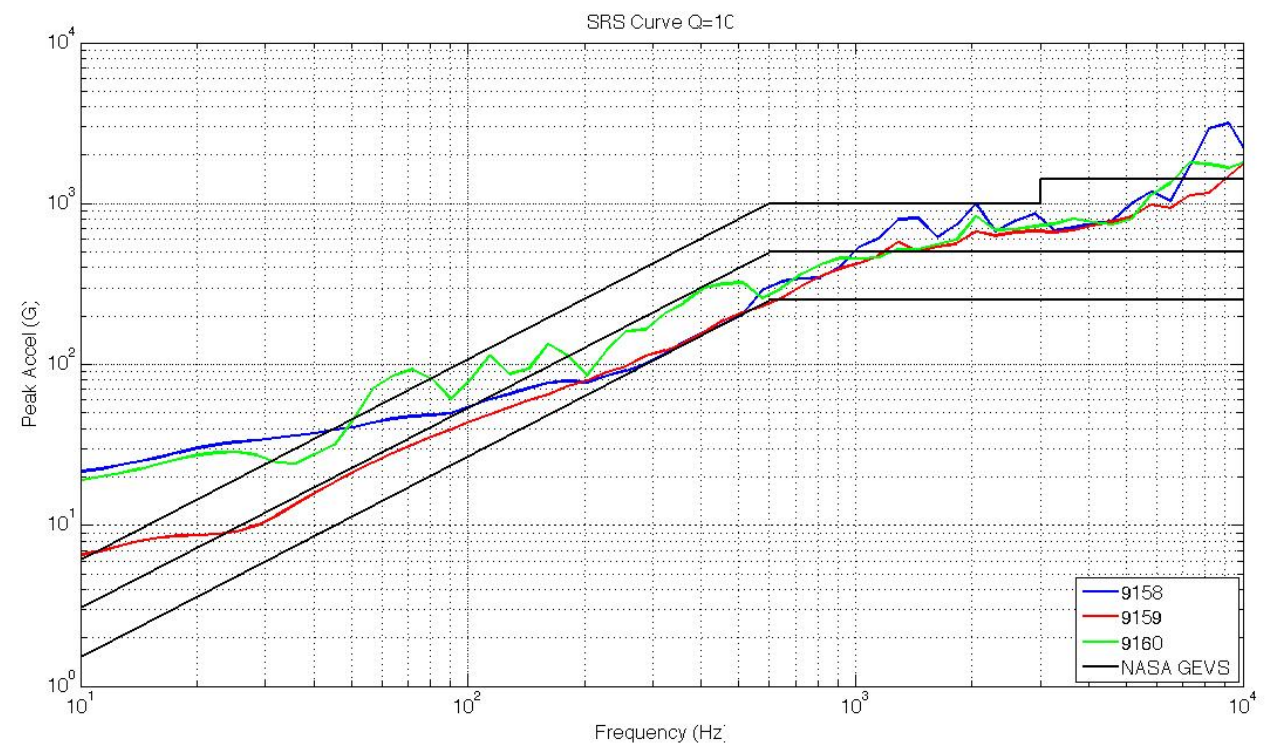

Figure 77. Z Axis Dispenser Shock Response Spectrum

The Acceleration Pseudo Velocity Shock Spectrum (APVSS) for the Box dispenser in the Y Axis is shown in Figure 78. The APVSS is a way of estimating the velocity response by dividing the acceleration frequency at each point of the Shock Response Spectrum Curve. For this set of tests the target was to be at least $50 \mathrm{in} / \mathrm{sec}$ and reach 100 in/sec. 


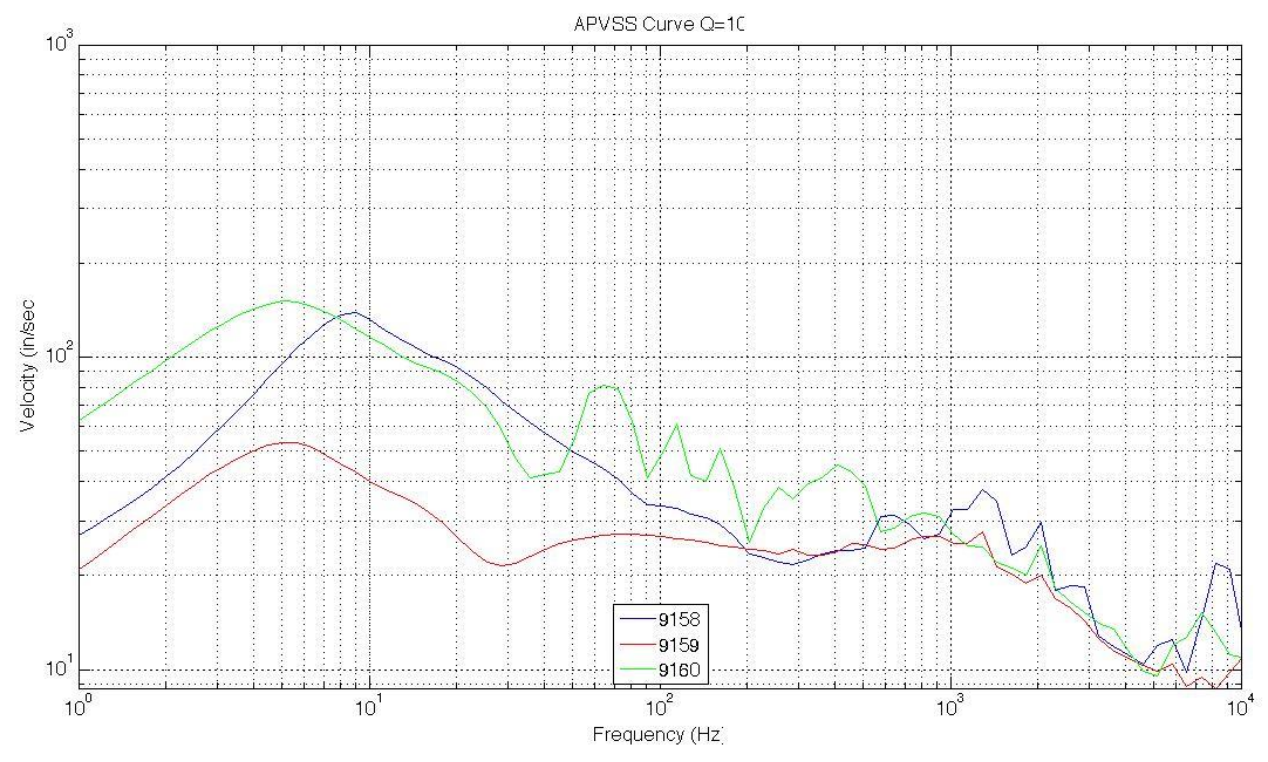

Figure 78. Z Axis Dispenser - Pseudo Velocity Shock Spectrum

\subsubsection{Z Axis 6U CubeSat Set Up}

After validating the results of the box dispenser in the $\mathrm{Z}$ Axis, the $6 \mathrm{U}$ structure was placed inside the dispenser and the same test was conducted. Figure 79 shows the box dispenser with the lid mounted before the shock test.

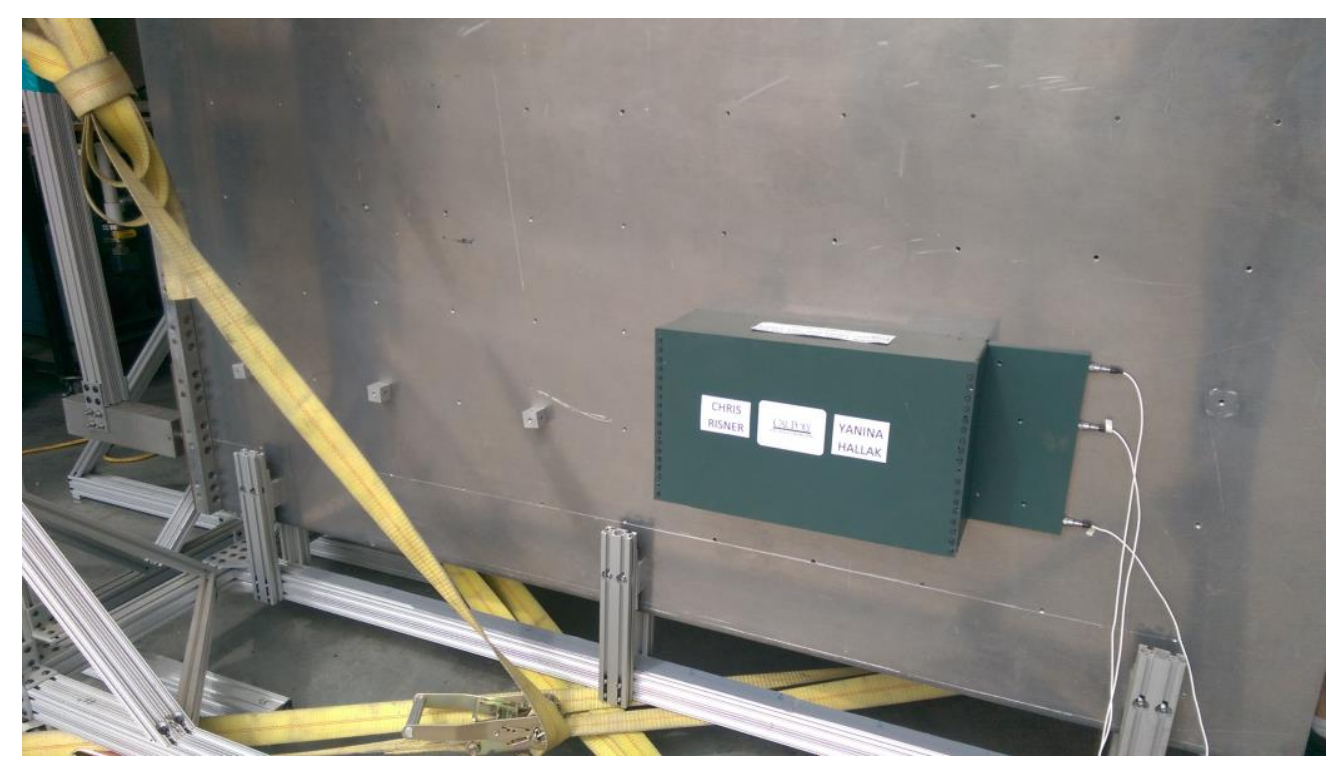

Figure 79. Z Axis Shock Test Set Up. Box Dispenser with 6 U CubeSat 


\subsubsection{Z Axis Output Curves Dispenser and 6 CubeSat: Run 1}

Two tests were performed per axis in order to obtain sustainable information.

Figure 80 and Figure 81 are shown the output curves for the test in the $\mathrm{Z}$ axis of the dispenser with the satellite for the first test.

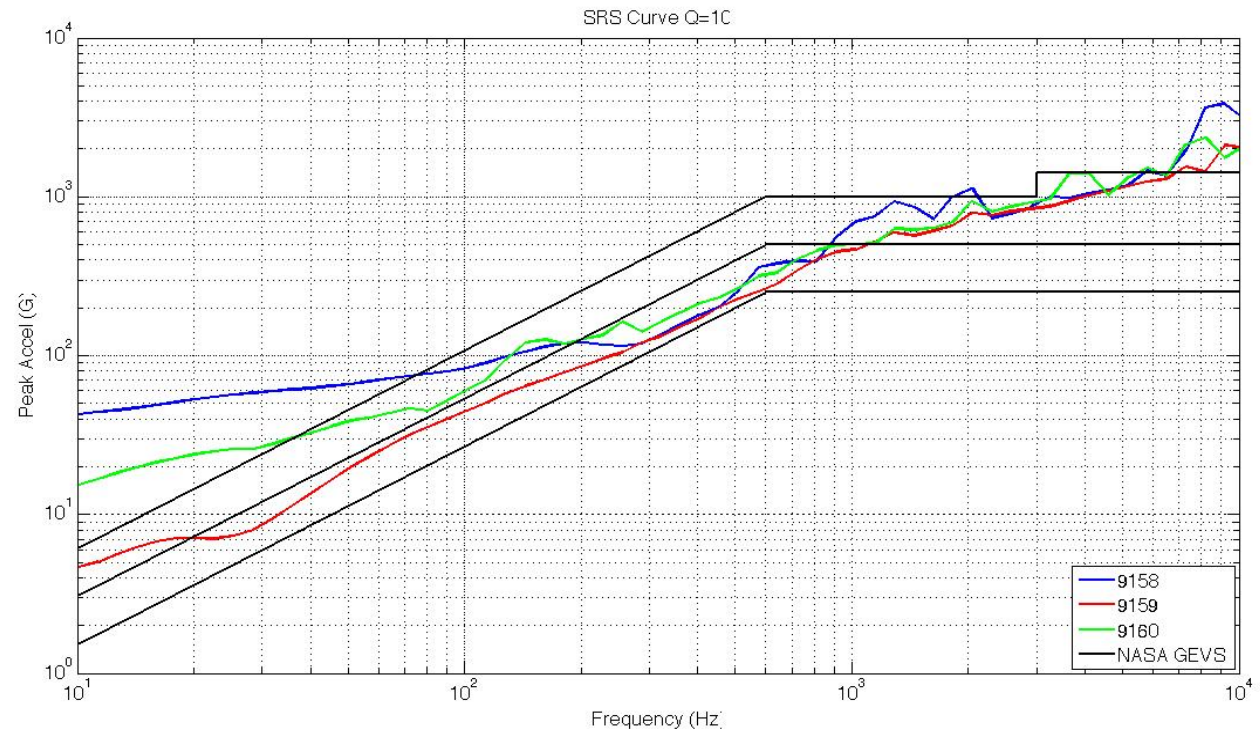

Figure 80. Z Axis, Dispenser with 6U CubeSat - SRS - Run 1

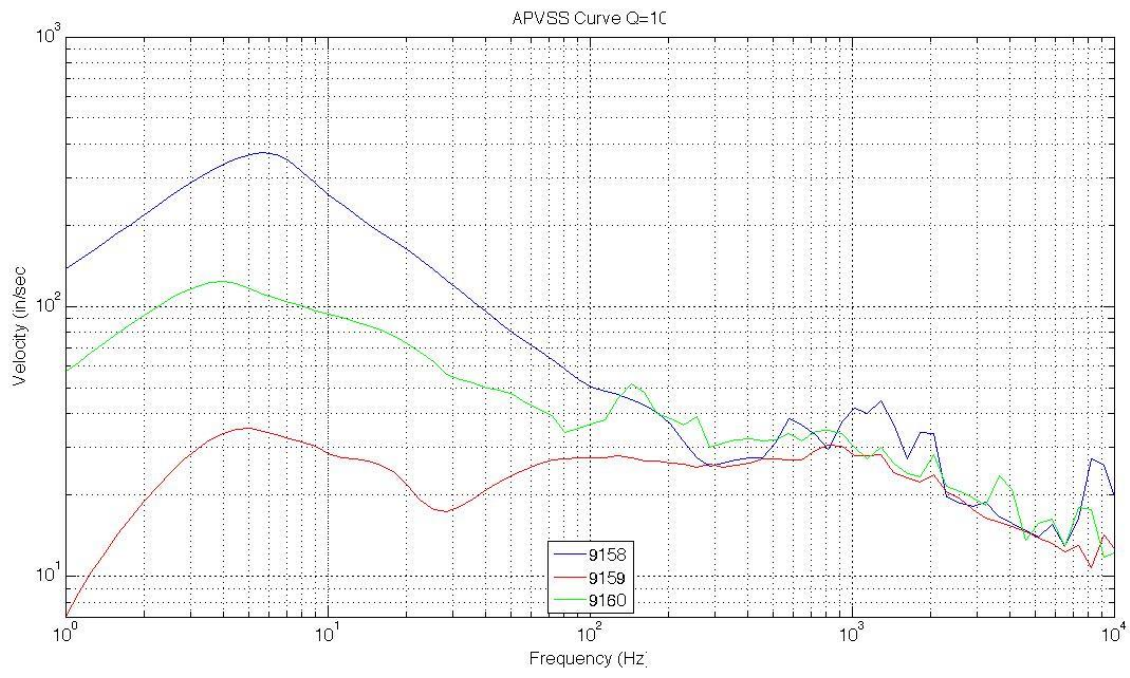

Figure 81. Z Axis, Dispenser with 6U CubeSat - APVSS - Run 1 


\subsubsection{Z Axis Output Curves Dispenser and 6 CubeSat: Run 2}

Figure 82 and Figure 83 are shown the output curves for the second test in the $\mathrm{Z}$ axis of the dispenser with the satellite.

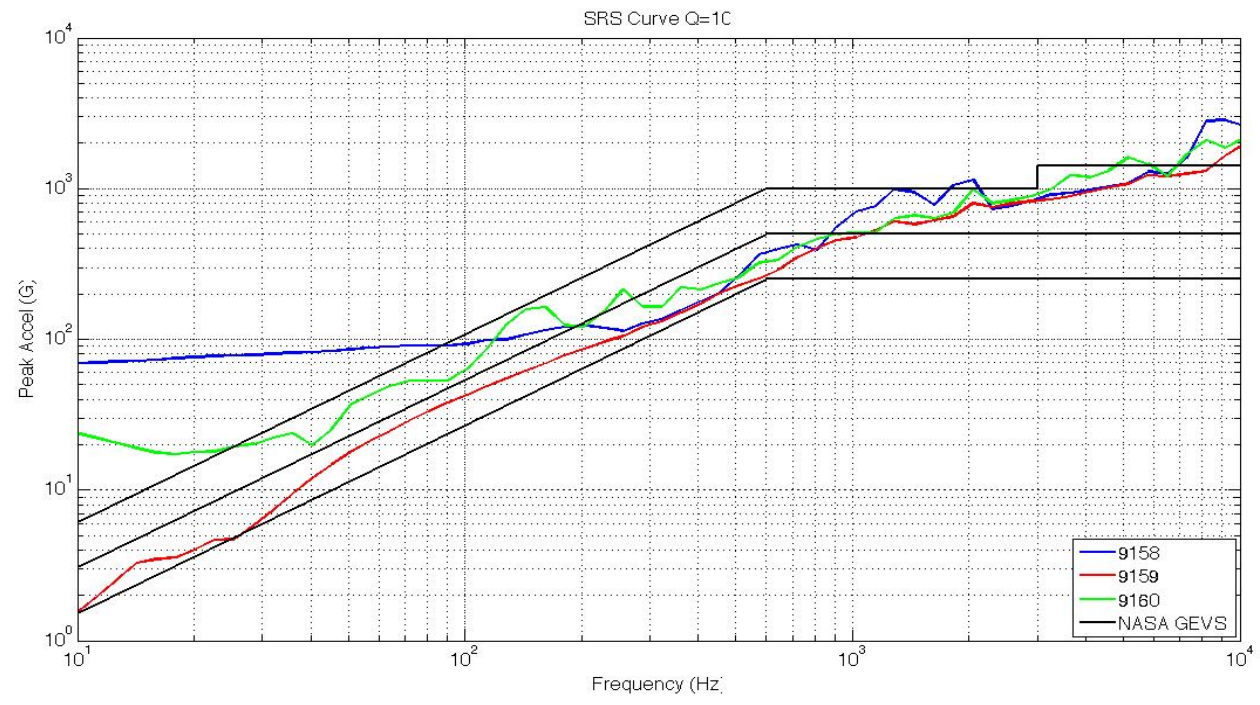

Figure 82. Z Axis, Dispenser with 6U CubeSat - SRS - Run 2

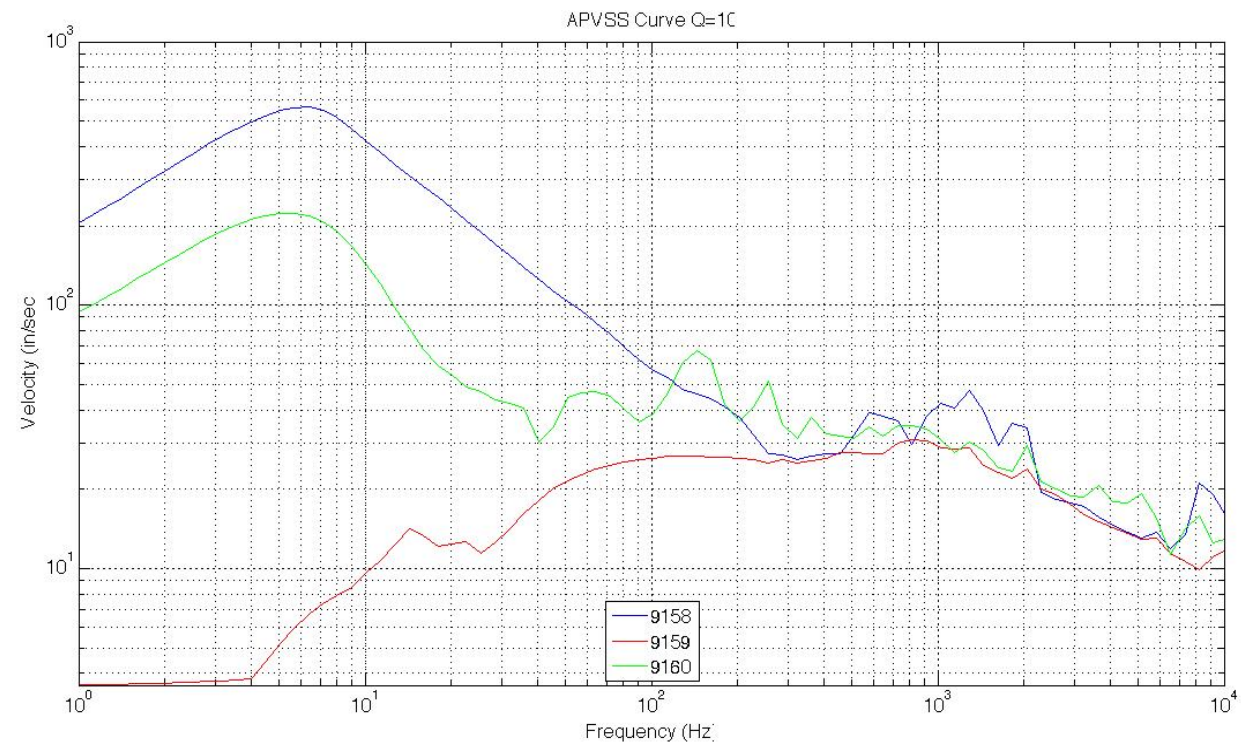

Figure 83. Z Axis, Dispenser with 6U CubeSat - APVSS - Run 2 


\section{RANDOM VIBRATION TESTING}

\subsection{Test Overview and Equipment Description}

In a random vibration test, the shaker imparts vibration at multiple frequencies simultaneously, with randomly varying acceleration at each frequency. Such tests attempt to simulate any of a variety of environments, such as vibration during ground transportation, the effect of ocean waves, and vibration caused by acoustic or aerodynamic

pressure fluctuation during launch of spaceflight hardware. (Instar Engineering and Consulting Inc, 2016).

In space applications, a random vibration test typically goes from 20 to $2000 \mathrm{~Hz}$. According to NASA Standards (NASA GSFC, 2016) the test should be controlled in order to have a Gaussian statistical distribution of acceleration at any point.

Since a random acceleration is not predictable at any point in time, the environment is defined by its frequency content. The acceleration spectral density (ASD), also known as power spectral density (PSD) versus frequency is the parameter for processing any random signal. Typical units for PSD are $\mathrm{g}^{2} / \mathrm{Hz}$.

\subsection{NASA Random Vibration Levels}

The NASA GEVS random vibration levels are designed to comprise a wide range of most of the common launch vehicles used to launch CubeSats (See Figure 84) .For this reason, the CubeSat Design Specification (California Polytechnic State University, 2013) uses NASA GEVS when the launch vehicle environment is unknown. In order to ensure that the $6 \mathrm{U}$ CubeSat structure meet this standard, the GEVS vibration testing levels were adopted. NASA GEVS levels are shown in Table 2. 


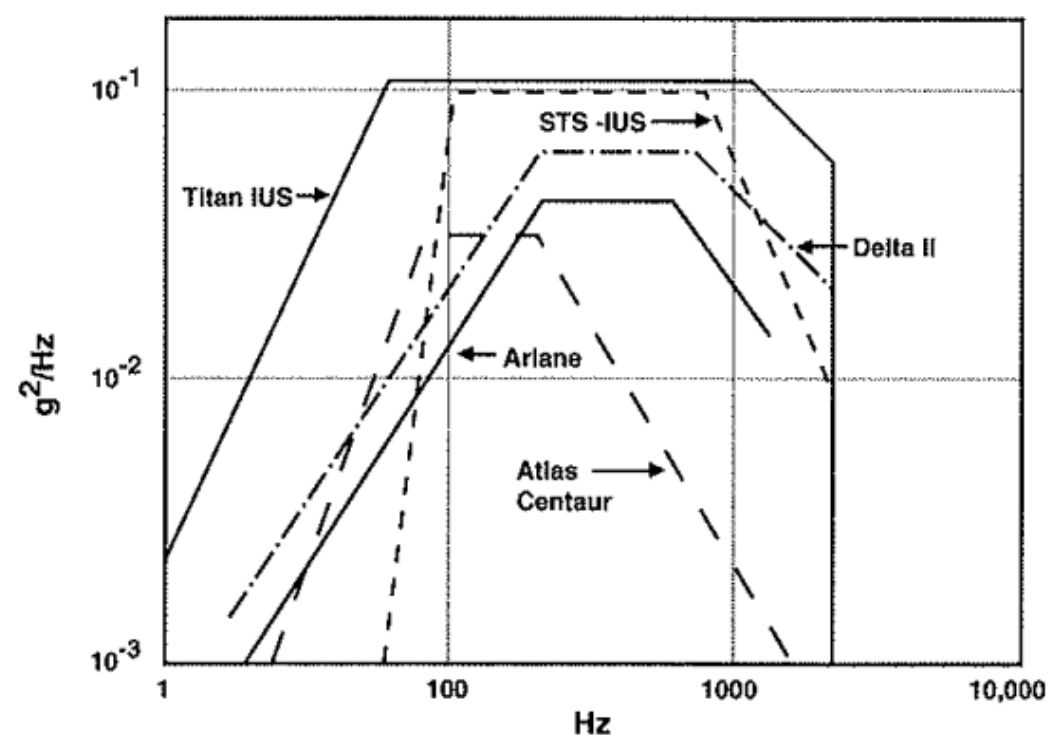

Figure 84. Random vibration levels for different Launch Vehicles. Image/SMAD

Since the structure has never been tested before, the levels adopted were Qualification, which are the highest.

Table 2. NASA GEVS Qualification and Acceptance Levels

\begin{tabular}{|c|c|c|}
\hline & Qualification & Acceptance \\
\hline Frequency $(\mathrm{Hz})$ & $\mathrm{ASD}\left(\mathrm{g}^{2} / \mathrm{Hz}\right)$ & $\mathrm{ASD}\left(\mathrm{g}^{2} / \mathrm{Hz}\right)$ \\
\hline 20 & 0.026 & 0.013 \\
\hline $20-80$ & $+6 \mathrm{~dB} / \mathrm{oct}$ & $+6 \mathrm{~dB} / \mathrm{oct}$ \\
\hline $80-500$ & 0.16 & 0.08 \\
\hline $500-2000$ & $-6 \mathrm{~dB} / \mathrm{oct}$ & $-6 \mathrm{~dB} / \mathrm{oct}$ \\
\hline 2000 & 0.026 & 0.013 \\
\hline Overall & $14.1 \mathrm{Grms}$ & $10.0 \mathrm{Grms}$ \\
\hline
\end{tabular}

\subsection{Experimental Setup and Procedures}

The Aerostructures and Composites Laboratory at Cal Poly is equipped with a shake table (Figure 85). For the 6U composite structure vibration testing, an Unholtz Dickie electrodynamic shaker was used. The shaker can be oriented vertically or horizontally for use with a slip table, allowing 3-axis testing without an additional test adaptor or bracket. 
The Structure was designed such that the spacecraft fundamental frequency is greater to the one of the launch system, as a general rule the first mode of the structure should be above $100 \mathrm{~Hz}$.

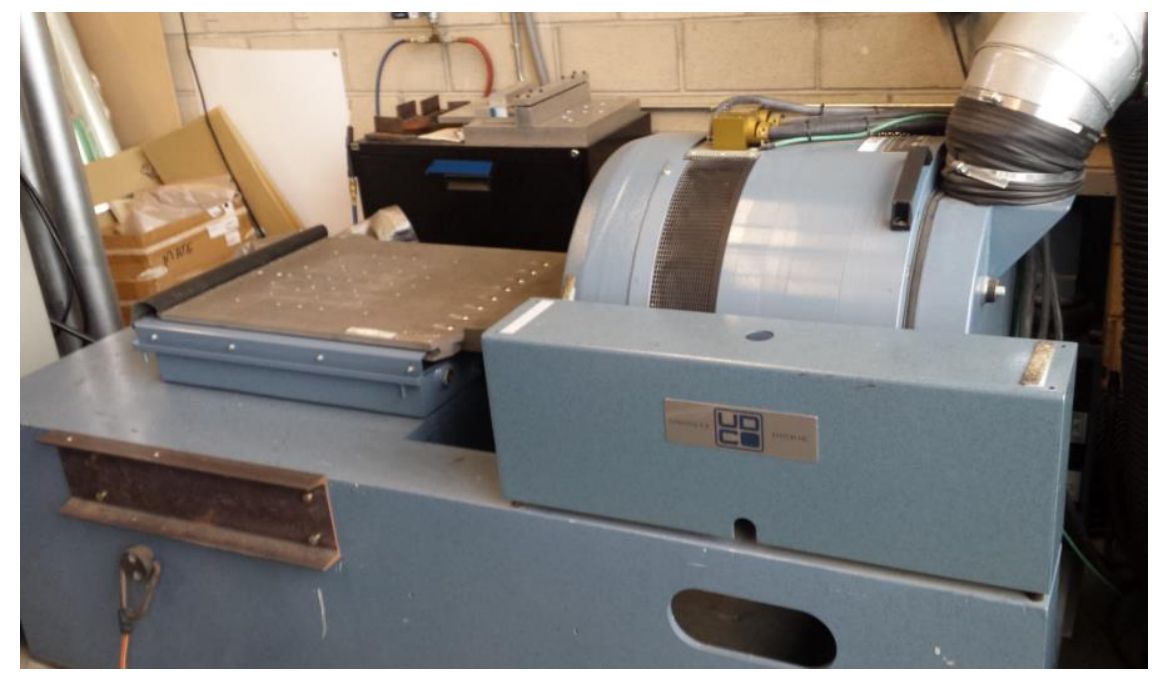

Figure 85. Shake Table at Cal Poly Aerostructures and Composites Lab

According to (Planetary Systems Corporation, 2016) "The maximum structural loading typically results from the dynamic response during random vibration testing and/or shock testing. These loads are dependent on the mass, stiffness, and dampening properties unique to each payload. All payload behave uniquely." Meaning this that even two payload mockups with the same mass will have a different responses. It was the intention of this study to test the structure with a payload that possess a representative mass. See Section for 4.3 Payload Manufacturing Process.

\subsection{Random Vibration Testing in the $\mathrm{Z}$ Axis}

\subsubsection{Z Axis Set Up and Procedure}

The random vibration test was performed in the $\mathrm{Z}$ Axis of the spacecraft. Due to some issues with the equipment it was not possible to test in the $\mathrm{X}$ and $\mathrm{Y}$ direction. 
The first step in the procedure was to mount the box dispenser to the shake table. In order to achieve that, eight screws were placed on the bottom part of the box and a wrench torquimeter was used to fix them, as it is shown in Figure 86.

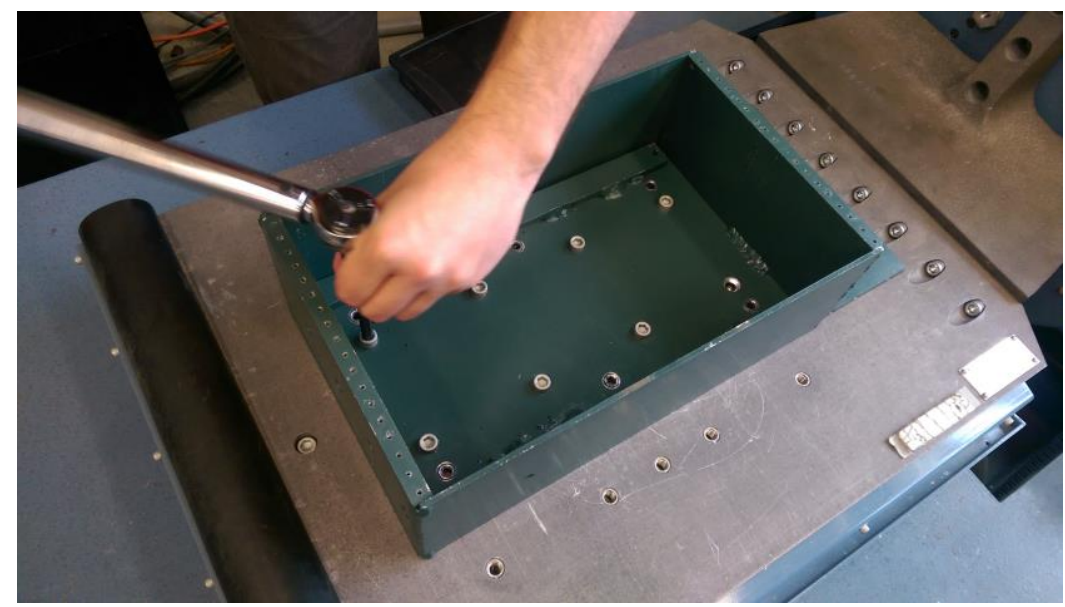

Figure 86. Box Dispenser Test Set Up in the Shake Table - Z Axis

The second step was to mount the accelerometers. As in the case of the shock test, the accelerometers were mounted outside the dispenser and not on the structure. A total of four accelerometers were placed on each of the four laterals of the box. Two were control accelerometers, and the other two were triaxle. The location of the accelerometers was a recommendation of the CubeSat Team and it can be seen in Figure 87 and Figure 88.

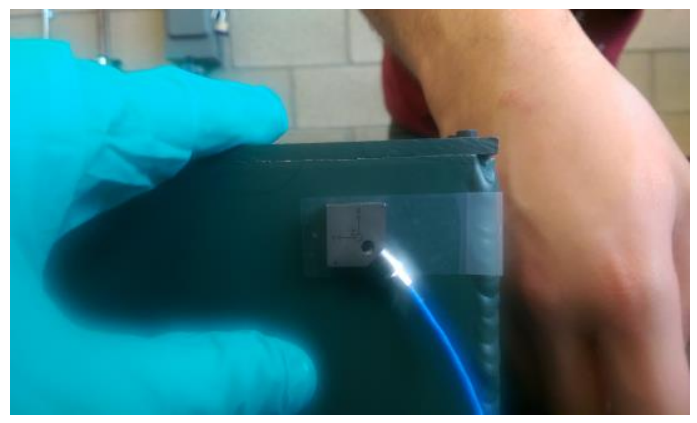

Figure 87. Triaxial accelerometer

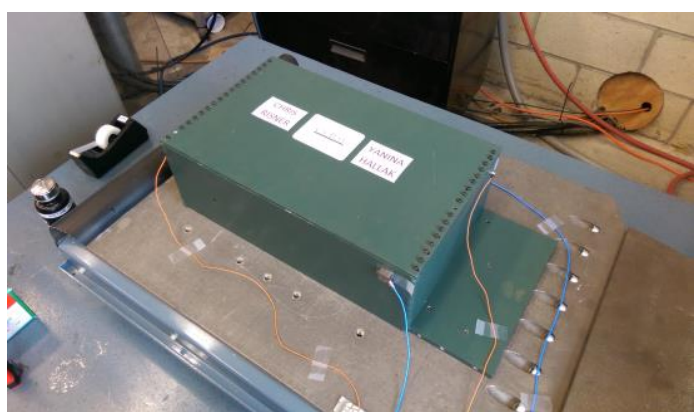

Figure 88. Accelorometers placement

A general view of the test set up is shown in Figure 89. Besides the shake table the equipment was completed with the signal amplifier (Figure 90), the data acquisition 
devices (Figure 91) and a computer with a software that registered the input and the output responses.

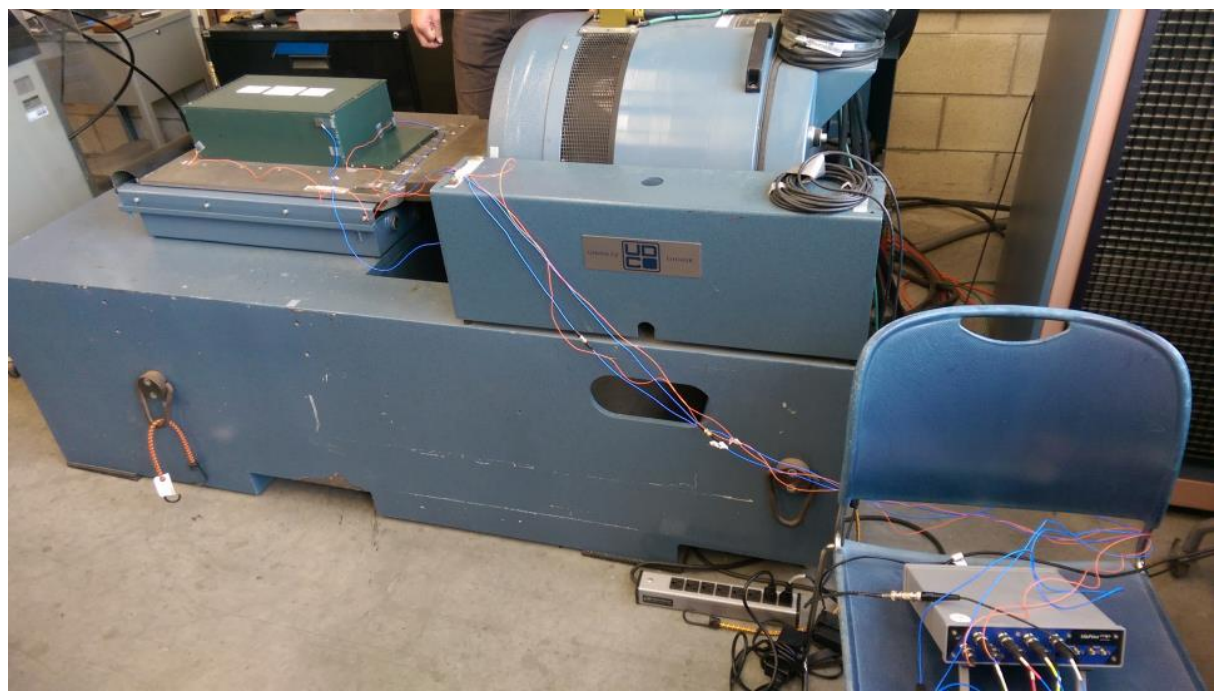

Figure 89. Test set up, accelerometers and data logger

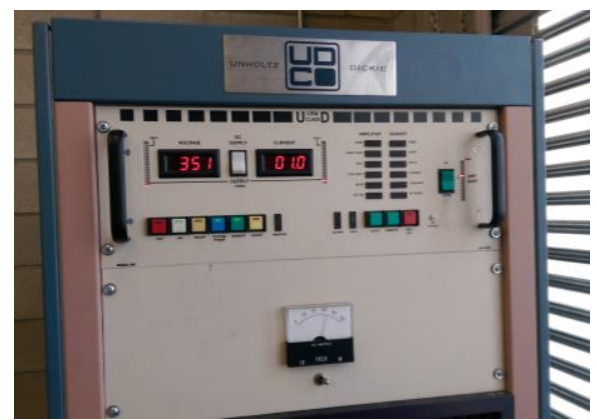

Figure 90. Shake Table Amplifier

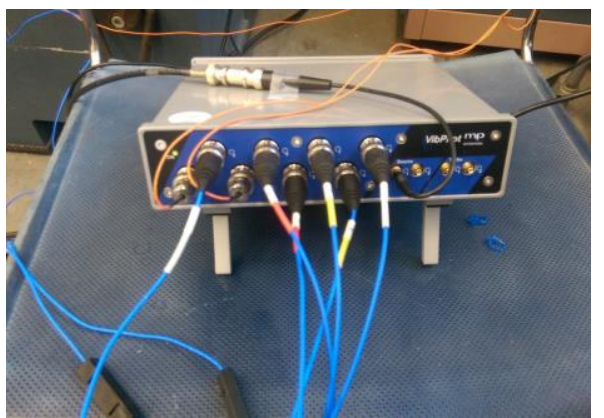

Figure 91. Data Acquisition Equipment

\subsubsection{Z Axis Test Input Levels}

The third step in the procedure was to input in a specific software the levels to be tested. For the case of this test, qualification levels descripted in Table 2 were tested.

A sine sweep is performed before and after the random vibration analysis is carried out. According to NASA (NASA Goddard Space Flight Center, 2013) "Sine sweep vibration tests are performed to qualify prototype/protoflight hardware for the low- 
frequency transient or sustained sine environments when they are present in flight, and to provide a workmanship test for all payload hardware which is exposed to such environments and normally does not respond significantly to the vibroacoustic environment, such as wiring harnesses and stowed appendages."

\subsubsection{Z Axis Box Dispenser Test}

The dispenser was first tested isolated and in a separate test the $6 \mathrm{U}$ structure was mounted inside and tested again. A pre and post sine sweep were carried out and the results comparing both tests can be seen in the following subsection.

\subsubsection{Z Axis Pre and Post Sine Sweep Response Curves: Box Dispenser}

In Figure 92 can be seen that the pre sine sweep and the post sine sweep for all the accelerometers has not changed.

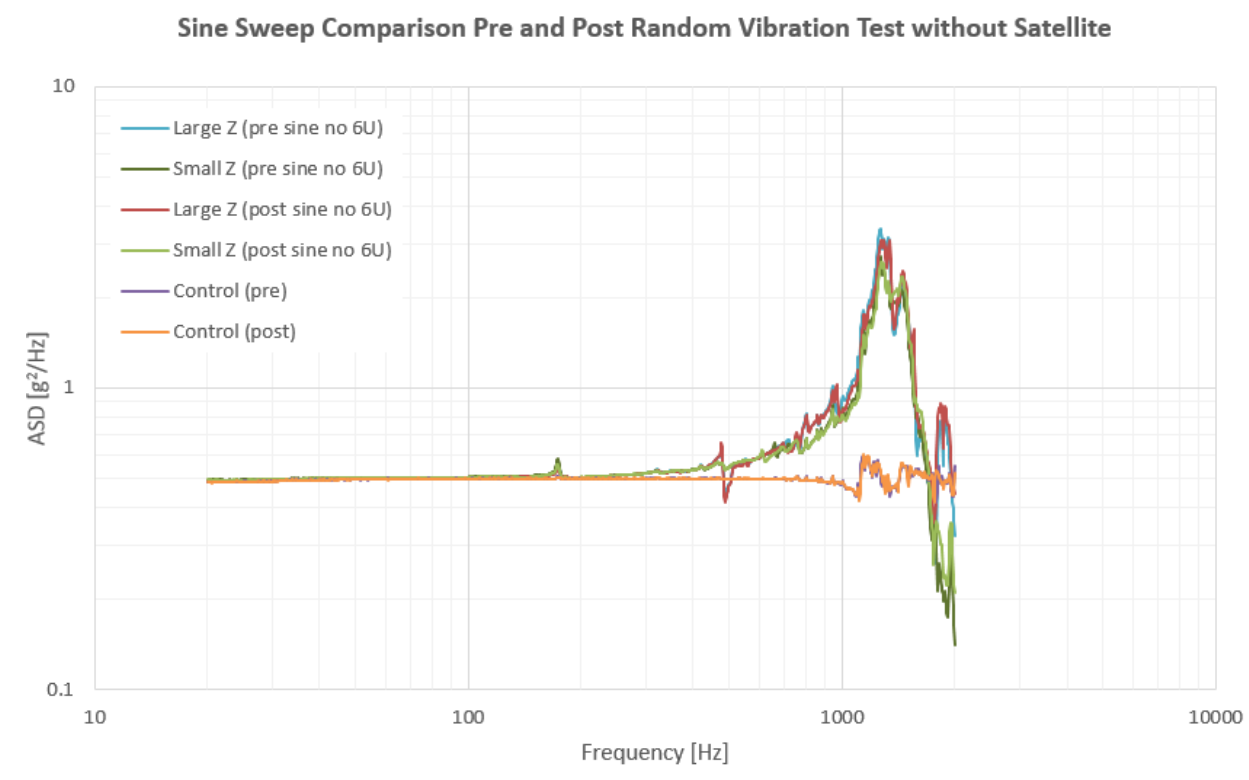

Figure 92. Pre and Post Sine Sweep - Z Axis - Dispenser

\subsubsection{Z Axis Random Vibration Response Curves: Box Dispenser}

After carry out the pre sine sweep, the random vibration test was conducted. The results of measurement of the accelerometers can be seen in Figure 93. It is shown that all 
the ASD values were within the upper bound and lower bound. The fundamental frequency of the box was approximately $1250 \mathrm{~Hz}$.

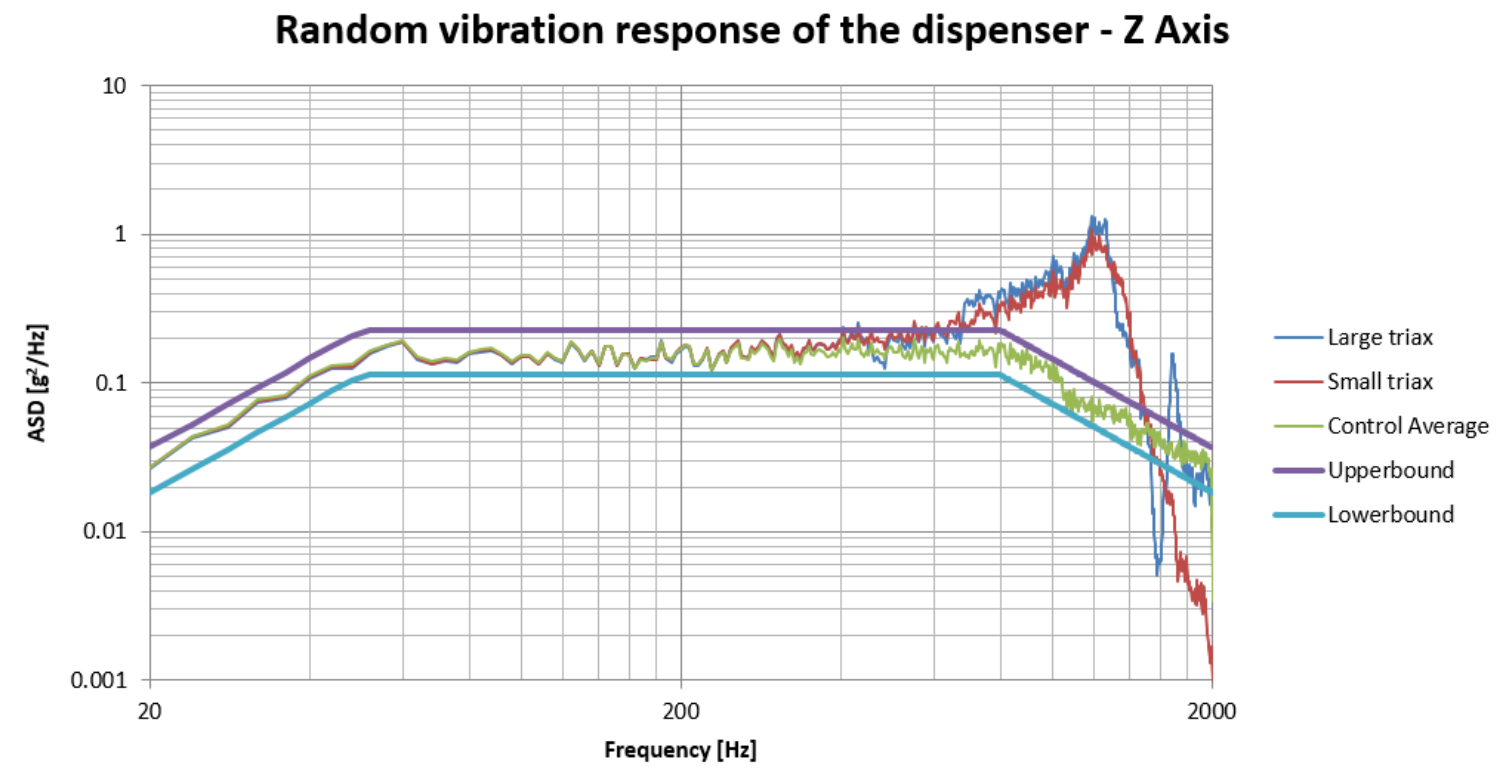

Figure 93. Random Vibration Response of the Dispenser

\subsubsection{Z Axis Box Dispenser with Satellite Test}

The $6 \mathrm{U}$ structure was mounted inside the dispenser as it is shown in Figure 94. Two aluminum plates were used to shim it. Then the lid was mounted and the structure was ready to run the pre sine sweep. 


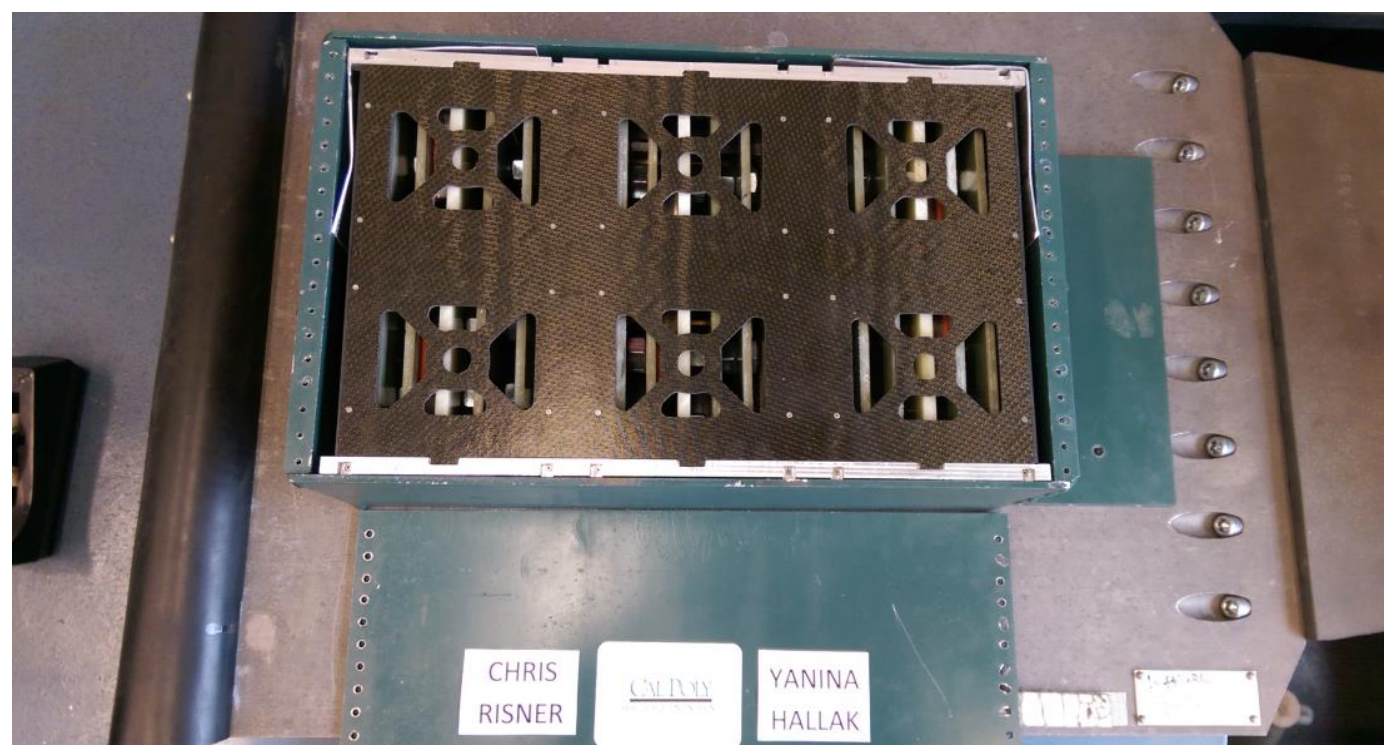

Figure 94. Box Dispenser and Satellite Test Set Up in the Shake Table

\subsubsection{Z Axis Pre-Sine Sweep Curves: Box Dispenser and Satellite}

In Figure 95 is shown the comparison between the pre and post sine sweep of the test that was done when the satellite was mounted inside the dispenser. The similarity confirmed there were no significant structural changes during the test.

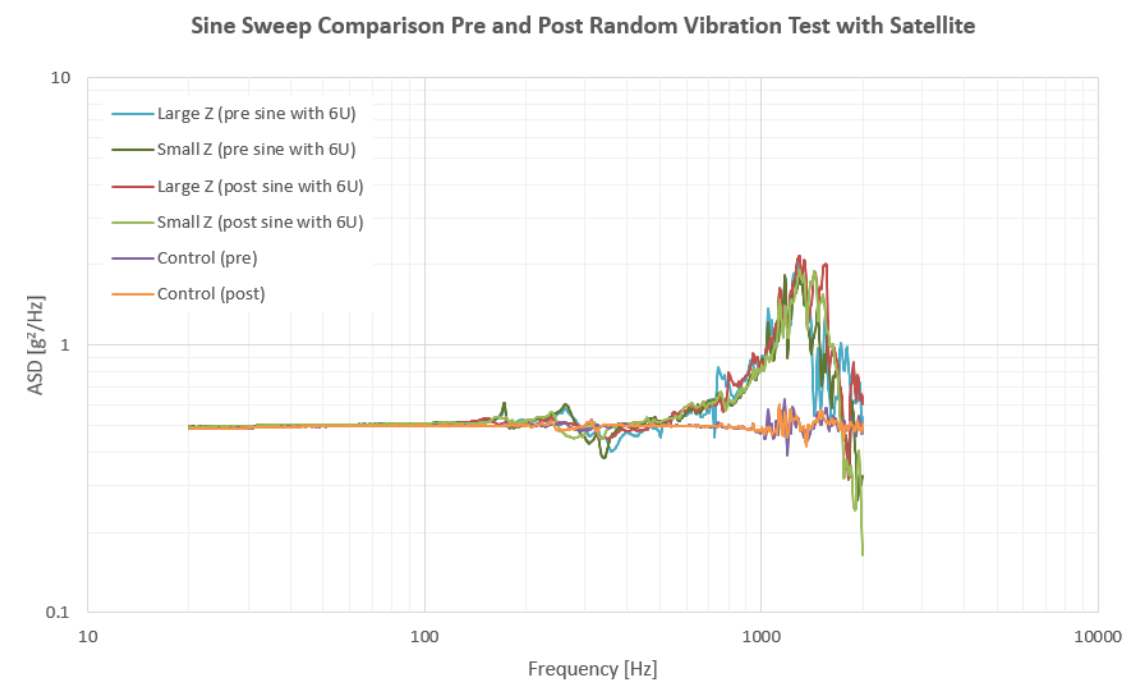

Figure 95. Pre and Post Sine Sweep - Z Axis - Dispenser with Satellite 


\subsubsection{Z Axis Random Vibration Curves: Box Dispenser and Satellite}

The random vibration response of the $6 \mathrm{U}$ structure is shown in Figure 96. As it can be seen the response was enclosed within the upper and lower limits. The fundamental frequency of the dispenser with the $6 \mathrm{U}$ structure was $1196 \mathrm{~Hz}$

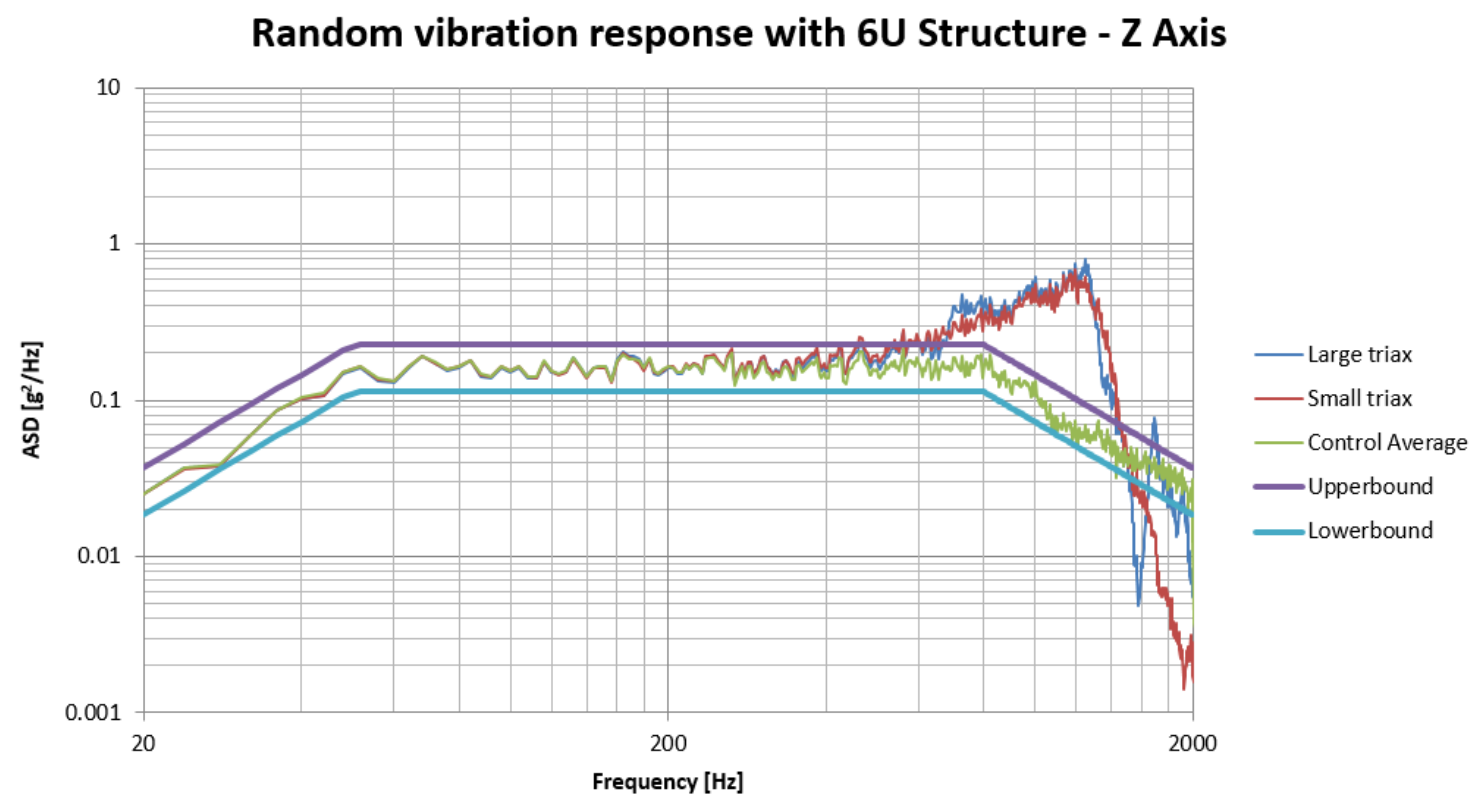

Figure 96. Random vibration Response dispenser with Satellite

Accelerometers were mounted outside the dispenser and not on the structure. This vibration test have demonstrated the structural fidelity required by the NASA GEVS-STD7000A (NASA Goddard Space Flight Center, 2013) qualification levels dictating small payload dynamic launch environment survivability requirements.

Figure 97 provides an easier comparison between the input and the response in a descriptive representation. 


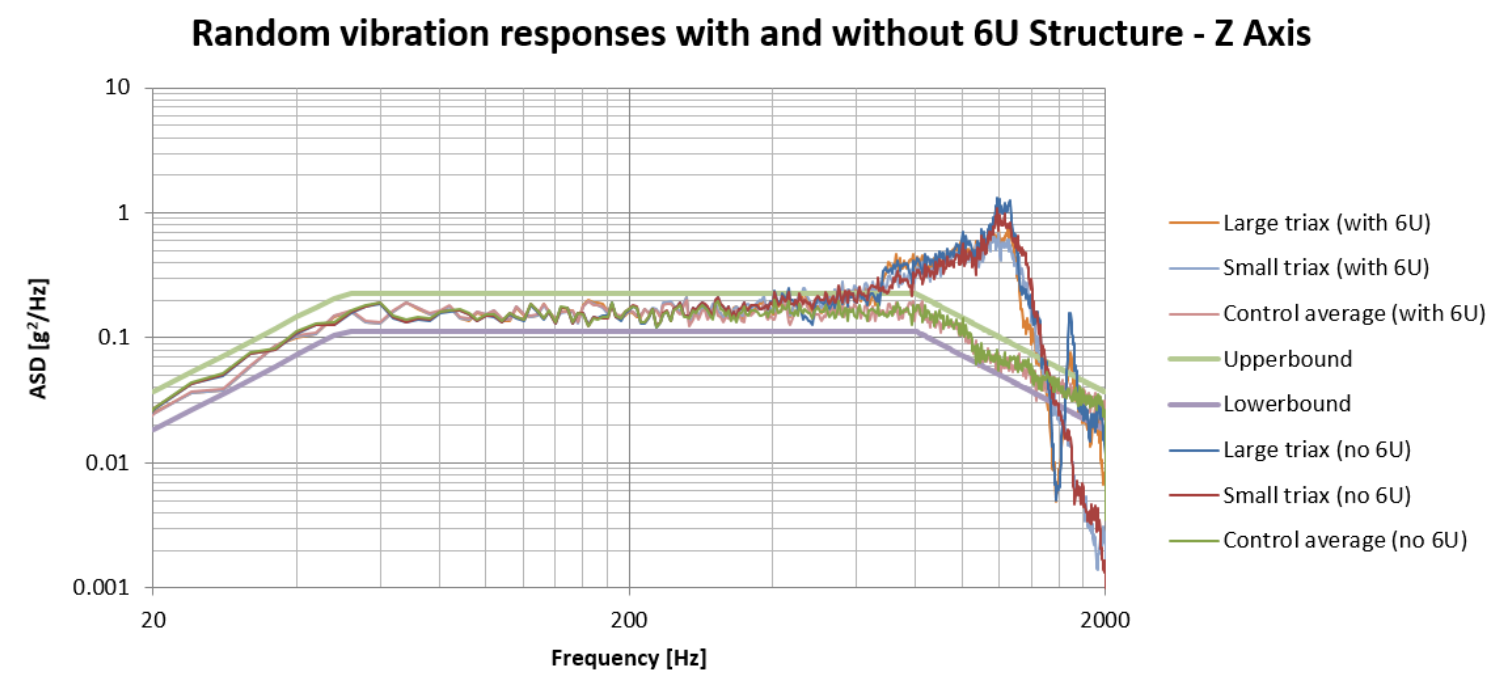

Figure 97. Dispenser and Dispenser + Structure Random Vibration response

Although it was not possible to perform the test in the other two axis, the vibration test in the $\mathrm{Z}$ axis have demonstrated the structural fidelity required by the NASA GEVSSTD-7000A (NASA Goddard Space Flight Center, 2013) qualification levels dictating small payload dynamic launch environment survivability requirements. 


\section{NUMERICAL FINITE ELEMENT ANALYSIS}

\subsection{Finite Element Model}

The finite element analysis of a $6 \mathrm{U}$ CubeSat was created. Two Finite element models were generated, meshed and run, using Abaqus/CAE and SolidWorks Simulation. It is vital to have correct material properties in order to have the numerical values validate the experimental values obtained from the vibration analysis. With Abaqus/CAE different static cases were modeled and Solidworks Simulation was utilized to determine the response of the random vibration analysis. The finite element models had approximately 65,000 elements and different study cases were ran.

\subsection{Mass Properties}

In Table 3 are listed the masses of the elements that were modeled in the Finite Element Model.

Table 3. 6U Total Masses

\begin{tabular}{|l|c|}
\hline & Aluminum 6061 \\
\hline 6U Structure & $1.23 \mathrm{Kg}$ \\
\hline Dummies loads & $2.64 \mathrm{Kg}$ \\
\hline Payload \& Batteries & $2.83 \mathrm{Kg}$ \\
\hline Total mass & $6.70 \mathrm{Kg}$ \\
\hline
\end{tabular}

\subsection{Material Properties}

In Table 4 and Table 5 the material properties of the finite element model are included. 
Table 4. Finite Element Model Material Properties for Aluminum 6061

\begin{tabular}{|l|c|}
\hline & Aluminum 6061 \\
\hline Material Type & Isotropic \\
\hline Density & 2.7 \\
\hline Young's Modulus & $68900 \mathrm{MPa}$ \\
\hline Poisson ratios & 0.3 \\
\hline
\end{tabular}

Table 5. Finite Element Model Material Properties for Composites Materials

\begin{tabular}{|l|c|c|}
\hline & LTM45/CF & G10/FR4 \\
\hline Material Type & Orthotropic & Orthotropic \\
\hline Fiber/Resin & Carbon Fiber / Epoxy & Fiber Glass / Epoxy \\
\hline E1 & $45092 \mathrm{MPa}$ & $24000 \mathrm{MPa}$ \\
\hline E2 & $45092 \mathrm{MPa}$ & $24000 \mathrm{MPa}$ \\
\hline E3 & $20000 \mathrm{MPa}$ & $24000 \mathrm{MPa}$ \\
\hline Nu12 & 0.096 & 0.12 \\
\hline Nu13 & 0.096 & 0.12 \\
\hline Nu23 & 0 & 0.12 \\
\hline G12 & $5000 \mathrm{MPa}$ & $2000 \mathrm{MPa}$ \\
\hline G13 & $5000 \mathrm{MPa}$ & $2000 \mathrm{MPa}$ \\
\hline G23 & $5000 \mathrm{MPa}$ & $2000 \mathrm{MPa}$ \\
\hline
\end{tabular}

\subsection{Static Model}

The static model of the $6 \mathrm{U}$ structure was created. The purpose of this study was to check lateral and axial maximum accelerations during launch as well as check reactions to verify and validate the finite element model. Three test cases were created one on each direction of the flight, $\mathrm{X}, \mathrm{Y}$, and Z. A gravity load of $21 \mathrm{G}$ was applied in the three directions. 


\subsubsection{Static Model in X Axis}

\subsubsection{Static Model Boundary Conditions}

The model was constrained in one of the sides of the $\mathrm{X}$ axis.

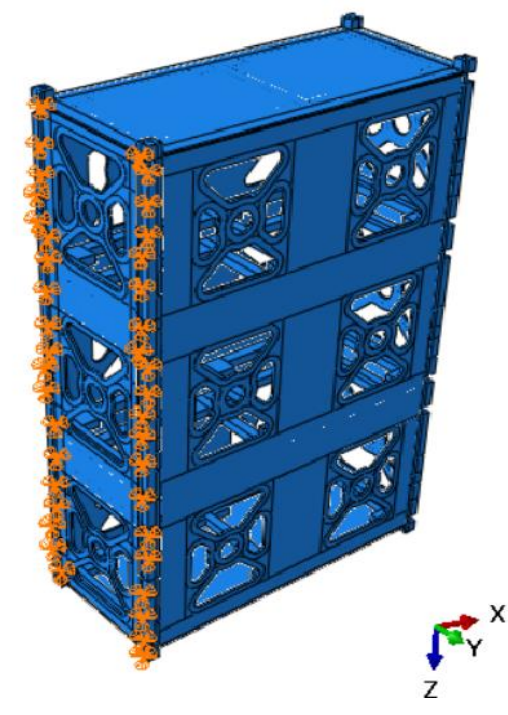

Figure 98. Static Test. 21g in $Y$ axis

\subsubsection{Static Model Loads}

The maximum axial acceleration

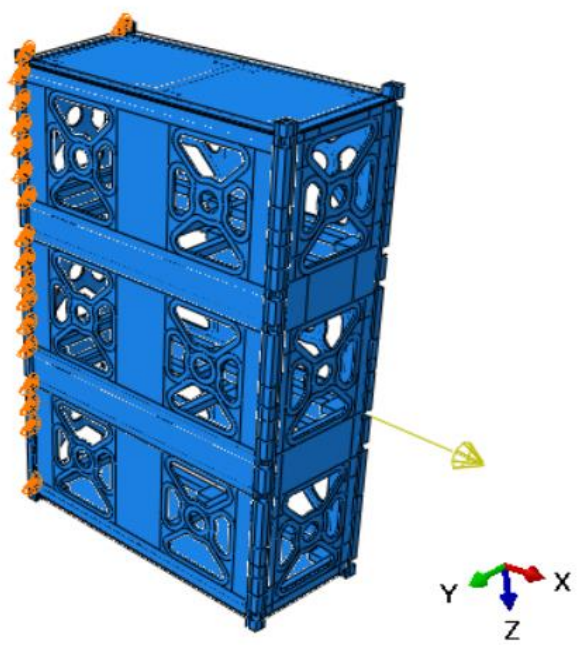

Figure 100. Static Test. 21g in $\mathrm{X}$ axis

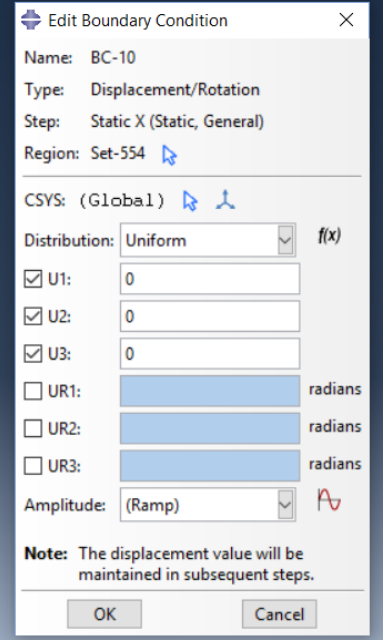

Figure 99. Static Test. Chart: Boundaries Conditions in X Axis

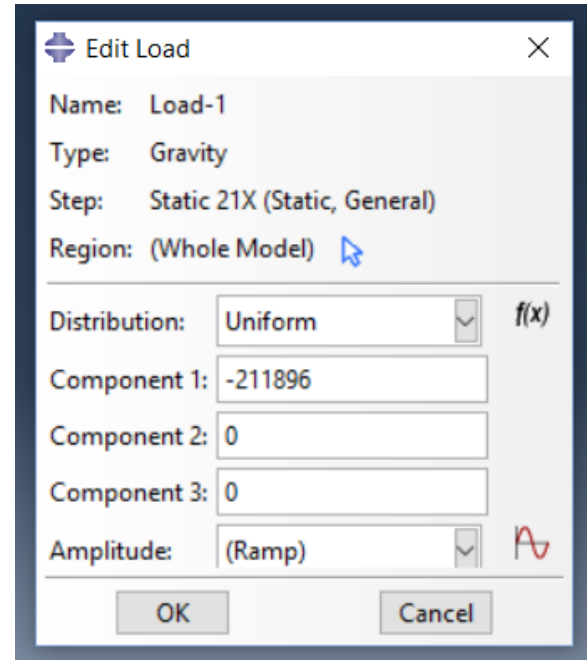

Figure 101. Static Test. 21g chart in $\mathrm{X}$ axis 
7.4.1.3 Static Model Results in X Axis

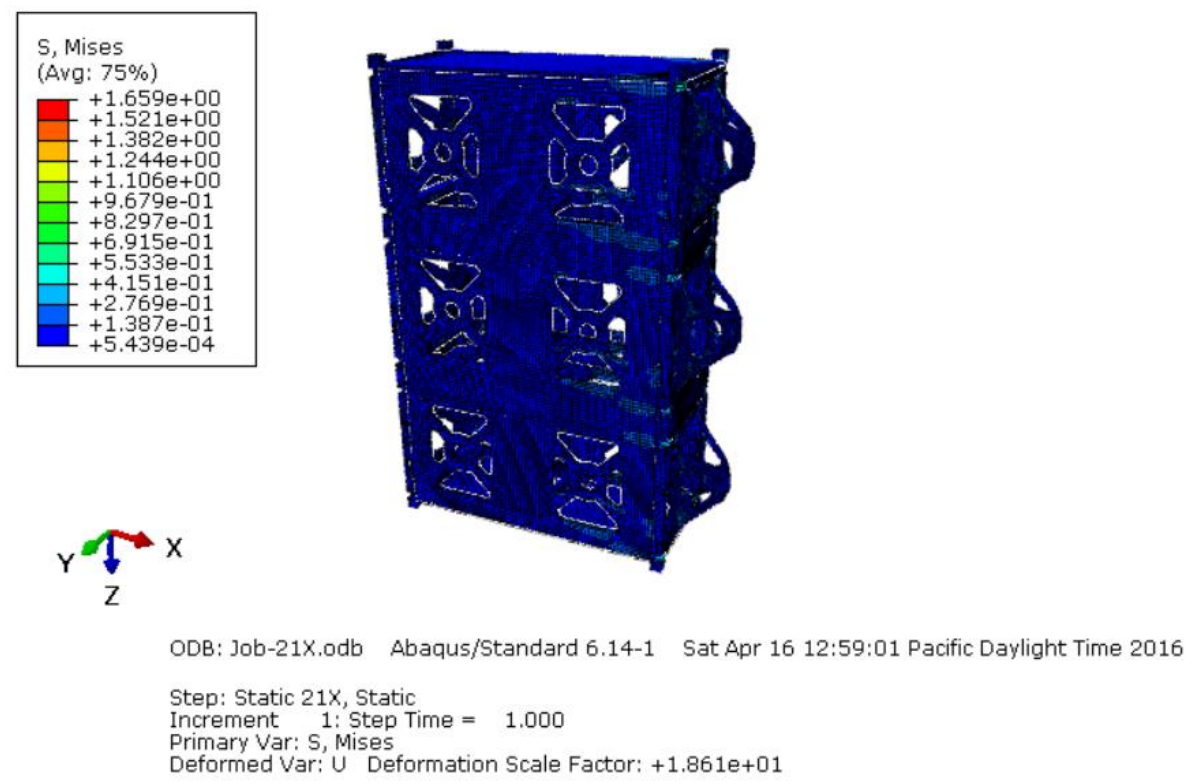

Figure 102. Stresses and deflections in the $\mathrm{X}$ Axis, after applying $21 \mathrm{G}$

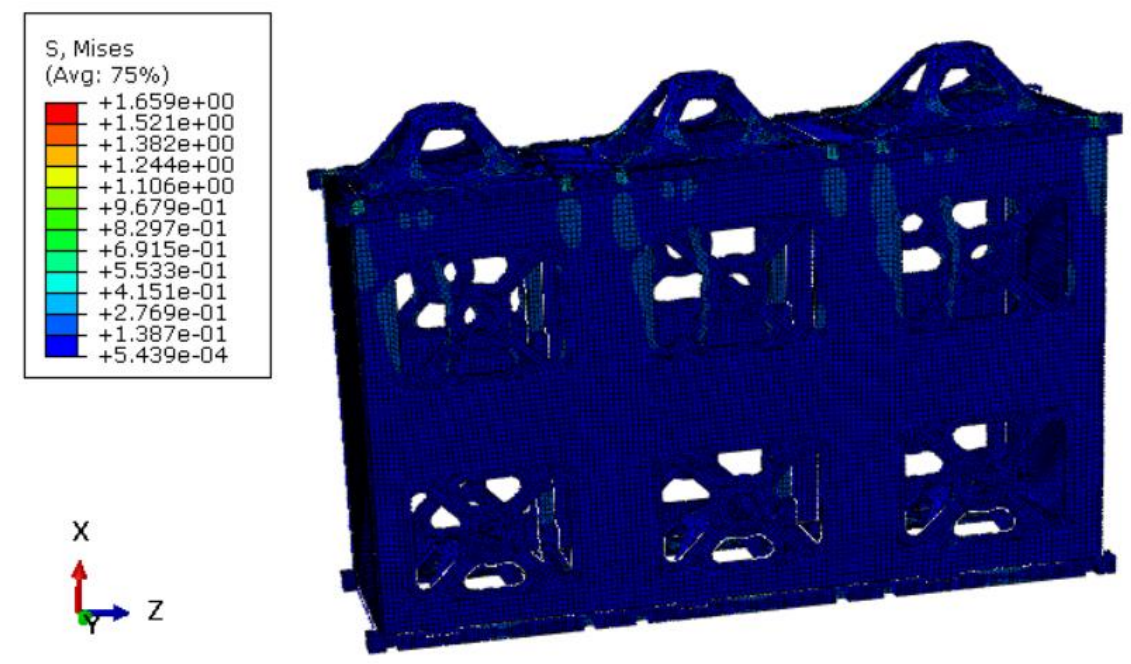

Figure 103. Stresses and deflections in the $X$ Axis, after applying $21 G$

\subsubsection{Static Model in Y Axis}

\subsubsection{Static Model Boundary Conditions}

The model was constrained in one of the sides of the $\mathrm{Y}$ axis. 


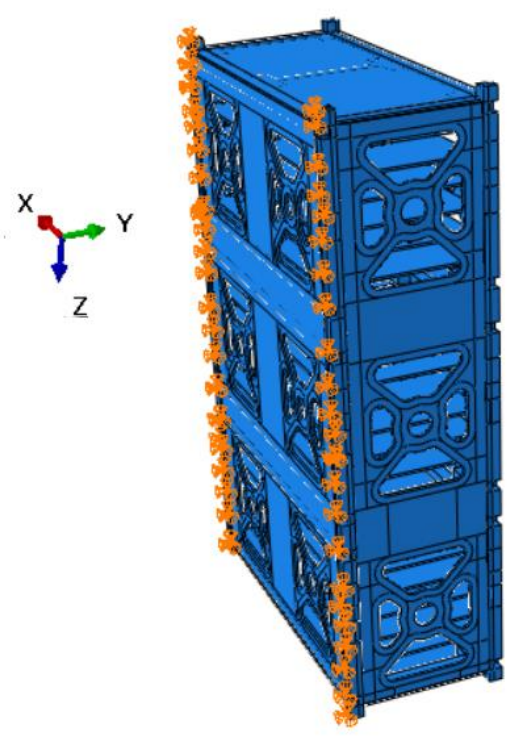

Figure 104. Static Test. Boundaries Conditions in Y Axis

\subsubsection{Static Model Loads}

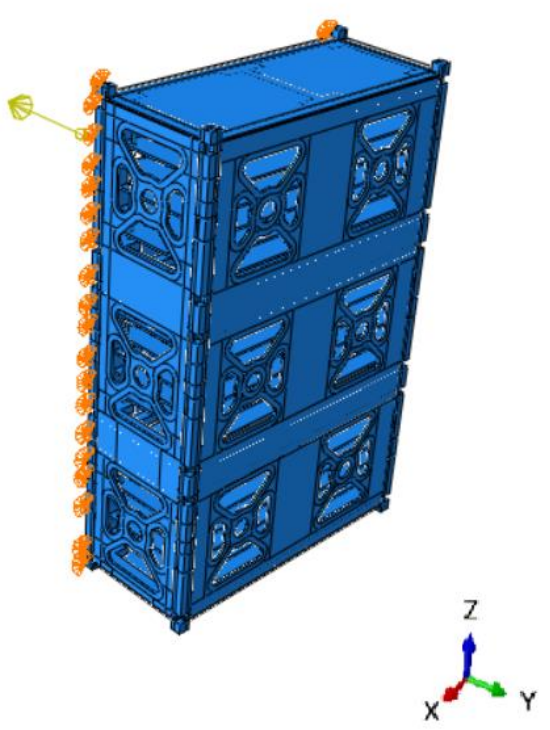

Figure 106. Static Test. 21g in $Y$ axis

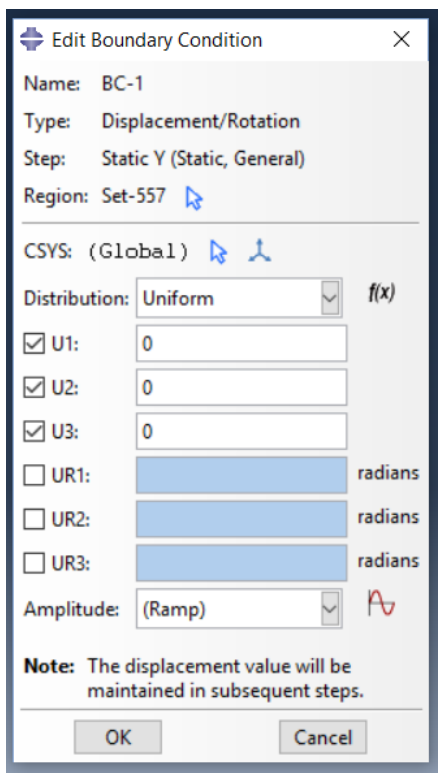

Figure 105. Static Test. Chart: Boundaries Conditions in Y Axis

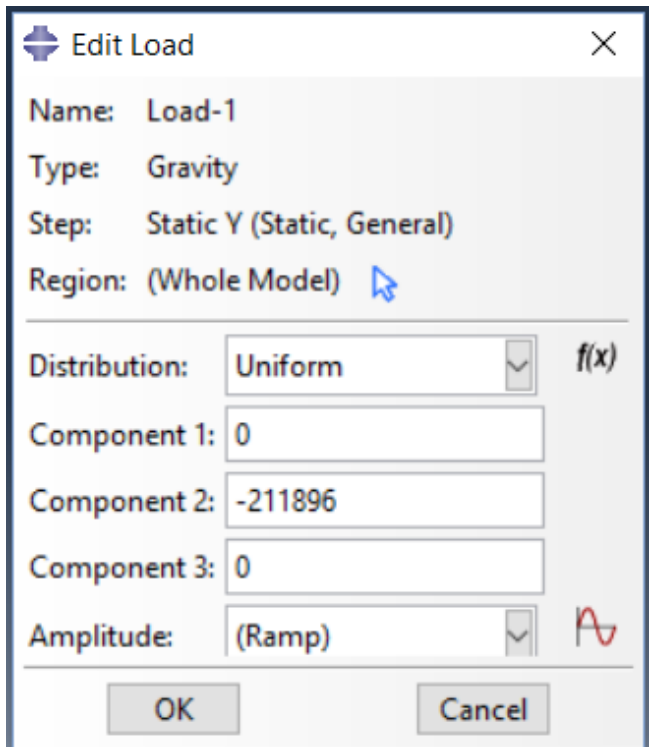

Figure 107. Static Test. 21g chart in $Y$ axis 
7.4.2.3 Static Model Results in Y Axis

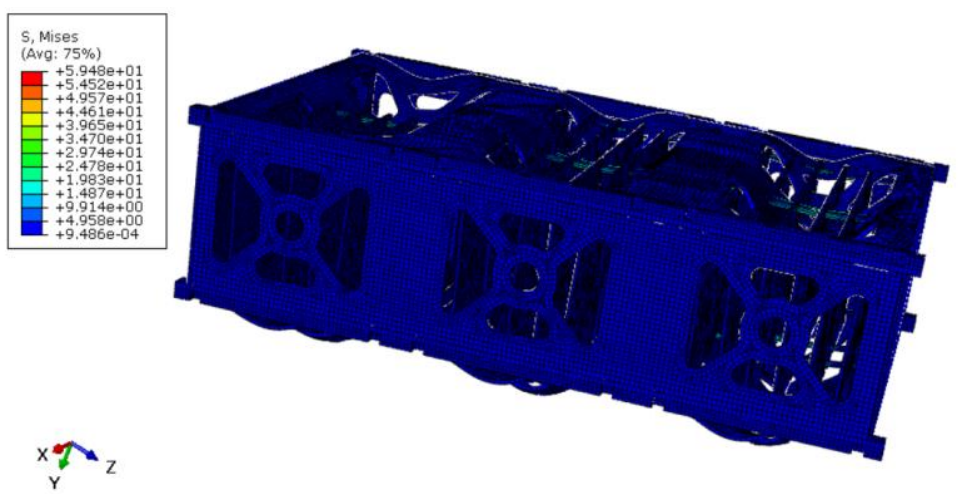

Model: Model - $21 Y$
File: C: (Users|Watson \Documents|Calpoly|599-Thesis\}Finite Element Modelffea3.cae Step: Static Y

Figure 108. Stresses and deflections in the Y Axis, after applying 21G

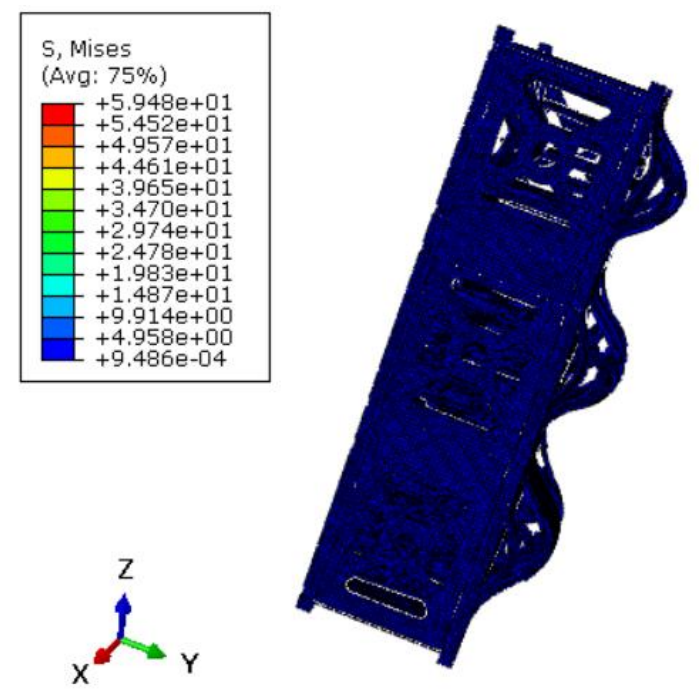

Figure 109. Stresses and deflections in the Y Axis, after applying 21G 


\subsubsection{Static Model in Z Axis}

\subsubsection{Z Axis Static Model Boundary Conditions}

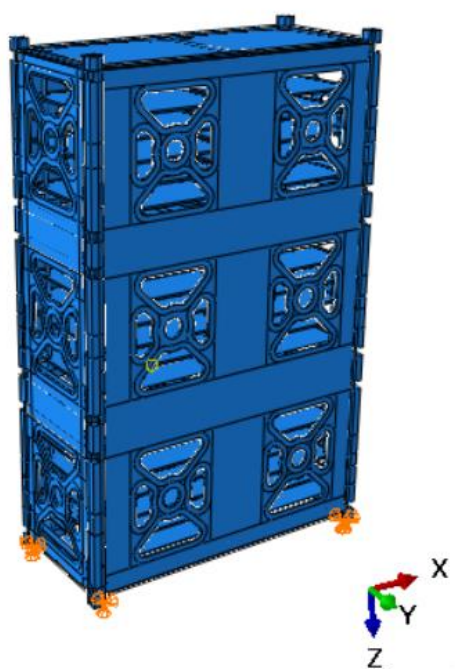

Figure 110. Static Test. Boundaries Conditions in $\mathrm{Z}$ axis

\subsubsection{Z Axis Static Model Load}

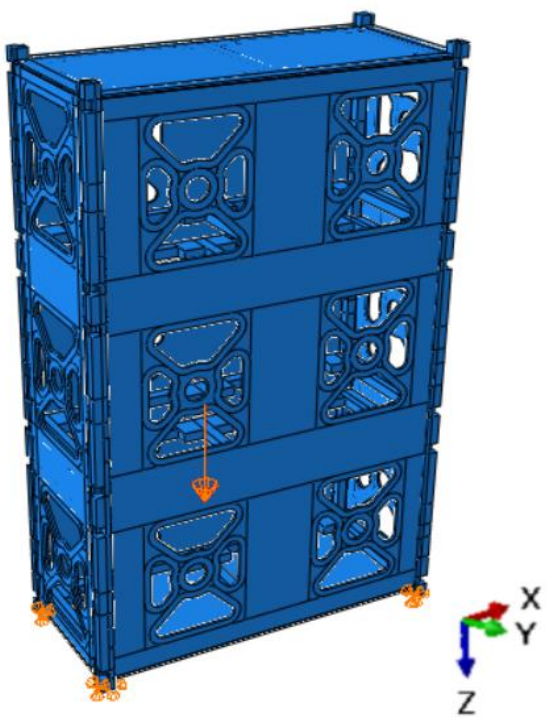

Figure 112. Static Test. 21g in $Z$ axis

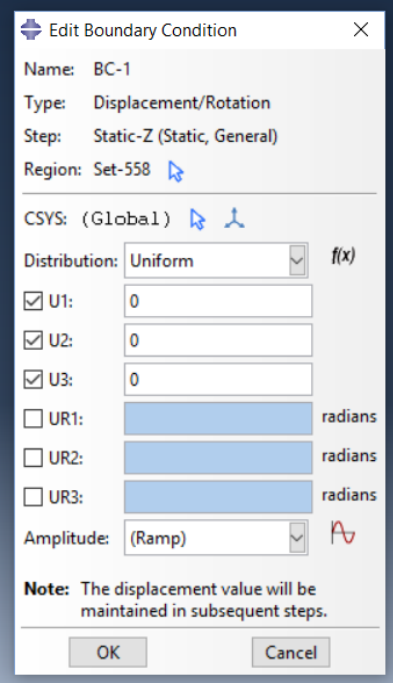

Figure 111. Static Test. Chart: Boundaries Conditions in $\mathrm{Z}$ Axis

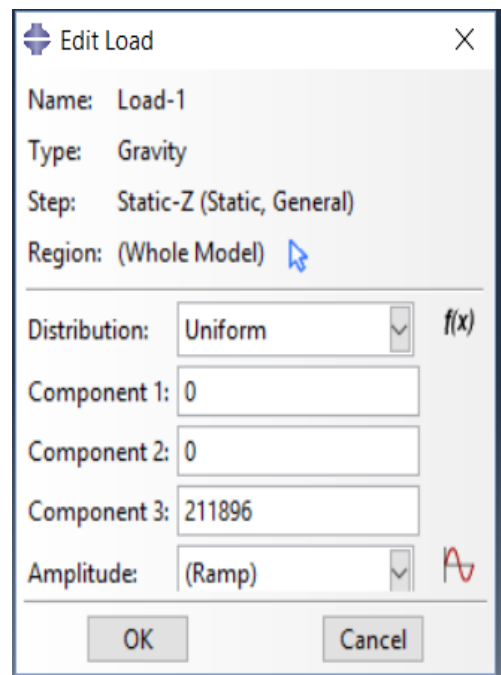

Figure 113. Static Test. 21g chart in $\mathrm{Z}$ axis 


\subsubsection{Static Model Results in Z Axis}
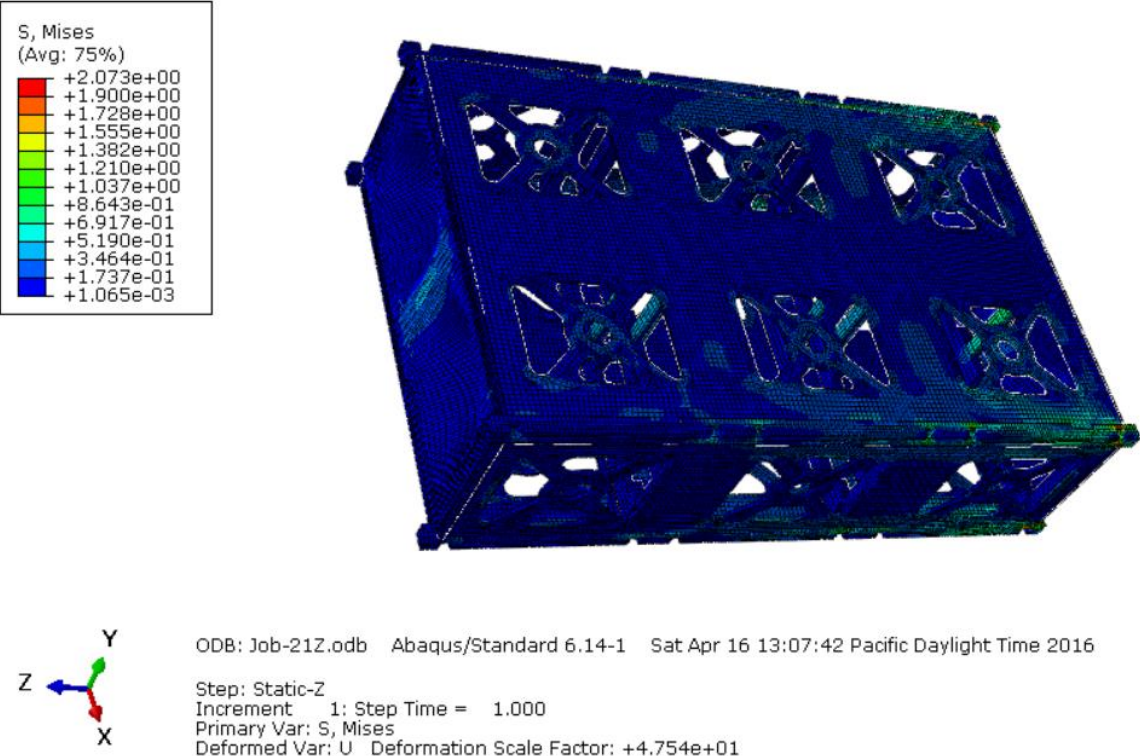

Figure 114. Stresses and deflections in the $Z$ Axis, after applying $21 G$
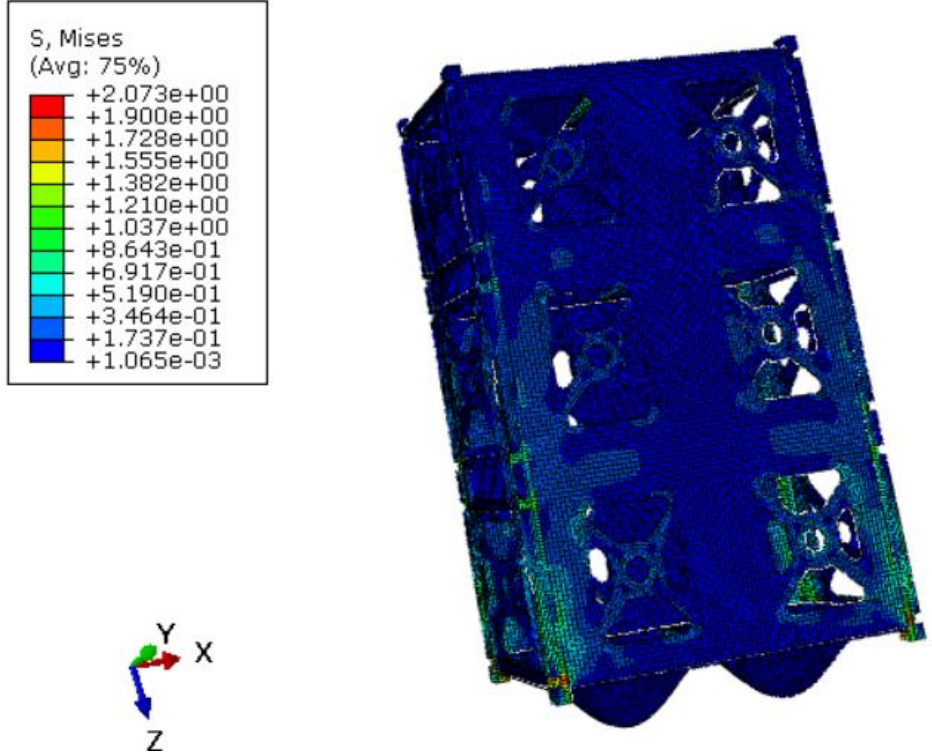

Figure 115. Stresses and deflections in the $Z$ Axis, after applying $21 G$ 


\subsection{Random Vibration Model}

\subsubsection{Random Vibration Model}

A finite element model of 65,000 elements was built and a random vibration analysis was ran. In Figure 116 is shown the random vibration mesh.

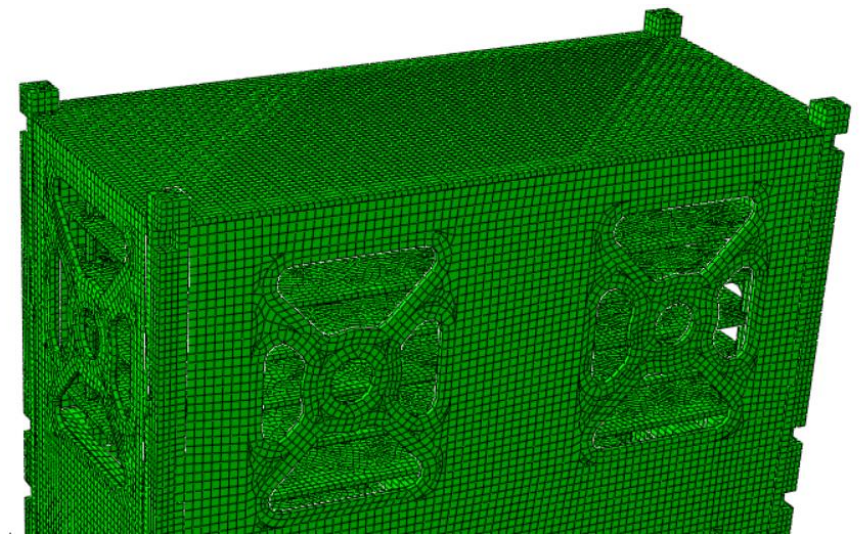

Figure 116. Random Vibration Model Mesh

\subsubsection{Random Vibration Input Function Loads}

In a random vibration study, loads are described statistically by power spectral density (PSD) functions. Power spectral density describes how the energy of the random process is distributed in the frequency domain. The units of PSD are the units of the load squared over frequency as a function of frequency. The NASA PSD curve is shown below Figure 118. The $\mathrm{X}$ axis (frequency $\mathrm{Hz}$ ) is plotted on a logarithmic scale for a clear illustration of the wide frequency range. The unit for Y-axis is amplitude2/ frequency. (Dassault Systemes, 2014). The solution of random vibration problems is formulated in the frequency domain.

Figure 117 and Figure 118 are shown the input base excitation function used to run the random vibration analysis. As it can be seen the values in the chart of the image 
correspond with the ones descripted in Table 2. NASA GEVS Qualification and Acceptance Levels.

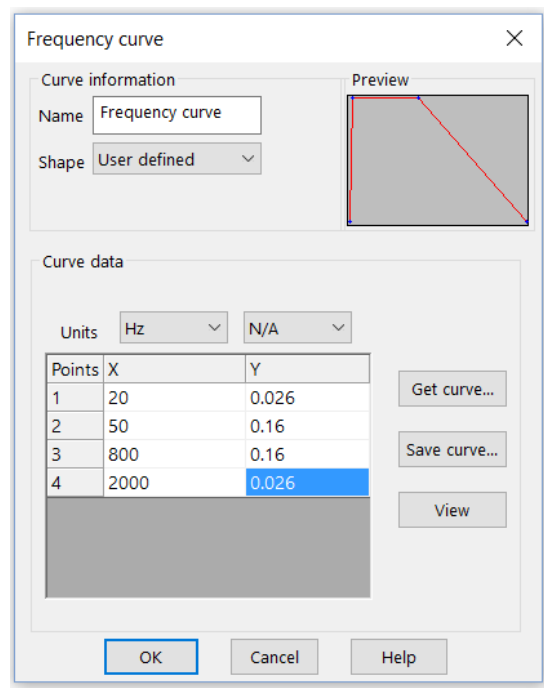

Figure 117. FEA PSD Definition

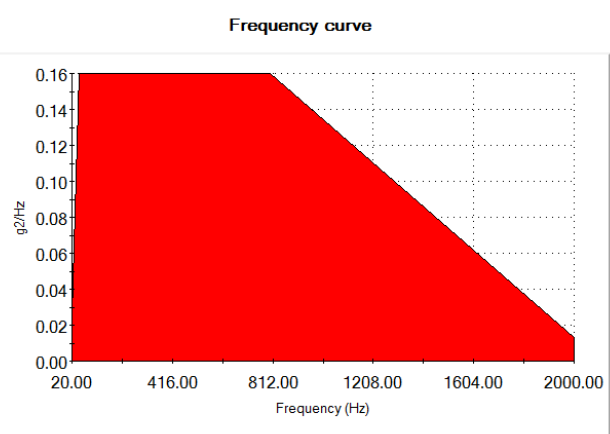

Figure 118. Frequency Curve for Random Vibration Analysis

\subsubsection{Random Vibration Results}

After running the study, root-mean-square (RMS) values, or PSD results of stresses, displacements, velocities at a specific frequency or graph results at specific locations versus frequency values can be plotted.

In Figure 119 was shown the fundamental frequency of the structure after applying the random vibration loads. For the same analysis the displacements related to the frequency are shown in Figure 120. 


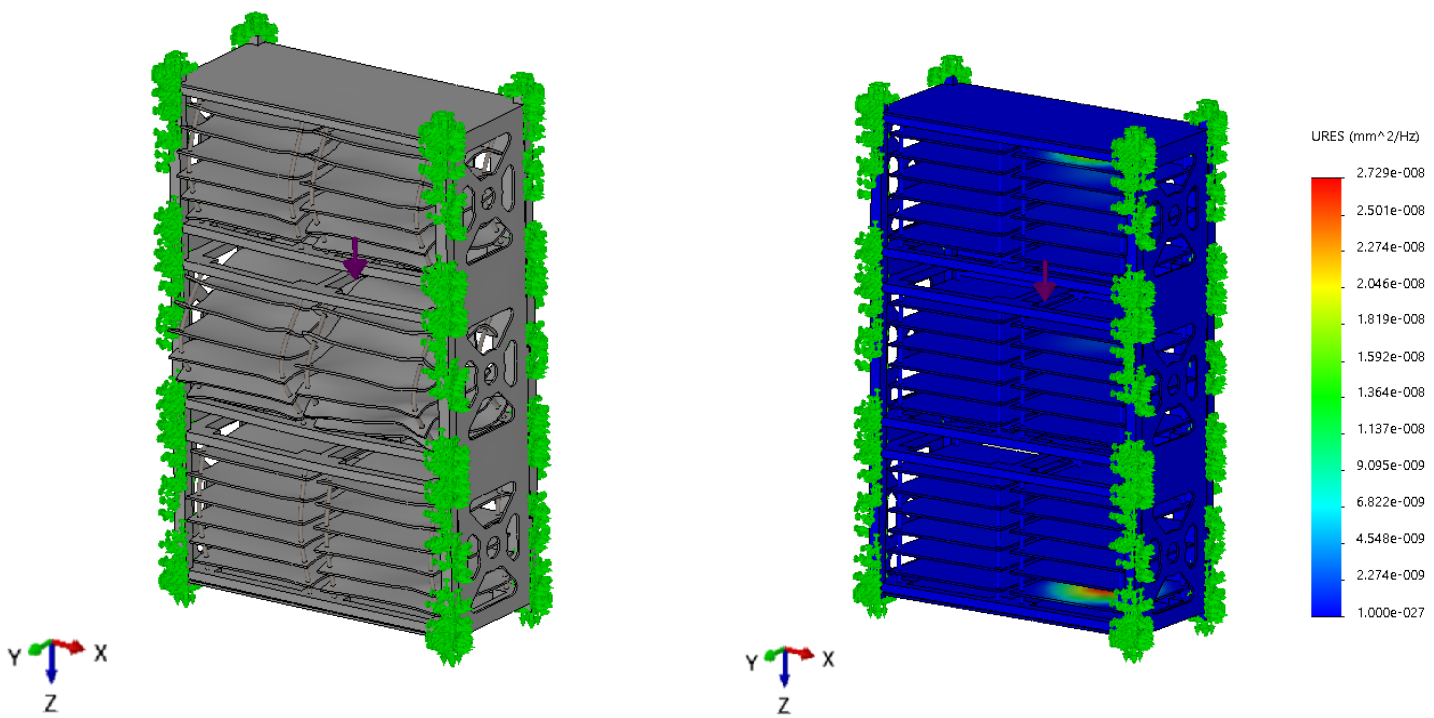

Figure 119. Random Vibration Response. Scale Factor 30 times

Figure 120. Random Vibration Displacements

The graphic response of the random vibration finite element analysis is shown in Figure 121. The software only permitted to pick six nodes and with them generated a response graph from the ASD levels versus Frequency. In this chart it can be seen that the peak response is close to the value obtained experimentally.

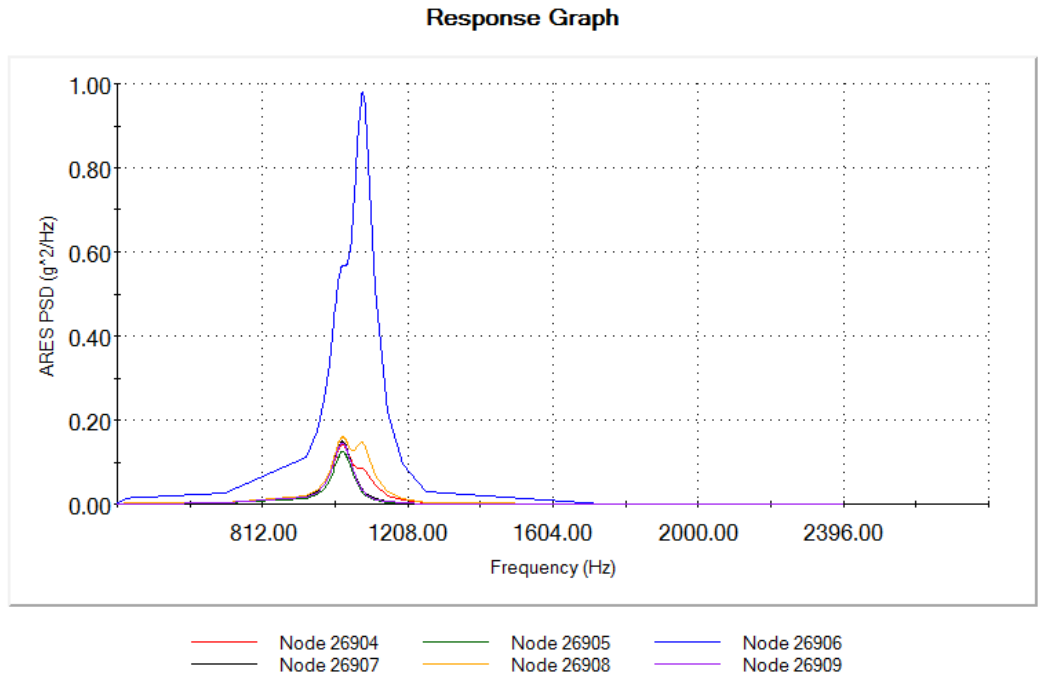

Figure 121. Random Vibration Response Graph. ASD vs Frequency (Z Axis) 


\subsection{Error percentage between the Numerical and Experimental Results}

The fundamental frequency of the dispenser with the $6 \mathrm{U}$ structure was $1196 \mathrm{~Hz}$ as it was shown in Section 6.4.4.2. The peak response given by the FEA model was $1135 \mathrm{~Hz}$ From this results of the resonance values it can be seen that the percentage of error between the experimental and the numerical analysis, is $5.1 \%$. 


\section{COMPARISON BETWEEN CUBESATS COMMERCIALLY AVAILABLE}

\subsection{U Structures Overview and Comparison}

As it was explained in the introduction for a $6 \mathrm{U}$ CubeSat the general dimensions are $226.3 \mathrm{~mm}$ in length, width of $100 \mathrm{~mm}$ and height of $366 \mathrm{~mm}$ and has a mass of $6 \mathrm{~kg}$ and no greater than $8 \mathrm{~kg}$. There is another version of the $6 \mathrm{U}$ standard that stipulates a height of $340.5 \mathrm{~mm}$ respecting the same dimensions for width and length. For developing this thesis the CubeSat Requirement Document (California Polytechnic State University, 2013) in addition to the 6U specification drawing \#TK-6UDSB-01 (Tyvak Nano-Satellite Systems, 2014) have been followed. At the moment of the writing phase of this thesis a version of 6U CubeSat Design Specification Rev. Provisional has been released, but was not taking into account for the developing of the presented structure. The main difference of this document with the previous version is that stipulates that the maximum mass for the satellite shall be $12 \mathrm{Kg}$. The researcher investigated about this requirement, and it was found that the restriction comes from the dispenser. Figure 122, Figure 123 and Figure 124 showed the structures that were compared in this chapter.

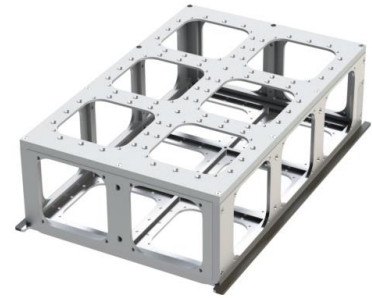

Figure 122. Supernova Credit/ Pumpkin Space

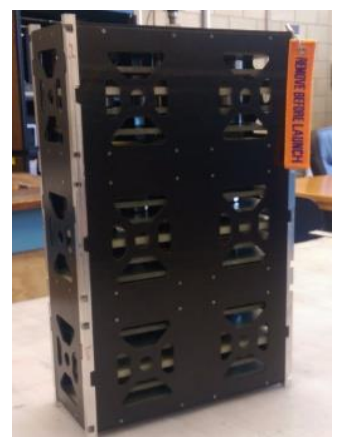

Figure 123. YaniSat-1 First Composite 6U

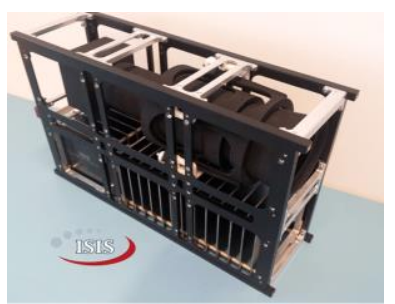

Figure 124. 6U Aluminum ISIS Space 
The structure studied is this Thesis was compared with $6 \mathrm{U}$ structures made entire of aluminum. In Table 6 are shown different characteristics of structures commercially available and the $6 \mathrm{U}$ structure of this research. The information was taken from brochures from the respective companies (Pumpkin, 2014) and (ISIS, 2015).

It was found on ISIS webpage that "Flight Heritage: No ISIS 6-Unit CubeSat Structures have flown in space yet, however, multiple units are slated for a launch in the upcoming 12 months.” (ISIS Space, 2016)

Table 6. Comparison between $6 \mathrm{U}$ Structures

\begin{tabular}{|c|c|c|c|}
\hline & ISIS 6U & $\begin{array}{c}\text { Supernova } \\
\text { ( Pumpkin) }\end{array}$ & $\begin{array}{c}\text { 6U Made of Composite } \\
\text { Materials }\end{array}$ \\
\hline Payload allowable mass & $12 \mathrm{Kg}$ & $12 \mathrm{Kg}$ & $12 \mathrm{Kg}$ \\
\hline Payload volume & 6400 & $7000 \mathrm{~cm}$ & 7050 \\
\hline Empty chassis mass & $1.1 \mathrm{Kg}$ & $1.64 \mathrm{Kg}$ & $1.24 \mathrm{Kg}$ \\
\hline Total length & $340.5 \mathrm{~mm}$ & $365 \mathrm{~mm}$ & $366 \mathrm{~mm}$ \\
\hline
\end{tabular}

It is also important to note that for the case of the ISIS Space structure, the height is about 1 inch shorter than the structure from Pumpkin and the one presented by the researcher. Until this moment ISIS Space does not offer 6U CubeSats of 366mm height. However the mass achieve by the composite structure is comparable lighter.

After testing the structure by mechanical shock and random vibration, it was possible to compare the masses between the Pumpkin $6 \mathrm{U}$ structure and the $6 \mathrm{U}$ composite structure, being this percentage of the mass reduction is around $25 \%$ or 400 grams.

In addition to the implementation of lighter materials, the researcher incorporated hardware of smaller size, from M3 to M2 or the equivalent 0-40 to 0-80, which helped to reduce the mass in a $90 \%$. The structure has a total of 152 screws size $0-80$, that weight 15 grams. 
Table 7, the mass breakdown for the composite structure, is shown. It can be seen that possible parts for future mass reduction in the composite structure, are mainly the carbon fiber panels, which take $52.4 \%$ of the total mass of the structure. The cut outs, which were done in the carbon fiber, tried to be similar to the cut outs that are done for aluminum structures. However, they can be made bigger in other to achieve a structure even lighter conservative. On the other hand, the top and bottom carbon fiber panels, did not have cut outs. This part of the structure is another source of improvement.

Table 7. 6U composite structure breakdown masses

\begin{tabular}{|c|c|c|}
\hline & Mass [kg] & Percentage [\%] \\
\hline Carbon fiber panels & 0.65 & $52.4 \%$ \\
\hline Fiber glass panels & 0.3 & $24.19 \%$ \\
\hline Aluminum rails & 0.255 & $20.5 \%$ \\
\hline Screws and hardware & 0.035 & $2.91 \%$ \\
\hline Total Mass & $1.24 \mathrm{Kg}$ & $100 \%$ \\
\hline
\end{tabular}

\subsection{Solar Panels Possible Configurations}

It was possible for the researcher based upon information received of Solar Panels (DHV, 2016), to illustrate different scenarios and weights for the 6U CubeSat structure. The same solar panels that can be mounted to the aluminum structures can be easily attached to the composite structure. In Figure 125 is shown how solar panels were attached to the Supernova structure made of aluminum. (Pumpkin, 2014) 


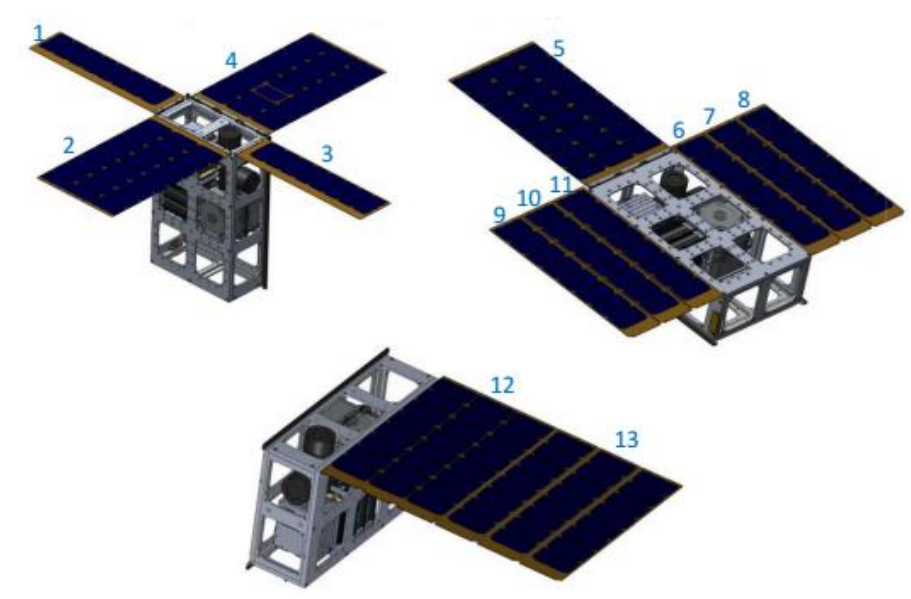

Figure 125. Possible Solar Panels Configurations Credit/Pumpkin Space

In Table 8 is shown information of four different configurations for solar panels that can be added either to the aluminum structure as the composite structure.

Table 8. Solar Panels Information Credit/ DHV Technology

\begin{tabular}{|c|c|c|c|c|c|}
\hline $\begin{array}{c}\text { Solar Panel } \\
\mathrm{N}^{\mathrm{o}}\end{array}$ & $\begin{array}{c}\text { Dimensions } \\
(\mathrm{mm})\end{array}$ & $\begin{array}{c}\text { Total } \\
\text { Weight }(\mathrm{g})\end{array}$ & $\begin{array}{c}\text { Qty Solar } \\
\text { Cells }\end{array}$ & Total Power & Comments \\
\hline 1,3 & $100 \times 365 \times 1.4$ & 173 & 8 & $8 \mathrm{~W}$ & $3 \mathrm{U}$ panels, 1 hinge \\
\hline $2,4,5$ & $222.5 \times 365 \times 1.4$ & 332 & 24 & $24 \mathrm{~W}$ & $6 \mathrm{U}$ panels, 2 hinges \\
\hline $6,7,8,9,10,11$ & $100 \times 365 \times 1.4$ & 175 & 8 & $8 \mathrm{~W}$ & $3 \mathrm{U}$ panels, 3 hinges \\
\hline 12,13 & $222.5 \times 365 \times 1.4$ & 335 & 24 & $24 \mathrm{~W}$ & $6 \mathrm{U}$ panels, 3 hinges \\
\hline
\end{tabular}




\section{CONCLUSIONS AND FUTURE WORK}

\subsection{Conclusions}

After designing, manufacturing and testing a $6 \mathrm{U}$ structure with composite materials, the questions that were formulated by the researcher at the beginning of this thesis paper were addressed in this chapter.

Is the conductivity of the composites good for spacecraft applications? Does the epoxy resin outgas in space? Sometimes the low conductivity of the composite materials is desirable for space applications. In the particular case of this thesis, an outgassing test of the carbon fiber LTM45/CF1803 was carried out and the total mass loss resulted from the test was less than the $1 \%$ requirement for spacecraft materials applications.

What if a CubeSat structure is made of composite materials? Will the machinability of the composite materials be easy as is the case of aluminum? Yes, it is possible. Working with composites was not a complex duty since they offer good properties for manufacturability and are easy to handle. For this thesis a commercial CNC router was employed to manufacture all the parts and no issues were encountered at the time of assembly.

Will the stiffness to weight ratio be enough to pass a random vibration test? Yes, even though due to an issue with the equipment it was only possible to test in the Z-Axis, the $6 \mathrm{U}$ structure of this Thesis was proven by Qualification Random Vibration Loads from NASA (NASA Goddard Space Flight Center, 2013), the structure responded optimally and no damage was seen after the test. The fundamental frequency obtained from the vibration test was $1250 \mathrm{~Hz}$. This value accomplishes the requirement of being greater that the launch 
vehicles systems, where as a general rule the fundamental frequency of the satellite shall be above $100 \mathrm{~Hz}$.

What about testing a composite structure in a shock test? No problems were seen while the shock testing was performed in the $6 \mathrm{U}$ structure. The satellite was proven in the three axes and the structure has presented no damage. The maximum acceleration shock response by the satellite was approximately $1500 \mathrm{G}$.

Comparing the structure presented in this Thesis with one $6 \mathrm{U}$ available in the market, a $25 \%$ mass reduction was achieved. This percentage could be even bigger if more material is shave away from the structure.

\subsection{Future Work}

The structure designed has promising applications for the future. However, better manufacturing equipment and methods can be implemented. A good point to continue this work can be to optimize different designs for the structure, reduce more mass from parts where the elements are not part of the main load path such as internal parts of the rails, vary plates thicknesses and implement other fixation elements.

As a future work the researcher suggests the possibility to explore the use of composite materials as a primary component of the rails of the CubeSat. Thermal testing is also suggested as a future work. 


\section{BIBLIOGRAPHY}

Abercromby, K. (2015). Spacecraft Environment Lab.

Advanced Composites Group. (2009). LTM 45 Component Prepreg. UK.

American Society for Testing and Materials. (2015). ASTM E595: Standard Test Method for Total Mass Loss and Collected Volatile Condensable Materials from Outgassing. West Conshohocken: ASTM.

California Polytechnic State University. (2013). CubeSat Design Specification. San Luis Obispo: Cal Poly.

Chung, D. D. (1994). Chapter 6 - Polymer-Matrix Composites. In D. D. Chung, Carbon Fiber Composites (pp. 116-124). Newton: Butterworth-Heinemann.

Dassault Systemes. (2014). Random Vibration Analysis.

DHV, T. (2016). DHV Technology - 6U Solar Panel Dimensions. Andalucia, Spain: DHV Technology.

EZ-Lok. (2016, March 15). Inserts for Plastics.

Instar Engineering and Consulting Inc. (2016, April 7). Vibration Testing of Small Satellites. Ramdom Vibration Testing.

ISIS Space. (2016, May 15). CubeSat Shop. Retrieved from http://www.cubesatshop.com/index.php?page=shop.product_details\&flypage=flypage.tpl\&product $\_$id $=45 \&$ category_id $=1 \& o p t i o n=c o m \_v i r t u e m a r t \& I t e m i d=66$

ISIS, S. (2015). CubeSat Structures. Netherlands: ISIS Space.

Jones, R. M. (1975). Mechanics of Composite Materials. Virginia: Taylor \& Francis.

Larson, J. R. (2010). Space Mission Analysis and Design. New York: Springer.

Larson, T. P. (2011). Spacecraft Structures and Mechanisms. Hawthorne and New York: Space Techology Library and Springer.

Mc Master Carr. (n.d.). Retrieved March 8, 2016, from www.mcmaster.com

NASA Goddard Space Flight Center. (2013, April 22). General Environmental Verification Standard. Washigton, United States.

NASA GSFC. (2016, January). Retrieved February 14, 2016, from Outgassing Data for Selecting Spacecraft Materials Online: https://outgassing.nasa.gov/

NASA, Goddard Space Flight Center. (2009). Hubble Space Telescope Servicing Mission 4. Retrieved from The Super Lightweight Interchangeable Carrier:

http://www.nasa.gov/mission_pages/hubble/servicing/SM4/main/SLIC_FS_HTML_prt.htm

National Research Council. (1994). Spacecraft Structures and Materials. In Technology for Small Spacecraft (p. 42).

Nomme, C. (2013). Mechanical Design of CubeSat Structures Using Composites and Polymers. Trondheim: Norwegian University of Science and Technology. 
Norwegian University of Science and Technology. (2015). Norwegian CubeSat Project . Retrieved from http://nuts.cubesat.no/

PC/104, E. C. (2008, October 13). PC/104 Specification. PC/104.org.

Planetary Systems Corporation. (2016). Payload Specification for 3U,6U, $12 U$ and 27U. Retrieved from http://www.planetarysystemscorp.com/

Pumpkin, S. S. (2014, October 2). 6U SUPERNOVA TM Structure Kit - Owner's Manual. San Francisco, California, United States.

Radius Space. (2016, May 04). Retrieved from www.radiusspace.com

Robert R. Johnson, M. H. (1981, July ). Thermal Expansion Properties of Composite Materials. Hampton, Virginia, United States.

Schläppi, B. (2010). Influence of spacecraft outgassing on the exploration of tenuous atmospheres with in situ mass spectrometry.

Spacecraft Applications of Advanced Composite Materials. (2002 ). In M. Kutz, Handbook of Material Selection (p. 1140).

Strong, J. (1938). Procedures in Experimental Physics. Bradley: Lindsay Publications.

Tyvak Nano-Satellite Systems. (2014, November). 6U CubeSat-B: CubeSat Specification. TK-6UDSB-01.

University of Patras. (2014). Qualification of Composite Structure for CubeSat Picosatellites as a Demonstration for Small Satellite Elements. Patras: University of Patras. 


\section{APPENDICES}

\section{APPENDIX A: OUTGASSING TEST DATA COLLECTED}

\begin{tabular}{|c|c|c|c|c|c|c|c|c|c|c|}
\hline \multicolumn{2}{|c|}{ S1 } & S2 & S3 & S4 & S5 & S6 & S7 & S8 & S9 & \multirow{2}{*}{$\begin{array}{l}\text { S10 } \\
2.052\end{array}$} \\
\hline 1 & 2.06 & 2.01 & 1.98 & 2.02 & 2.005 & 2.015 & 2.005 & 2.025 & 1.999 & \\
\hline 2 & 2.038 & 2.015 & 1.99 & 2.03 & 2.007 & 2.02 & 2.01 & 2.017 & 1.994 & 2.043 \\
\hline 3 & 2.05 & 2.02 & 1.973 & 2.021 & 2.01 & 2.03 & 2.02 & 2.04 & 1.997 & 2.047 \\
\hline 4 & 2.052 & 2.023 & 1.982 & 2.01 & 2.01 & 2.025 & 2.017 & 2.021 & 1.997 & 2.044 \\
\hline & & & & & & & & & & \\
\hline average & 2.05 & 2.017 & 1.98125 & 2.02025 & 2.008 & 2.0225 & 2.013 & 2.02575 & 1.99675 & 2.0465 \\
\hline $2 *$ stdev & 0.018184 & 0.011431 & 0.013988 & 0.016361 & 0.004899 & 0.01291 & 0.013565 & 0.020091 & 0.004123 & 0.008083 \\
\hline & & & & & & & & & & \\
\hline & & & & & & & & & & \\
\hline & & & & & & & & & & \\
\hline & & & & & & & & & & \\
\hline \multicolumn{11}{|c|}{ not say anything } \\
\hline & 2.068184 & 2.028431 & 1.995238 & 2.036611 & 2.012899 & 2.03541 & 2.026565 & 2.045841 & 2.000873 & 2.054583 \\
\hline & 2.031816 & 2.005569 & 1.967262 & 2.003889 & 2.003101 & 2.00959 & 1.999435 & 2.005659 & 1.992627 & 2.038417 \\
\hline & & & & & & & & & & \\
\hline & & & & & & & & & & \\
\hline After & S1 & S2 & S3 & S4 & S5 & S6 & S7 & S8 & S9 & S10 \\
\hline 1 & 2.025 & 1.988 & 1.991 & 2.001 & 1.995 & 1.988 & 2.026 & 2.001 & 1.992 & 2.045 \\
\hline 2 & 2.029 & 1.985 & 1.993 & 2.004 & 1.993 & 1.989 & 2.024 & 2.001 & 1.995 & 2.037 \\
\hline 3 & 2.03 & 1.988 & 1.994 & 2.003 & 1.993 & 1.987 & 2.03 & 2.003 & 1.991 & 2.027 \\
\hline 4 & 2.033 & 1.985 & 1.997 & 2.004 & 1.992 & 1.989 & 2.028 & 2 & 1.997 & 2.026 \\
\hline \multicolumn{11}{|l|}{5} \\
\hline average & 2.02925 & 1.9865 & 1.99375 & 2.003 & 1.99325 & 1.98825 & 2.027 & 2.00125 & 1.99375 & 2.03375 \\
\hline stdev & 0.006608 & 0.003464 & 0.005 & 0.002828 & 0.002517 & 0.001915 & 0.005164 & 0.002517 & 0.005508 & 0.017991 \\
\hline mass loss & 1.012195 & 1.512147 & & 0.853855 & 0.734562 & 1.693449 & & 1.209429 & 0.150244 & 0.623015 \\
\hline average $\mathrm{Tl}$ & 0.973612 & set $1-10$ & & & & & & & & 0.063327 \\
\hline stdev & 0.498229 & & & & & & & & & 0.191109 \\
\hline & & & & & & & & & & \\
\hline \multicolumn{11}{|c|}{ not say anything } \\
\hline & 2.035858 & 1.989964 & 1.99875 & 2.005828 & 1.995767 & 1.990165 & 2.032164 & 2.003767 & 1.999258 & 2.051741 \\
\hline & 2.022642 & 1.983036 & 1.98875 & 2.000172 & 1.990733 & 1.986335 & 2.021836 & 1.998733 & 1.988242 & 2.015759 \\
\hline
\end{tabular}




\begin{tabular}{|c|c|c|c|c|c|c|c|c|c|c|}
\hline \multicolumn{2}{|r|}{ S11 } & \multirow{2}{*}{ 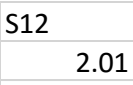 } & \multirow{2}{*}{\begin{tabular}{|r} 
S13 \\
2.037
\end{tabular}} & \multirow{2}{*}{$\begin{array}{ll}\text { S14 } & \\
& 2.05\end{array}$} & \multirow{2}{*}{$\begin{array}{l}\text { S15 } \\
\quad 2.044\end{array}$} & \multirow{2}{*}{$\begin{array}{l}\text { S16 } \\
2.013\end{array}$} & \multirow{2}{*}{$\begin{array}{l}\text { S17 } \\
2.025\end{array}$} & \multirow{2}{*}{$\begin{array}{l}\text { S18 } \\
2.006\end{array}$} & \multirow{2}{*}{$\begin{array}{l}\text { S19 } \\
2.011\end{array}$} & \multirow{2}{*}{$\begin{array}{ll}\text { S20 } & \\
& 2.02\end{array}$} \\
\hline 1 & 2.012 & & & & & & & & & \\
\hline 2 & 2.012 & 2.009 & 2.035 & 2.048 & 2.045 & 2.013 & 2.03 & 2.005 & 2.01 & 2.02 \\
\hline 3 & 2.013 & 2.009 & 2.038 & 2.047 & 2.046 & 2.014 & 2.026 & 2.007 & 2.01 & 2.022 \\
\hline 4 & 2.011 & 2.007 & 2.037 & 2.046 & 2.044 & 2.012 & 2.026 & 2.006 & 2.009 & 2.019 \\
\hline & & & & & & & & & & \\
\hline & & & & & & & & & & \\
\hline average & 2.012 & 2.00875 & 2.03675 & 2.04775 & 2.04475 & 2.013 & 2.02675 & 2.006 & 2.01 & 2.02025 \\
\hline $2 *$ stdev & 0.001633 & 0.002517 & 0.002517 & 0.003416 & 0.001915 & 0.001633 & 0.004435 & 0.001633 & 0.001633 & 0.002517 \\
\hline & & & & & & & & & & \\
\hline & & & & & & & & & & \\
\hline & & & & & & & & & & \\
\hline \multicolumn{11}{|c|}{ not say anything } \\
\hline & 2.013633 & 2.011267 & 2.039267 & 2.051166 & 2.046665 & 2.014633 & 2.031185 & 2.007633 & 2.011633 & 2.022767 \\
\hline & 2.010367 & 2.006233 & 2.034233 & 2.044334 & 2.042835 & 2.011367 & 2.022315 & 2.004367 & 2.008367 & 2.017733 \\
\hline & & & & & & & & & & \\
\hline After & S11 & S12 & S13 & S14 & S15 & S16 & S17 & S18 & S19 & S20 \\
\hline 1 & 2.01 & 2.008 & 2.038 & 2.046 & 2.045 & 2.011 & 2.026 & 2.006 & 2.01 & 2.021 \\
\hline 2 & 2.011 & 2.009 & 2.037 & 2.044 & 2.044 & 2.012 & 2.024 & 2.005 & 2.009 & 2.019 \\
\hline 3 & 2.012 & 2.008 & 2.037 & 2.045 & 2.043 & 2.013 & 2.024 & 2.006 & 2.008 & 2.018 \\
\hline 4 & 2.01 & 2.008 & 2.036 & 2.045 & 2.043 & 2.013 & 2.023 & 2.006 & 2.008 & 2.02 \\
\hline \multicolumn{11}{|l|}{5} \\
\hline average & 2.01075 & 2.00825 & 2.037 & 2.045 & 2.04375 & 2.01225 & 2.02425 & 2.00575 & 2.00875 & 2.0195 \\
\hline stdev & 0.001915 & 0.001 & 0.001633 & 0.001633 & 0.001915 & 0.001915 & 0.002517 & 0.001 & 0.001915 & 0.002582 \\
\hline mass loss & 0.062127 & 0.024891 & & 0.134294 & 0.048906 & 0.037258 & 0.12335 & 0.012463 & 0.062189 & 0.037124 \\
\hline \multicolumn{3}{|c|}{ average $\mathrm{Tl}$ set 11 - 20} & & & & & & & & 0.219009 \\
\hline stdev & & & & & & & & & & 0.128499 \\
\hline & & & & & & & & & & \\
\hline \multicolumn{11}{|c|}{ not say anything } \\
\hline & 2.012665 & 2.00925 & 2.038633 & 2.046633 & 2.045665 & 2.014165 & 2.026767 & 2.00675 & 2.010665 & 2.022082 \\
\hline & 2.008835 & 2.00725 & 2.035367 & 2.043367 & 2.041835 & 2.010335 & 2.021733 & 2.00475 & 2.006835 & 2.016918 \\
\hline
\end{tabular}




\begin{tabular}{|c|c|c|c|c|c|c|c|c|c|c|}
\hline \multicolumn{2}{|r|}{ S21 } & S22 & $\mathrm{S} 23$ & S24 & $\mathrm{S} 25$ & S26 & S27 & S28 & S29 & \multirow{2}{*}{$\begin{array}{l}\text { S30 } \\
\quad 2.018\end{array}$} \\
\hline 1 & 2.044 & 2.05 & 2.032 & 2.011 & 2.041 & 2.028 & 2.03 & 2 & 2.041 & \\
\hline 2 & 2.042 & 2.051 & 2.032 & 2.012 & 2.04 & 2.028 & 2.029 & 2.001 & 2.042 & 2.018 \\
\hline 3 & 2.041 & 2.05 & 2.032 & 2.01 & 2.042 & 2.027 & 2.029 & 2.002 & 2.041 & 2.02 \\
\hline 4 & 2.04 & 2.051 & 2.031 & 2.012 & 2.041 & 2.028 & 2.03 & 2.002 & 2.03 & 2.025 \\
\hline & & & & & & & & & & \\
\hline & & & & & & & & & & \\
\hline average & 2.04175 & 2.0505 & 2.03175 & 2.01125 & 2.041 & 2.02775 & 2.0295 & 2.00125 & 2.0385 & 2.02025 \\
\hline $2 *$ stdev & 0.003416 & 0.001155 & 0.001 & 0.001915 & 0.001633 & 0.001 & 0.001155 & 0.001915 & 0.011372 & 0.006608 \\
\hline & & & & & & & & & & \\
\hline & & & & & & & & & & \\
\hline & & & & & & & & & & \\
\hline \multicolumn{11}{|c|}{ not say anything } \\
\hline & 2.045166 & 2.051655 & 2.03275 & 2.013165 & 2.042633 & 2.02875 & 2.030655 & 2.003165 & 2.049872 & 2.026858 \\
\hline & 2.038334 & 2.049345 & 2.03075 & 2.009335 & 2.039367 & 2.02675 & 2.028345 & 1.999335 & 2.027128 & 2.013642 \\
\hline & & & & & & & & & & \\
\hline After & S21 & S22 & S23 & S24 & S25 & S26 & S27 & S28 & S29 & S30 \\
\hline 1 & 2.036 & 2.044 & 2.029 & 2.007 & 2.038 & 2.025 & 2.025 & 2.001 & 2.035 & 2.01 \\
\hline 2 & 2.038 & 2.043 & 2.03 & 2.009 & 2.037 & 2.025 & 2.025 & 2 & 2.034 & 2.01 \\
\hline 3 & 2.037 & 2.044 & 2.03 & 2.008 & 2.036 & 2.026 & 2.024 & 2 & 2.035 & 2.009 \\
\hline 4 & 2.035 & 2.043 & 2.028 & 2.009 & 2.037 & 2.025 & 2.025 & 1.999 & 2.034 & 2.011 \\
\hline \multicolumn{11}{|l|}{5} \\
\hline & & & & & & & & & & \\
\hline average & 2.0365 & 2.0435 & 2.02925 & 2.00825 & 2.037 & 2.02525 & 2.02475 & 2 & 2.0345 & 2.01 \\
\hline stdev & 0.002582 & 0.001155 & 0.001915 & 0.001915 & 0.001633 & 0.001 & 0.001 & 0.001633 & 0.001155 & 0.001633 \\
\hline mass loss & 0.257132 & 0.34138 & 0.123047 & 0.149161 & 0.195982 & 0.123289 & 0.234048 & 0.062461 & 0.196223 & 0.507363 \\
\hline \multicolumn{11}{|c|}{ average TI set 21 - 30} \\
\hline \multicolumn{11}{|c|}{ stdev } \\
\hline & & & & & & & & & & \\
\hline \multicolumn{11}{|c|}{ not say anything } \\
\hline & 2.039082 & 2.044655 & 2.031165 & 2.010165 & 2.038633 & 2.02625 & 2.02575 & 2.001633 & 2.035655 & 2.011633 \\
\hline & 2.033918 & 2.042345 & 2.027335 & 2.006335 & 2.035367 & 2.02425 & 2.02375 & 1.998367 & 2.033345 & 2.008367 \\
\hline
\end{tabular}




\section{APPENDIX B: DATA SHEETS}

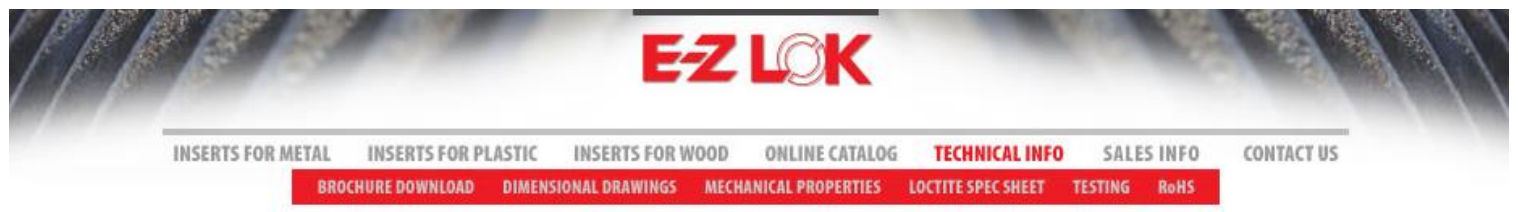

Free-Cutting Brass, UNS C 36000

\begin{tabular}{|cc|}
\hline COMPONENT & WT. \% \\
\hline $\mathrm{C}$ & $60-63$ \\
\hline $\mathrm{Fe}$ & Max 0.35 \\
\hline Other & Max 0.5 \\
\hline $\mathrm{Pb}$ & $2.5-3.7$ \\
\hline $\mathrm{Zn}$ & 35.5 \\
\hline
\end{tabular}

\begin{tabular}{lrrr}
\hline PHYSICAL PROPERTIES & METRIC & ENGLISH & COMMENTS \\
Density & $8.49 \mathrm{~g} / \mathrm{cC}$ & $0.307 \mathrm{lb} / \mathrm{in}^{3}$ & at $20^{\circ} \mathrm{C}\left(68^{\circ} \mathrm{F}\right)$
\end{tabular}

\begin{tabular}{|c|c|c|c|}
\hline $\begin{array}{l}\text { MECHANICAL } \\
\text { PROPERTIIES }\end{array}$ & METRIC & ENGLISH & COMMENTS \\
\hline $\begin{array}{l}\text { Tensile Strength, } \\
\text { Ultimate }\end{array}$ & $338-469 \mathrm{MPa}$ & $49000-68000 \mathrm{psi}$ & \\
\hline Tensile Strength, Yield & $124-310 \mathrm{MPa}$ & $18000-45000 \mathrm{psi}$ & Depending on temper \\
\hline Elongation at Break & $53 \%$ & $53 \%$ & in $457.2 \mathrm{~mm}$ \\
\hline Modulus of Elasticity & $97 \mathrm{GPa}$ & $14100 \mathrm{ksi}$ & \\
\hline Bulk Modulus & $140 \mathrm{GPa}$ & $20300 \mathrm{ksi}$ & Typical for Steel \\
\hline Poisson's Ratio & 0.31 & 0.31 & Calculated \\
\hline Machinability & $100 \%$ & $100 \%$ & $\begin{array}{r}\text { UNS C36000 (free-cutting brass) }= \\
100 \%\end{array}$ \\
\hline Shear Modulus & $37 \mathrm{GPa}$ & $5370 \mathrm{ksi}$ & \\
\hline
\end{tabular}

\begin{tabular}{lrrr} 
THERMAL PROPERTIES & METRIC & ENGLISH & COMMENTS \\
\hline CTE, linear $250^{\circ} \mathrm{C}$ & $20.5 \mu \mathrm{m} / \mathrm{m}-{ }^{\circ} \mathrm{C}$ & $11.4 \mu \mathrm{in} / \mathrm{in}-{ }^{\circ} \mathrm{F}$ & from $20-300^{\circ} \mathrm{C}\left(68-570^{\circ} \mathrm{F}\right)$ \\
Thermal Conductivity & $115 \mathrm{~W} / \mathrm{m}-\mathrm{K}$ & $\begin{array}{r}798 \mathrm{BTU}-\mathrm{in} \\
/ \mathrm{hr}-\mathrm{ft}^{2}-{ }^{\circ} \mathrm{F}\end{array}$ & at $20^{\circ} \mathrm{C}\left(68{ }^{\circ} \mathrm{F}\right)$ \\
Melting Point & $885-900^{\circ} \mathrm{C}$ & $1630-1650^{\circ} \mathrm{F}$ & \\
Solidus & $885^{\circ} \mathrm{C}$ & $1630^{\circ} \mathrm{F}$ & \\
Liquidus & $900^{\circ} \mathrm{C}$ & $1650^{\circ} \mathrm{F}$ &
\end{tabular}

800.234.5613 EZ LOK v-310.323.5613 f-310.353.4444

240 E. Rosecrans Ave, Gardena, CA 90248 email: sales@ezlok.com 


\section{APPENDIX C: 6U CUBESAT STANDARD DRAWINGS}
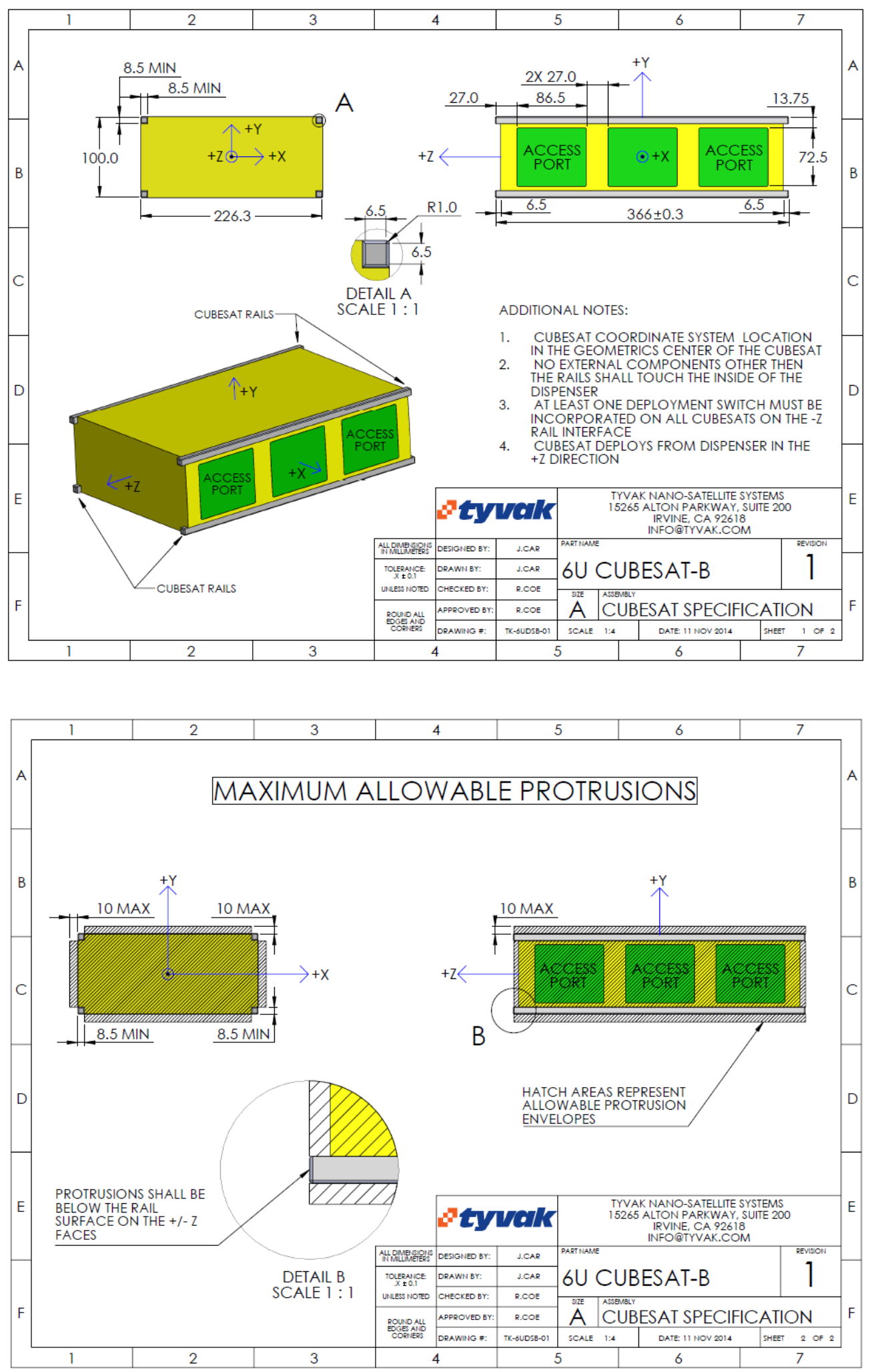